

1 

1) $1 \mathfrak{1}$ กิ

82

islåndifden Drnitbologit

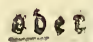

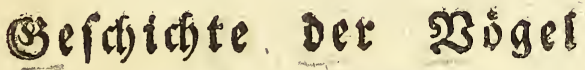

Sถ์

ริกิเ

Sriesrich Fraber,

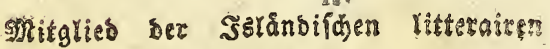

(5) efexty af af

topentragen, 1822

Wuf Soften Des Berfaffers

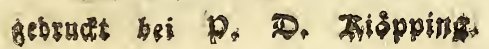




$$
\begin{aligned}
& Q 2 \\
& 690 \\
& I_{2} \\
& \text { BII }
\end{aligned}
$$

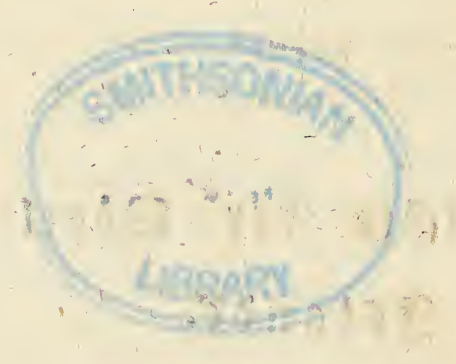


S m. Mai bez Sabrez I 8 I 9 pegelte id nach Šsland, um mit loniglich bånif ther uno der Sopengagner

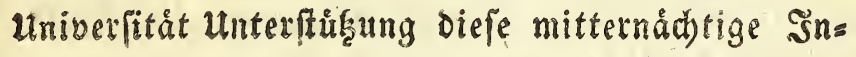
fel zu bereifen. Intereije für Die 3oologie, infons. Derbeit fur die Drnithologie, lodte midh nadh bies fem fernen Felfenlande, befien grofjte Streden, vors nebmlich långs-ber Meereskífte, no es mir weder

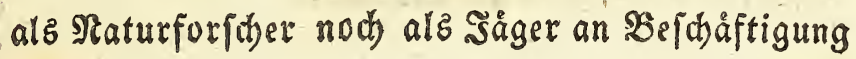
feblte, ich brittbalb sabre bereif'te. Stadboem idf orei Sommer uno zmei Winter in \$̇land verlebt batte, Eebrte id gegen Ende bes Septembers I 82 I

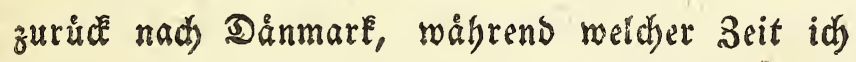
viele, und gum sheil neue Beobachtungen "iber Lebensart, Ssanderungen u. f.m., zumal ber borealen

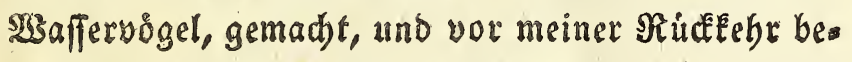
Deutende Gammlungen von şo̊geln und ibren Eiern nach Dånmare gejand babe. Da bas ęoniglidye

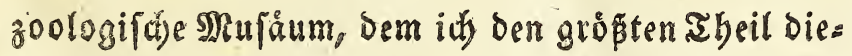
fer Sammlangen ủbergab, fhon eine bebcutende

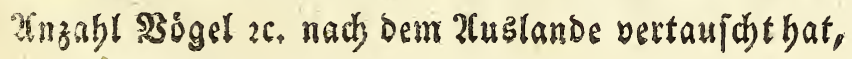




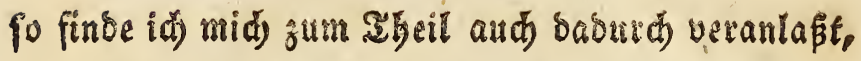

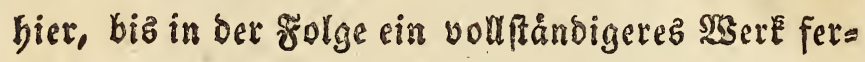
tig werden Eamn, cine vorlåufige (jeichidhte ber iz:

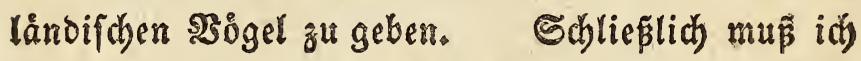
nod) bemerken, Dap biefe abbandlung burdjaus blop Das Sejultat eigener erfabrung ift, bie id in ber Satur felbit, auf ermidenden Sagotouren, uno burd) phyfologifhe uns anatomijhe Interjuchuns gen, erroorben babe. Die Matur gab mir ein juarf" febendes leibliches 2utge; wie weit baz geiftige ges feben bat, muf ich Dem billigen untheile bes sejers uberlafiem.

\footnotetext{
Gopengagen, sen 28ften Geburar, I822.
} 


\section{Divifio l.}

\section{Terreftres \\ Ordo I.}

Accipitres.

Genus I.

\section{Falco (Linn.).}

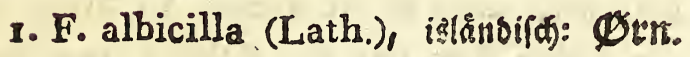

5

in nicht feltener Standoogel. Er toridt rober an fart. be, Eseftalt, Stimme now Sitten oon bem Dánifhen $a b$. Ee ift monogam. 2fn Dem sెergungsfithigen, ben man bei bem תefte trifft, iff ber Edmang fete rosib; Sopf unb Şals find ball, boch) nicht rein rosip. 3mei Mal babe ii) fein Neft, beibe Nale in bem fübreftlidfẹn Jolano, gefunder. Çz roas auf Dec bơhften Copize sines zugång= lichen Lavafelfens, $\frac{\pi}{4}$ 2neile vom I2Rerre, angelegt, grob unb flach, bie Unterlage große నangmurzeln ober Reifer, im Difcus Stroh uno झoos. Das erfte Neft fanb i

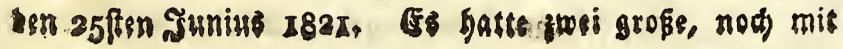


grauen, am Stopfe wriffen, Flaumfedern befeģte Junge. Das eine von biefen war viel Eleiner als bab andere, lag,

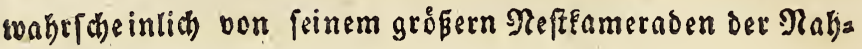
rung beraubt, tobt im Refts. Das andere Reft batte, ben 5 ten Jutius I82I, ein Junges, bas beinahe flick rar,

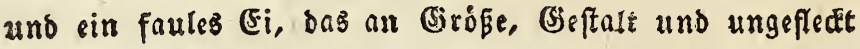
weiffer, boch nidjt fo rein weiffer, Fatbe bem Ei ber Procell. glacialis glich. 1 In beiben Meftern logen aufges whrgte Şarkugeln von jungen Canis lagopus, ferner Uria troile, U. grylle, Larus tridactylus, Procellaria glacialis, Cyclopterus lumpus $u_{0}\lceil\cdot \mathfrak{w}$. balb verwej't. 2(ts ich mich bem Nefte näberte, Eamen beibe 2ulte mir laut fafreiend entgegen und umireif'ten mich, boch fieffen (iie nid)t auf mich berab. fonberm bielten fid immer auffer ber Ed)ußweite. Die Sumgen in ben Meftern liegen auళs.

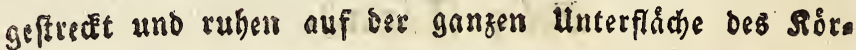
2er3; fobon bann baben fie bie Etimme ber Zltten, theils auch eirem beifern faut, ber bem Etshnen sines hungris

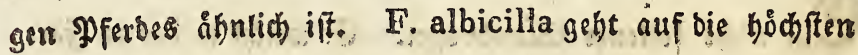
seerge, und fitbet båfig auf Salmo alpinus in ben Ges wåffern ber Bergebenen, någrt fich boch auch gropentbeils vom 2faje.

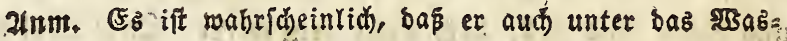
fer fiỏ rourbe ein Sif sin F. albicilla gefangen und fifon tobt war.

\section{T. islandicus (Lath.), isł. fálti. Dalur.}

Eim nidjt fortena Etandoogel. Er folgt bem (E)ange.

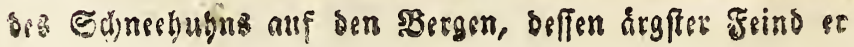




\section{$(3)$}

ift. Esin Neft fand ith me sin einziges Mal, ben Gtent

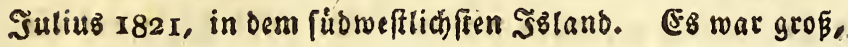
flach, in Dem oberften Iheil einer unzuginglichen Feltens wand, $\frac{7}{2}$ Biertetmeile vom Meere, nngelegt. Der Sunger waren 3, alle erroachien; die 3 hatten fhon bas Meft vers

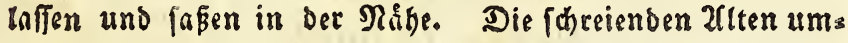

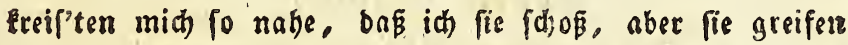
nidst an, wie Sterna ober Leftris. Die aften batten nidje allein baz sunge im Mefte, fonbern nudi bie beiben aubs geflogenen, rsichtidy mit Uria troile, U. grylle, Alca torda, Mormon fratercula, Larus tridactylus verfefien.

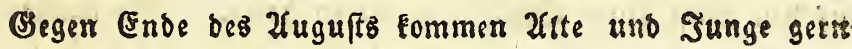
ben Şåufern nåber, wo fie fid) an bohen Etellen fesert, uno fich oft mit ben $\Re$ aben balgen. Die meiffe 2lbart, mit mebreren ober wenigeren dunEeln flecten, ift ziemlid felten; id babe fie nut in ben 2Bintermonathen gefeben. - Ebedem bradhte man vorziglich bieferi falten von J̈z

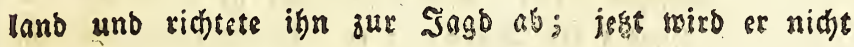
mebre zu Diefem (5)ebrauche gefangers.

\section{F. Lanarius (Linn.), is}

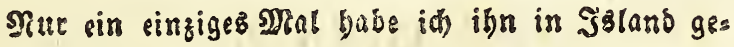

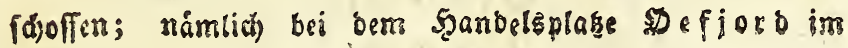

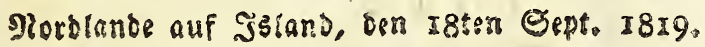

4. F. cælius (Meyer.), iəl. Smirill.

Jinbet fict bin amb rieber, commt an gegen Eads

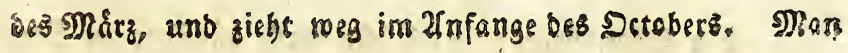
Hat mir feine 4 (Fier gebradis, pie benen be F. tinanaculus 


\section{(. 4.)}

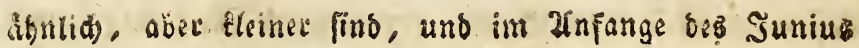
in Felienrigen gefunden waren. Er ftopt beftig nuf bis Eleinen Pasferes.

\section{Genus 2. \\ Strix (Linn.)}

I. Str. nydtea (Linn.), iริ .....

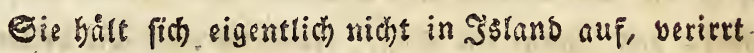

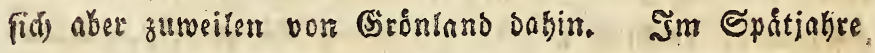
I8I 7 wutre cime umter Sstand gefangen, bie fith mübe auf den Maft cines Săiffez gerworfen batte. Sie wurbe mir lebendig-nadh Ropentagen gebracht, tobtete bei Tage

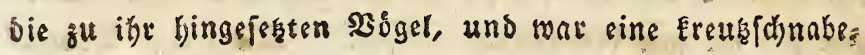
lige WGatt.

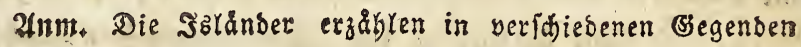
bez Eanbes yon einer Eute, bis boch fehr feltent geféten wirb. Gie befdretiben fie ungefähr roie Rinné's Str. aluco; da es mir aber nidyt gełungen

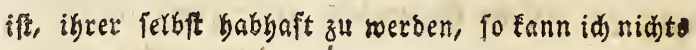
వatůbes beftimmen.

\section{Ordo 2: \\ $P$ i c a \\ Genus 3. \\ Corvus (Linn.).}

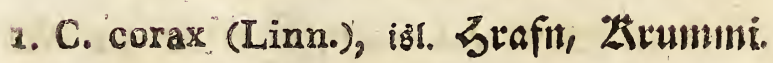

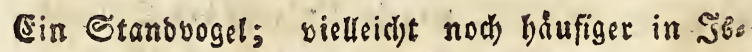

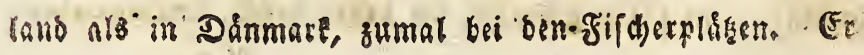




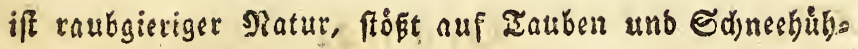

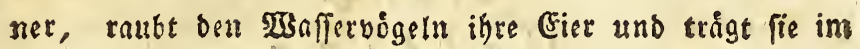
Shnabel fort, fallt bie zum Dörres aufgebångter Fif h) an, bebt Sabaltbiere mit fich in bie Ruft und zerfdlaggt Tie gegen bie felfon, wie id mit Venus islandica, Car. dium groenlandicum unb C. edule, mit Pecten islandicus und Mytilus edulis gefeben babe; auch nimmt er mit Beeren von Empetrum nigrum uno Vaccinium fürtieb.

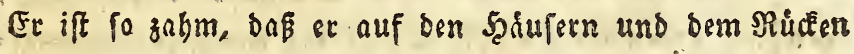
weidender \$ferbe rubt. Edjon gegen End be des̉ Mårz fängt Die Begnttungşzeit an; Dann lâst er ein wobltlingendes clongsclong bơren, fthwebt mit ber Bnttinn unter mans cherlei Wendungen in ber Ruft und liebeof't pe fifend mie aufgebläbeten Febern und rounderlichen Drebungen das Sop= fes. Seine Eier legt er in freilen Gerjentwinden. - Dis

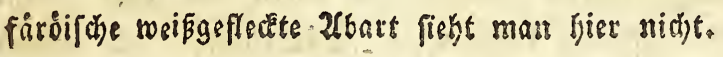

\section{C. cornix (Linn, $)_{0}$, iิ $\ell_{0} \ldots$}

Sommt zutweilen bin uns wieser nuf bem Lanbe gum Borfdsin, berfoswindet aber batb mieber. Im Juliub uns 2uguft I8I9 fab ich einige bavon auf bem Norbtanbse

\section{C. corone (Linn.), iิติ.....-}

Selbft fand id ibn nicht; aber in ben fubmeftlids

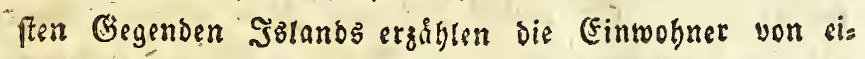
nem Bogel, wobon fith zuweilen sinige im Epåtjabre feben raffen, fich ober nur furz auf ber Jnfel aufbalten. Saids Der Befdyreibung iftes C. corone, ber fich zutweilen yon

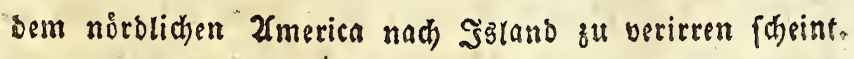

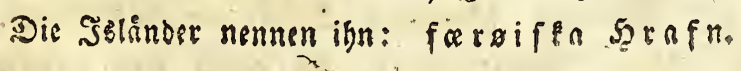




\section{$(6)$ \\ Ordo 3. \\ $G a l l i \| a_{0}$ \\ Genus 4 . \\ Tetrdo (Linn.).}

8. T. Islandorum (mihi), ist. నiifapa. Kkieri

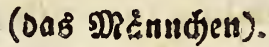

Sefthreibung: Det Sdnabel mittelmåsig, geroolbt, gegert bie ftumpfe Epife cirt wertig zufammenges Drủctt, fohmarzbraun mit blafferer Epiže. Die Nafen. lócher mit Febertt bebedit. Dis Bunge Eurz, flad niebers

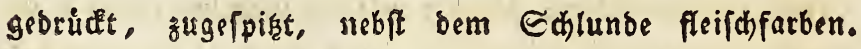
2Bei ben (Erwach fenen beiber (Befd)led)ter find im Sommer und Binter bie Edwungfebern (bavon bie 7-10 erften

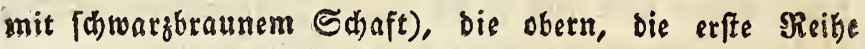
ber Sdrwungfebern bedecfenden, Dedefedern, alle untere

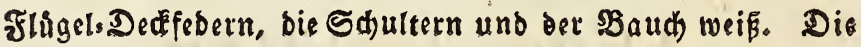
I4 eigentliden Steuerfebern forwarz mit weiffer $\$ B a f i s$ unb, im \$inter breiter, im Sommer fthmaler, weiffer Epige.

Das alte Mannchen in reiner Sommer: tracht. Die 2fugen mit brouner Jriz. Die 2lugens

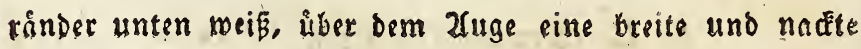
rotbe Şaut, warzig uno gezadt, snfdimetlent in ber $B_{e}=$

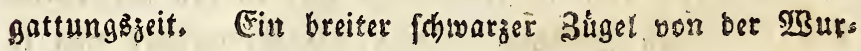
sel bes Ednabels butch bie ?lugen. Etim, Edyeitel, Şinterfopf, Radern, Schlafe, Siegle und ber obere Theil Der BSurgel mit fowwarzen und roftrothen wetlenformigen Streifen von gleider 3 rcite; jebe Feber endigt mit eis nem febr fämalen fdwarzen Bande an ber Epize.

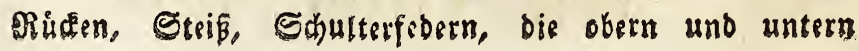


langen Dreffebern, wolthe beinate bie Steuerfebern vers bergen, ber untere geil ber (s) pochondern, Seiten des unterleibes, die langen Jeberis Der Sdiene find auf dab feinfte wellenformig roft: braun und fdwarz gewaffert, Dod fo, baß bas Roftbraune vorberrferend ift: jebe Feber endigt fich meiftenz mit sinem (c)malen fchwarzen Banbe und eis ner noch fomalern weiffen Spike. Die Mitte bes. Un: terleibez, ber 2ffer, bie niebern Febern ber Sdhiene, die ben ganzen Lauf unb bie 3eken, zroat pparfamer als in Binter, bedecéenden Febern find toeis. Dis mittelften un: eigentlichen Steuerfebern (rectrices fpuriæ), welthe ubee

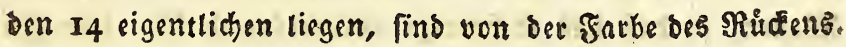
Man bekommt felten ein Minnchen in reinee Sommertracht, gewoigntidy iff fein Sileid mefr ober ment= get mit ben reiffen Federn des 2 Binterg genifht.

Das alte M\&nnden in reiner $\mathbb{B}$ inter: tracht. Ģanz meíp. (sin febr breites fohroarzes Banb

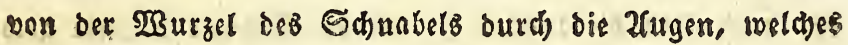
Die Mangen gnm kebect und, weniger breit, gerade bis zum $\Re$ acen fortgefetzt wirb. Die Febern, melche bie aeben bededen, find fo lang, baef fie bie Rlauen verkergen. Die 4 mitselften uneigsutlidyen Etenerfedsrn, twelde $\mathfrak{u} b e r$ ben I4 eigentlichen fotwarzen Steuerfedern liegen, fint meiß̄, an ber \$Bafiz mit braunen Schåften.

Sn biefe నracht ift ez vom 2ruggange des Ro= vembers bis zum 2infange bes 21prils gefleidet.

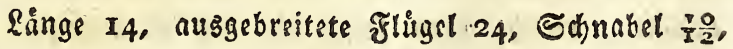

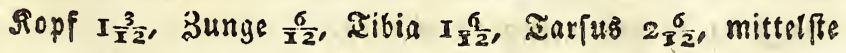

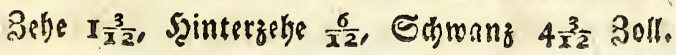




\section{$(8)$}

Das alte 2 beibden in Sommerteadt. Die Ifugen mit brauner Sris. Die nadte Şaut ủber

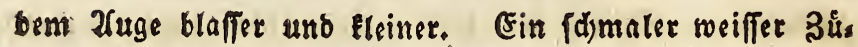
get von ber Wurzel bes Sdnabels burch bas 2luge. Die Stirn roftroth mit fommalen braunen Bellenlinien. Die Sdheitel fabwarz mit fodmalen roftrothen Råndern. Sd) uns Sefle gelb mit bunteln Fledén, bie leşte beinabe unt

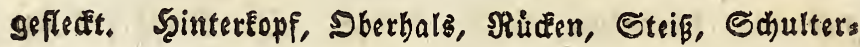
febern, bie obern flügelbedfebern, weldhe bie leķten Reis ben ber Sdroungfebern bebecken, bie obern Dedefedern Ses Sdmanzes, und bie 4 uneigettlichen Steuerfebern Fino formarz mit fobmalen roftbrnuner und : reisgetben

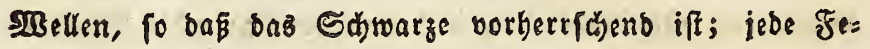
ber endigt mit einer braßggelben Spize. Der untere agheil Der Gurgel, Bruft, Borberbauch, Şypodonbern, bie un= tern Deceffebern bes Edwwanzes und bie langen Gebern Dee Sdhiene mit gleid breiten folwargen uns roffrothen 20sellentinien, fo bas feine von biefen garben vorbertfdent ift, boch find bie langen Fedeen ber Edjiene beinnbe gell - Whe Fleden. Der Baud) ift ungeflect getb; ber Xfter, bie antern Federn ber Sthiene, ber Lauf finb ungeffedt weiflid).

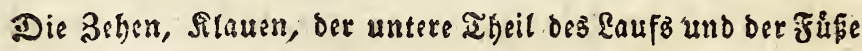
find ganz von Febern entblóst, fo auch ber Bautio nach sem 3 rütem. Die meiften von ben fajwarzen Stsuerfes bern find beinahe ohne weiffe Spise.

Sn ber garbenvertheilung gleit)t ef fohe bem SBgeibden von $T$. Faliceti ( $T$ emm.) ober $T$. fubalpinus (Nills), welde eben fo neenig ats T. lagopus (aucto. rum) in satand gefunden werben.

Das alte 23 eibden in reiner 23 inter:

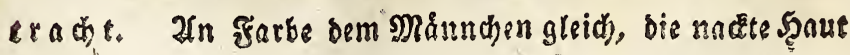




\section{( 9 )}

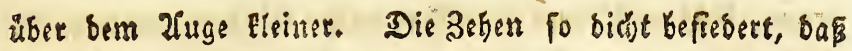
bie Slauen verborgen fins. Der fthwarze š̉gel von ber

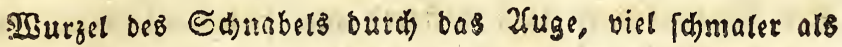
bei bem MRanden, wirb binter bem Juge bis garabe ir ben Nacen fortgefét uno dabreiter.

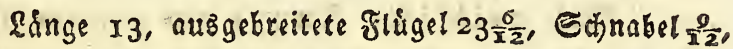

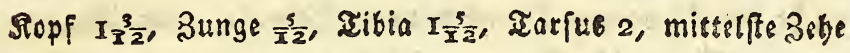

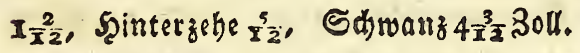

Die jungen $\mathfrak{R} \mathfrak{a} \mathfrak{n}$ den Ecmmen gleid ben erften Binter in Wintertracht unb gleichen bann ben als ten Weibden.

Die iungen $\mathfrak{B}$ eibdacub baben, wenn fie in Bsintertracht getommen find, gleid bas breite fol to a $\mathfrak{x}_{6}$ ze $\mathfrak{B}$ anb vom $\mathfrak{X}$ uge bis zum $\mathfrak{A}$ acken。 aber nod im November uno December teine Spur von

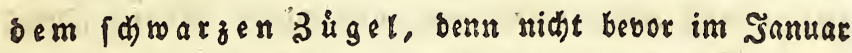

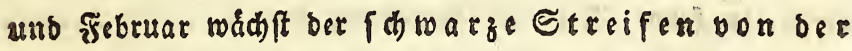

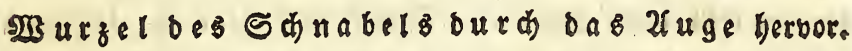

Das månnliche รunge im รulius, 14 I a ge a 1 , mit neutid erhaltenen Febern, if 5 Soll lang. Der Sberfdnabel fdwarg, ber Utnterfanabel blas bleifar= ben. Die fleine nač̃te Şaut ůber bem Zuge bla . Scheitel und J̧intertopf braun mit fabratger Einfafiung. Stitn und 2(ntlis graulich. Die Săjlåfe bunfielgefledt. (Ein Strid yon ber Sanabelturzel zum Xfuge, unb yon den Geiten dez Şintereppes ourd ben

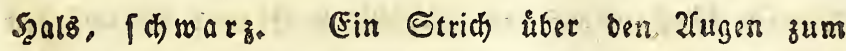
Nacken weiß. Der Rủden rofffarben mit fobtwarzen uno

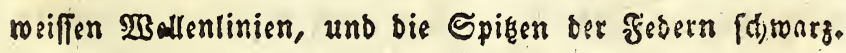
Der Bogel unten graulid,. Die Sd)wumgfebern grous 


\section{( 10.$)$}

Eraun, blä roftbraun gewaffert und gerånbert, mit weiffer Spige, ihre obern Decefedern mit blä roffrotben 2 Bellen. Dir Steuserfedern bla

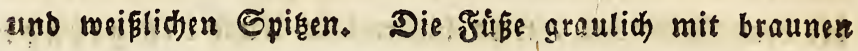
stausn.

Das weiblide $\Im$ unge son gleidem Wltter bat nidjt ben fhisarzen Streifen vom Edjnabel zum Jluge.

Wonn bie Sommertradtt an bie Stelle ber $23 i n=$ sertracht tritt, fo zeigt fie fich exf auf oer Sdyeitel, am Siintertopfe und Scalfe; darauf bred)en bie Sommerfes Dern auf bem Sorberrúcen und ben Edultern hervor; bann iff ber ganze Rưcen bis an bie Dedfedern bes

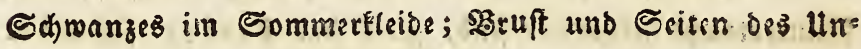
terleibez getién zuleşt in diefés itber.

Diefe Speciez, die Szlands cinziger Tetrao ift, fdgeint nod nidjt befdrieben, und biefer ifolitten Sinfel eigen, żu \{ens. Reine Befdreibung von T. lagopus aucțorum will bazu paffen. Selbft yon bem T. lagopus ber nadbbartidfen Faunen, nimlidh bem grơnlónbifchen, Wefdrieben von gabricius in Fauna groenlandica, uns bem norwegifhen, befdrieben von $\mathfrak{R}$ ill fon in Fauna fuecica unter bem Ramen $T$, alpinus, weldhe zrei ibens. tifd find, ift ber islandifhe verfhieben. Sdyon bie Bes bauptung mehrerer Naturfunbigen, Daß ber norwegifde T. lagopus fid im Sommer nie nuf ben Ebenen fes ben laffe, war mir auffalleno, da ber iståndifche peine Sungen baufiger auf ben gebujhhigen Ebenen als ouf ben Bergen ausbrůtet, unb erft gegen oen winter biefe unbes singt befteigt; id babe aber aud (belegentheit gebabt, Qng Mannden bez normegifhen T. lagopus in Ecmmet: 


\section{( I I )}

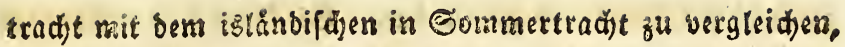
uno fie firt garzz verfdiesen. Der Sd)nabel bes istån.

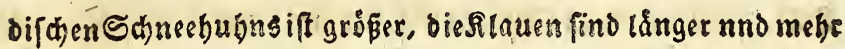

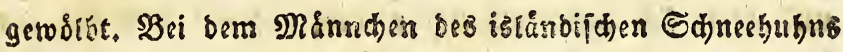

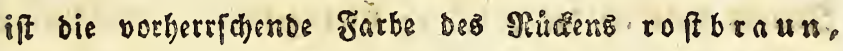

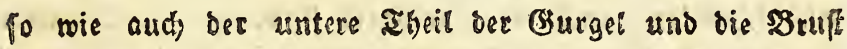
yollfommen bie Farbe bes srüdens babes. Bei bem nors rnegifden T. lagopus ongegen firco Untergats und $5 \mathrm{gru}$ fegr bunEel und foft ogne Ettcifen. Ebenfalle fdjeint ed sin

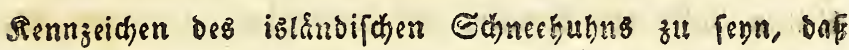
beibe (Seffletedter in jebem alter im sainter bas treite fdrwarze Band vom 2luge bis zum Raden als Foorts fersung bes sủgets baben.

T. Islandorum ift ein Stanbyoget in Şรtanb unఠ ủberaus baufig auf ber ganzen Infer. Das 2Beibden befommt früh pein Sommertleit, nod) elbe es Eier legt, gegen Enbe bes Mai's; bas Manndten hingegen, bas

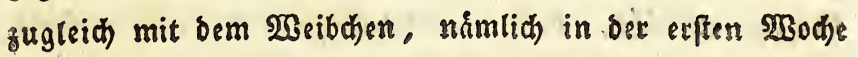
Des Xprils, anfängt bie bunten Sommetedern zुน befoms men, ift boch nodh gegen Enbe bes Mai's weis mit buns tem Sopfe, und nidjt eher, als gegen Ende bes 2fugufte, in ungemildster Sommertradt, bie es fobon wieber gegen Ende bes Septembers anföngt za verlieren, fo daß ez ges gen Enbe bes Sctobers, wie Dab Weibchen, wieber in yols

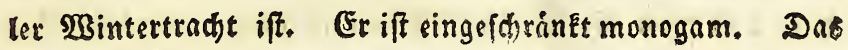
Manndien bleibt immer in ber Mibe bes brütenden Beibs d)ens; roenn bie Sungen ausgebrütet find, entfernt erfes res fich von ber Familie. Borziglid in ber Begattungz: geit låpt bas Minnd)en, wenn es auffliegt ober fich nies

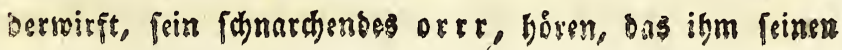




\section{$(x 2$,}

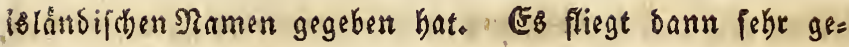
fchrwind mit faum bewegten Ftheln, ftrigt fajråg in bie

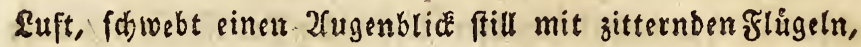
und soirft fich bann plóstich nicber. Sn ber \$Ritte bes Sunius babe ich bie 9 bie 14 Eier gefunben, die Eleiner und fomaler, auth mebr rothgelb fino, als die bes nors sogif hen $T$. lagopus, und viele gróbere und Eleinere braune Jleceen baben. Das 2 Beibchen legt fie in ein funftofes, aus welten Blåttern zufammengefdarttes, Meft unter ciner Eleinen Salix ober Betula, und zroar båufiger in gebůfdois gen Ebenen unb auf ben niebrigften Bergebenen, als böber

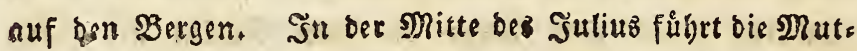
tet bie fleinen Jungen und fammelt fie gltudend, wie bie Şenne; biefe antworten mit einem Laute, ber ber Rods fimme ber $E$. nivalis nabe fommt. So wie bas Sdneres buhn ůberbaupt vortrefflid) zu laufen, fich zu budeen unb ğ verbergen weí, fo fint bic sungen, weun ignen eine Bisfabr auffiost, ben Jugenblice zerftreut und verftect,

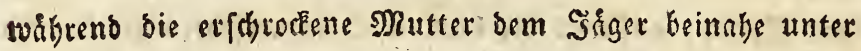

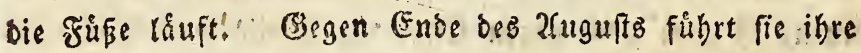
sungen nodj in ben Iballern; diefe findo bann cben fo gró, als fic, und bis auf ben fowarzen Bügel ber Minndtsen, von

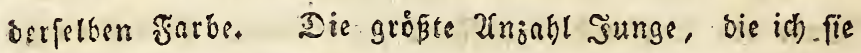

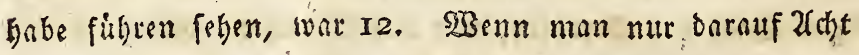
bat, daß́ man Die Mutter fdjont, fo sann man leidft ben ganzen arupp, sinz nach brm andern, wrgfoleffien; benn bie Mutter fliegt, von bem Eechuffe erfd)redit, z'war mif,

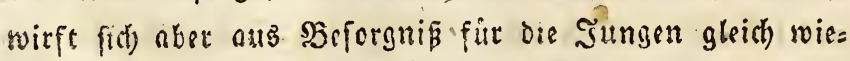

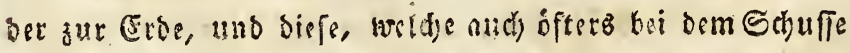

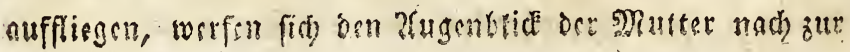




\section{( 13 )}

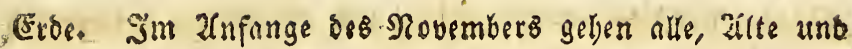
Sunge, auf bie bobdten Berge, und bleiben, oft in gropern

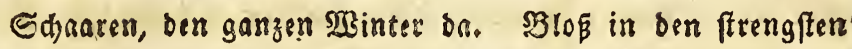

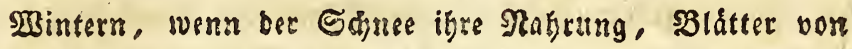
Empetrum nigrum, Dryas octopetala, burthaub bebecit, werben fie grzwungen, fich in bie fubalpini(a)en Regioner betab zu begeber, tro fie fir bon sinofpen vor Salices uno Betulæ nalgren; ia fie meroen bann fogar ganz hera's in bie Thiler getrieben, wo fie ausgefunngert in bie 230 hnun:

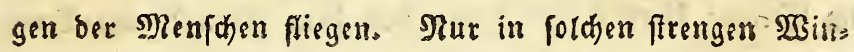
tern wagen fie 68 , von Norb: Şzand ủber bie 6 Meilers breite Merrenge 'nach G5 rimsse zu fliegen, um auf bies per Eleinen Snfel, bie im \$Binter felten mit bohem Edynes bebedt ift, ifre Rahrung zu finden. Sie baben gern bes ftimmte Rubeplåge, mebrentheils auf hoben Eteinen, wots auf fie, wabrideinlidh gegen barte 2Bitterung, Sorrath von obgenannter Nabrung einfammetn.

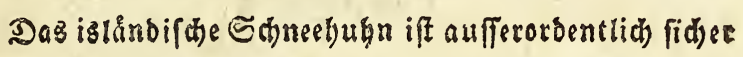

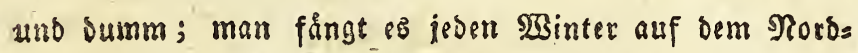

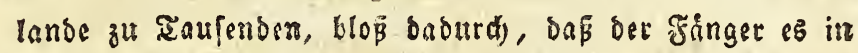
feine Sdilingon treite. SDft nerbirgt es fich biz an ber Sopf im Schne, und wiro bem Saager blop burch feine Spur, unb burdh feimen fóftrarzen Etreifen vom Sannabel burdi) baz 2fuge. zum Racten, verrathen.

Schlieplich tann id nidt unterlaffen sin bemerfenz:

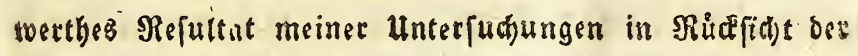

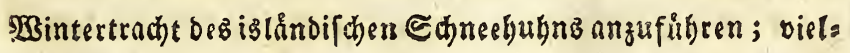
leidht haben bie Strnithologen bei ifren Beobadtungen ber

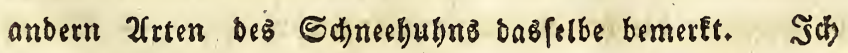

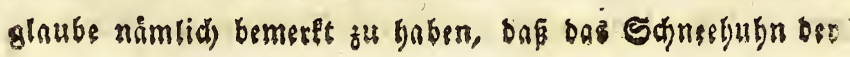




\section{$(84)$}

J̧3tånber nur bie Sommerfebern burch bie Mauje befommt. Daß̈ aber bie meiflen Federn bez wointers Eeine Folge

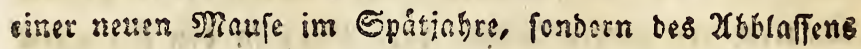
ber Sommerfedern, firbo. Ja ben Btutfedern fand idi ftets bie bunte Commerfoster, nie bis maiffe Winterfever; $D a=$

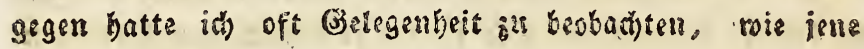

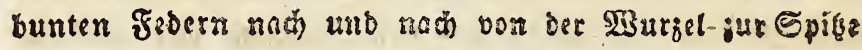

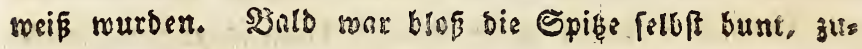

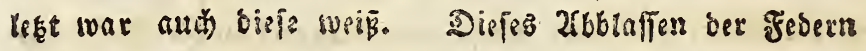

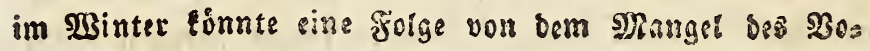

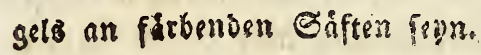

\section{Ordo 4 . tras $f e r e s$. \\ Genus 5 . Loxia (Linn.).}

1. Lox. ferinus (Scopoli), iฮl.....

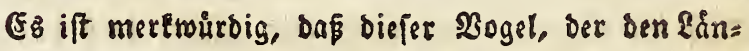
Sazn bes fübliden Europa, eigen ift, uno weder in Dins mart nod) Edybobm gefunden spirb, Soch zumeilsm nadi

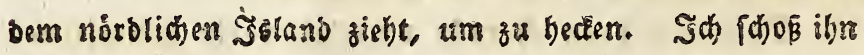

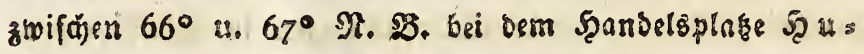
Ravit, ben saten Geptbr. I819, toabricheinlidy in peimer

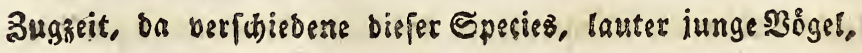

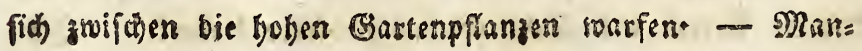

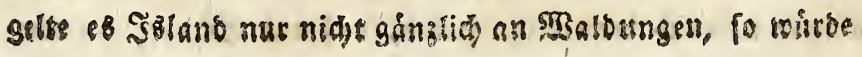




\section{( 15$)$}

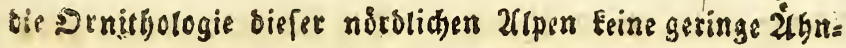
lidfert mit ber ber Sdbreiser 2l(pen baben.

\section{Genus 6. \\ Emberiza (Linn.).}

1. E. calcarata (Temm.), iв ....

WBitb gewoogntidy nicht in Istanb gefunben; blog im frübling I82I fabe id) cinzelne auf bem Sưdlanbe un. ter E, nivalis。

2. E. nivalis (Linn.), isf. Sniótitlíngr, Gól。 Ariftia.

Sft båufig. Die meiften überwintern, einzetne ziles Jen reg. Cie hat Wintertracht. J̈m Sommer if ber

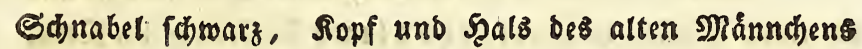

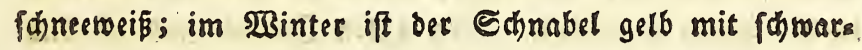
zer Epize, und ber Siopf Eaftanienbraun angetaufen. Dodh. ift ber unterfdied bei bem Weibden geringer. Der $\mathfrak{B}_{0}=$ gel, befonders das Minnchen, if im Sommer alfo weiffer als im Winter. Sm 2infang Des 21prils ift ber Echnas bet balb gelb und balb falsonrs, und bald darauf ife bec Boget im Sommerlleibe; gegen Ende des 2lugufts foongts Der idswarze Sahnabel wisber an gelb zu merben, aber bee 3ogel ift erft im 2tnfange bez Novembers in Mintertrachto

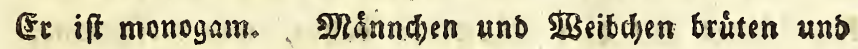
furttern beibe. Sm ber, erfern Das Nefft im Norblande, unten in ben Ihalern, in Steins

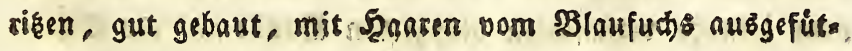
Aert, im Difcus \$ferbshaar. Der Gier fing 50 Denen bes. 


\section{(I) IG}

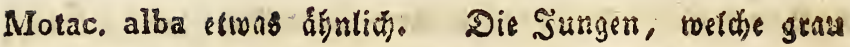

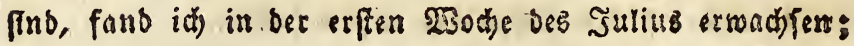
ouf ber füblichen Seite bes Eendez aber [ajon ben I8ters Junius. Eeegen bas Spåtiaht zirght bie ganze familie auf bie Felfen, um fich bafeleft von sem Camen ber \$berg=

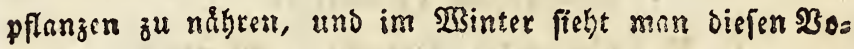

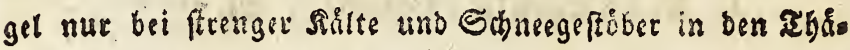
lern. Edjon im 2 nnfange bes MR\&rz fángt er an auf bene डd)res zu givitfigern, und fingt in Eommer angenebmo

\section{Genus \%. Fringilla (Linn.).}

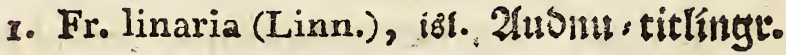

Diefe Species ift felten in Jstanb. SH habe fie nue an ciner Etetle, in frniofted a lens Geftråud im Norbs lanbe, Geden-gefunder. Den I3ten sullus fand id bas Neft in ben niebrigen Sirkenbůchen; bie sungen twaren ausgeflogen, aber in ber Rabe bractete bie 2tten einem

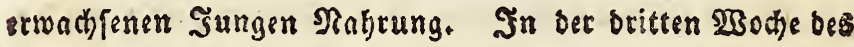
Septembers fand i并 diefe Fringilla nod trappmeife irs

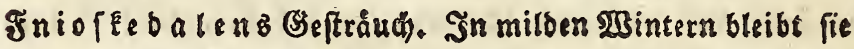
in Sstand. So lisp fie fich im 2Binter $1819-20$ bei bem

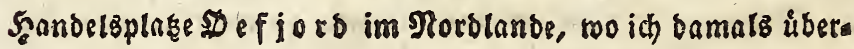
minterte, bann uns warn in Eleinen Sdjaaren Feten. Sik (nom immer mit bem Sübroinbe babin, und verfotwand. senn Rorbminb eintrat. Die jungen Månd)en battern eize İratht, febte åtntid) ber bet Fr. flaviroltris, mit eis nem beinake verwifchten blaßgetben Banbe auf ber Sabeis

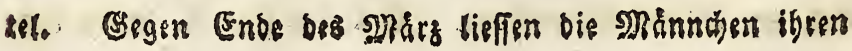




\section{(I) )}

nidht unangenebmen, aber leife grwitfdernben, bisfang auf bem Sdyne boiren, worin oft ihre sodftimme pibersis vortinm.

\section{Genus 8 . \\ Turdus (Linn.).}

I. T. iliacus (Linn:), iฮl. Stógar profit.

Şin und wieder in ben Eleinen Birsengeftráuchert,

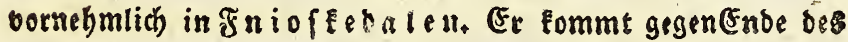
Mårz, und nimmt bann zumeilen, faft ganz yor Filite ess

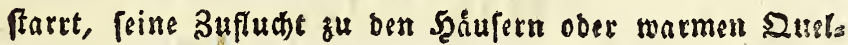
len. Im Frůbjahe ndight ex fid meiftens yon Curculio. nes. Noch ben gten November babe id) ifn auf bem Sưdz

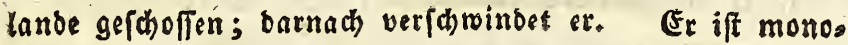
gam, Pånnd)en und Beibchen brůten, unb bringen bers

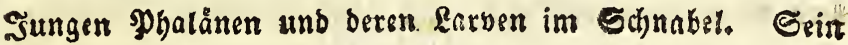
Neft feģt er nisorig in Birkenbůfó)en. Mitten im Sunius bat ex Eiet; mitten im sulius babe idh ibn ben aubgeflos genen Sungen Rabrung bringen fohen. Noch) im Seps

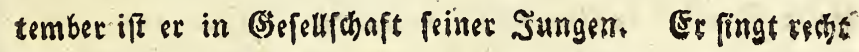
angsnelgm, aber in furzen Strophen.

\section{Genus 9 . Motacilla (Lath.).}

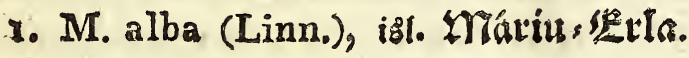

siemlid båufig, fogar in ben nórblidffen Oesegens ben ber J̄nfel. Der Tag ifrer 2fneunft tear in den Soms

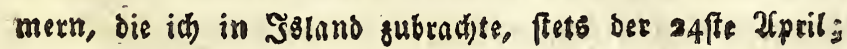
mitten im Eeptember apridminbet fis misder, Gis ifp 


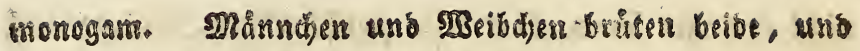

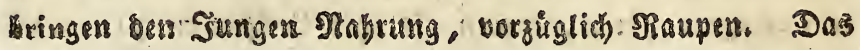

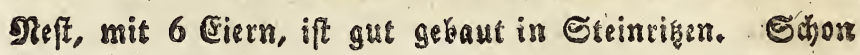
in ber Mitee bes Surrias fabe id fie ben Sungen Mabrung

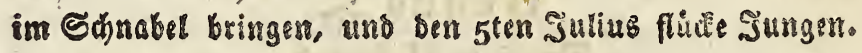

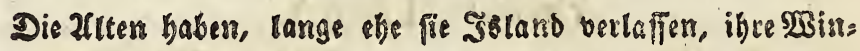
uettracht, ber ber Iungen gleich, angelegt. Der (Befang iff groitidherno und laifes?

\section{Genus 10. \\ Saxicola (Bechrt.).}

1. S. oenanthe (Bechft.); ist. Stcinsepill.

Ifn feinigen Etellen, welche fie pogar auf ben hio. bers $23 e$ ergebenen aufficht, foft båufiger als bie \$orberges Genoe. Siz commt vom zoften Ipril biz 4 ten Mni ast, und sieht in Det smeiten 250 dhe deb September wieder

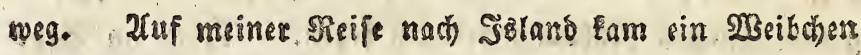
biefer Epeciss in einem Gtum, zo speilen von allem

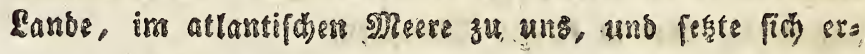

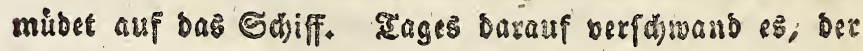

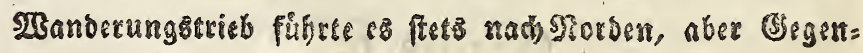

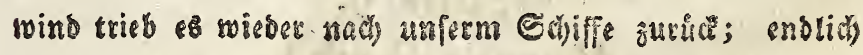

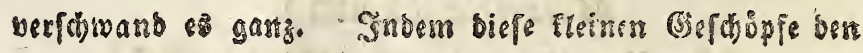

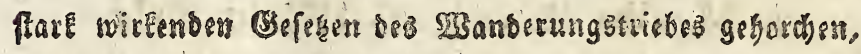

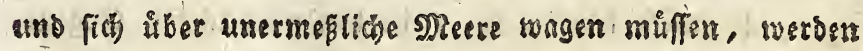
fie oft eine Beste ber vafenben Elemente. S. oenanthe ift monogam; Minnchen uno 2 eibchen bringen ben Surs

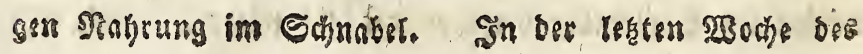




\section{( I9)}

Siunius fanb ing tleine Sumgen, ben sten Sulius fah id fie flide.

\section{Genus II. \\ Sylvia (Lath.).}

2. S. troglodytes, iहr. Mifabrósiv, Rinoill.

Wito bin unb wieber im ganzen farbe gefunben; sin Stanbooget, ber fith zul Enbe bes Jugufís ben Şåu. fern nåbert, und bie \$orratbztammern ber Șzเånber bes

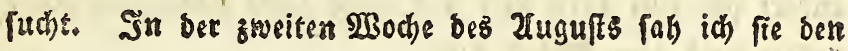

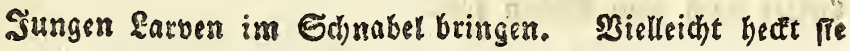

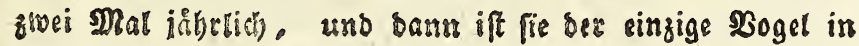

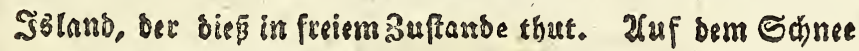
fimgt fie im ISBinter mit tauter Stinume.

\section{Genus I2. Autbus (Bechnt)}

1. A. pratenfis (Bechlt.), ibl. (Brátitlingt, Difuteiturge:

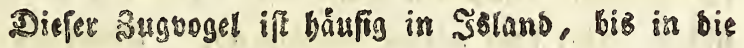

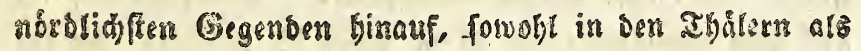
auf Den niebern sergeberren. Er Fommt Den affen-

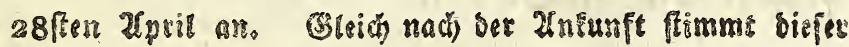

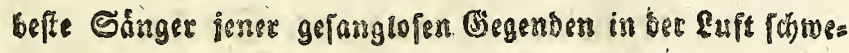

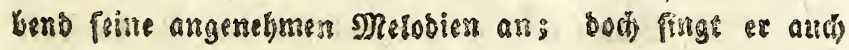

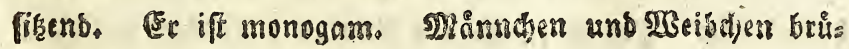

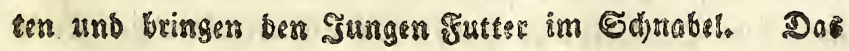
Neft mit cierm fano id, auf bem Nordrande gegen Ens

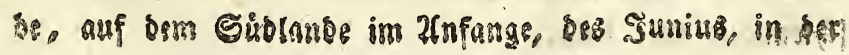




\section{( 30$)$}

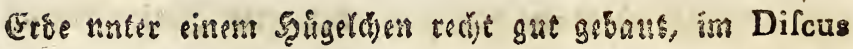

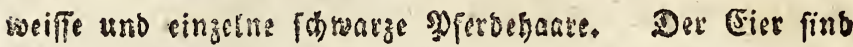

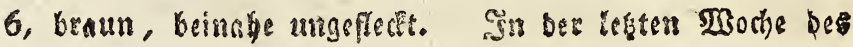
Juning babe iail fie fohon auf sem Giblambe mis Maupen

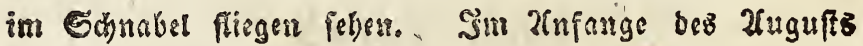

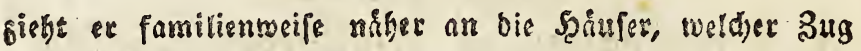
bis in bie SRitte des Septembers bauret, be er verfüwin= bet. Zuf meiner Ridtreife nati Sinmar Ém ein A. pratenfis mitten auf bem atlontifacn Mreers an bis Sibiff. rubete fid) cine furze Bcit aus, uno ferste bami !eine Reife weiter nach bem Siben fort.

\section{Gerus I3. Hirundo (Limo).

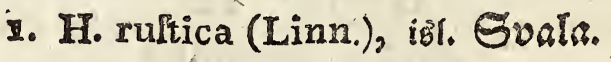 \\ Sie veritrt fich fefre felten nach ştans. 26uf bem

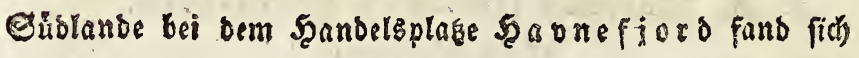

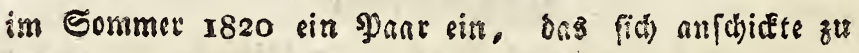 miffen, aber balb wieber verformand. Cenfalls fah ich nuF Dem storblande, ben Balg cinee H. ruftica, bie iss} Eommer I8I8 gefangen wax.

\section{H. urbica (Linn.), iริโ. Guala.}

Eie fommt nod feltme nach solanb, als bie Bor?

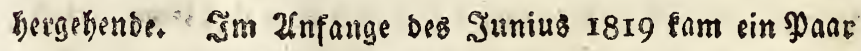

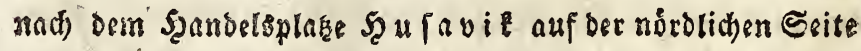

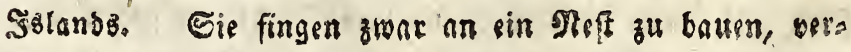
phwauden aber barb. 


\section{(22) \\ Genus I5. \\ Chavadrius (Linn.):}

x. Ch. hiaticula (Linn.), iฮి. Sant , Lóa.

Sft ziemlich hâfig; fommt an vom 22 ften biz 28 ffert Unvil, und witb banu in (sefeurdaft mit Tringa alpina

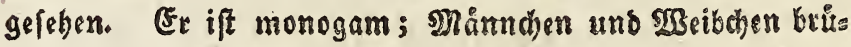

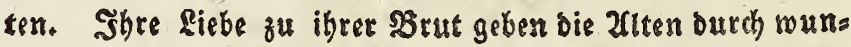
berlide (Seberben, wenn fie in (Befabr ift, baburd) zo ets Eennen, baß fie mit boingenben Flügetn unb ausebebreites tem Echwanze den Bauth långs der CExde binfohleppen. Die 4 Eier besfelben fand id ins Eande, fornobl am Mres

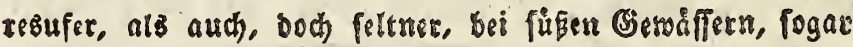
bei ben sanchen ber niebern Bergebenen. Begen Ende

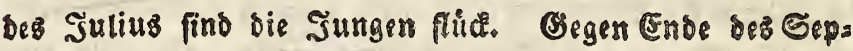
aembers gieft ex fort. Er folwinmt gumeillen yon felbft, aber felten une nathe am ufer.

2. Ch. pluvialis (Linn.), iริ . Lóa.

Şiufig auf Miefen und niebrigent Bergebenen. fommt an vom I6ten bis 2Iften 2ipril in peinec Gommer. tracht, worin er noch im 2rnfange bes 2rargufte gatleibet iff. Er if monogam. Seine 4 Cier, ein wenig gróp̄et

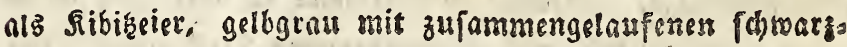
braunen Fledern, fand ich auf ber blopen Eroe in Şiget. den, gegen Ende bes Mai's. Ere iff fo mild in ber 23 ars Drtungzzeit, als zahm in der Begatntngzzeit. Gegen Ende Des Sulius bat ex errachlente sunge, uns ift in Bepells fichaft mit biefen von 2infang bes Iugufts bis gu Enve Des Sctobers, be bie tegten wegzieben, boch blsisen zumpis 


\section{( 23$)$}

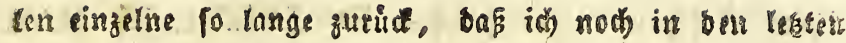

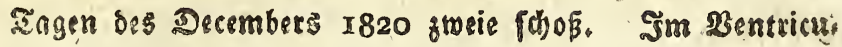
10: Curculiones, Sorben, Grasecims, Seeren von Empetrum un Vaccinium.

\section{Genus 16. \\ Calidyis (Illiger.).}

1. C. arenaria (Hlig.), ialo $=\ldots$

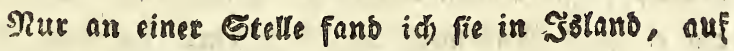

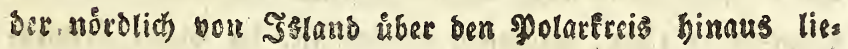

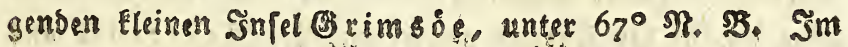

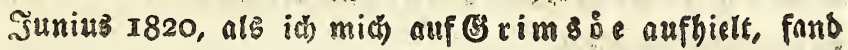

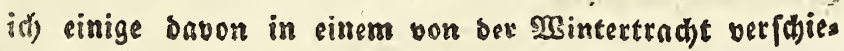
Donen Rleide am Strande unter Tr. alpina Iaufen, ber

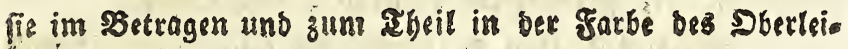
bes glidjen. 30rnig, mit gefentem Şarfe uns aufgeblåbe= ess febern, verfolgter fie $\mathrm{Tr}$. alpina, $\mathbf{T r}$, maxitima uno Sir. collaris, nl3 beneibeten fie biefen bie am Stranbe auf: gelcfone Stabrung. Sogleich ich ibe (Eier nidt fanb, fo

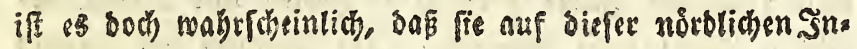
fil sifiet.

\section{Genus 17. Arder (Linn.).}

1. A. cinerea (Latho), iร่l, Бegti.

Einzelne taffen fich jeben Frubling und Şerbft is

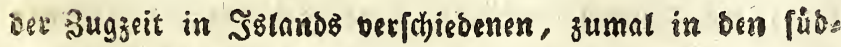
litben, Segenben feben. Sogar auf (5) rim tor mo

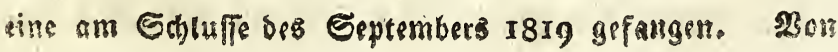




\section{(24)}

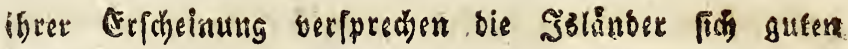
Jild fang.

\section{Genus 18. Nunzenius (Brisf.).}

I. N. arquata (Lath.), iÊ. ....

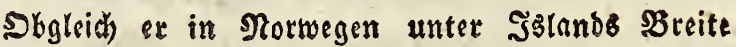

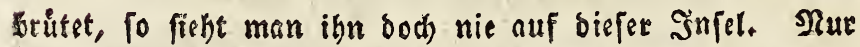
ein einziges Ment weis idh, Das einer bafelbft, Den 6 ten Eeptember 1819, gefthoffen morben ift, ba biefer Nume-

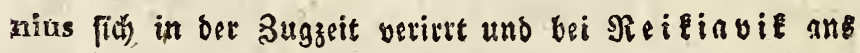
ufer gerworfen batte.

2. N. phæopus (Lath.), i⿱宀. Spót.

saito faft eben fo båufig als $\mathrm{Ch}$, pluvialis uns an benfelber Etellen gefunber. Fer exommt an in ben leęten Tagen Des Zeprils und in ben erften Iingen bes Mni's, ift monogam, und bat große Riebe zu feiner Brut.

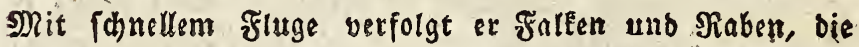
feinem Refte nabe Eommen. Im Znfange bes Sunius giebt fein trillernber und flótender Ion zu exEennen, baß er fid) paart. Seine 4 Eier, an Farbe und Gróbe benem ber Lestris pomarina gleid, olivengrút, mit, zumal am biden Enbe, zufammengeghafter fohnarzbraunen Fllecen, findet man beinabe obne Unterlage in Den Şĭs gelchen ber $23 i e f e n$ unb bodigelegenen 5zeiben. Begen

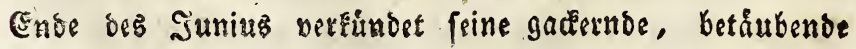
Etimme, daß er sunge bat. Diefe find fhon in ber

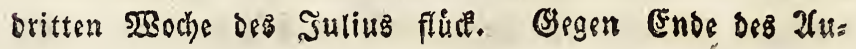




\section{$(25)$}

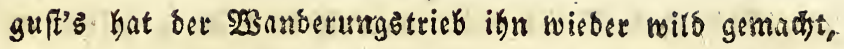
und or fliegt bann bod) in ber 2 nft, big or in ber Mitte bes Eeptembers ganz verfatwindet. Im Mentrisulo: Infecten, Nerita littoralis \&c.

\section{Genius I9. \\ Línofa (Leisler).}

x. L. melanura (Leisl.), isl. Jatroteta.

$33 i r b$ nur in bem fubliden şgrand, und zwar in Xrnes und $\Re$ angroualle: Syşel, boch ba nidfe

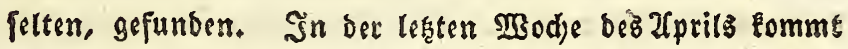
fie an, da man fie am Etrande fiebt; fdjon in ben exfrers

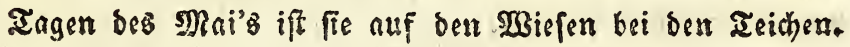
Sie if monogan. Bas Mannchen ift bei biefer Speciez, wie bei bem Genuz ber Phalaropus, Eleiner utro nidfe fo fhoin, als bas weibchem. Die Eier babe ith nidht ges funben; fie werben von ben Eintwohnern, wie bie bes $\mathbf{N}$. phæopus, an Farbe, Eeftalt und beinabe von berferbern

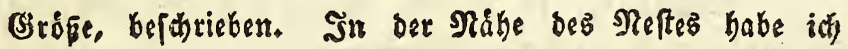
ben $\mathfrak{B o g e l}$ oft gefeben, bet bann zahm fliegend den MBan= folen umereif't, fich nabe vor ibm nisberwirft unb, wie

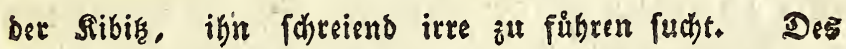

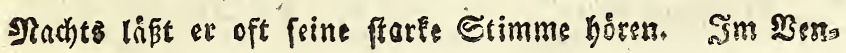
sticulo: 2 afferpflangest.

\section{Genus 20.}

Totanus (Bech(t).).

7. T. calidris (Bechlt.), เฮ็. Eteltuk: sft ziemlid kiufig auf 2 Biefen und niebrigess

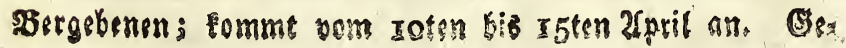




\section{( 26$)$}

gett Ende bess Mai's finbet man fajon feine 4 gelblichen (Fier mit fobwarbraunen Flecten in Şigelden und un= tec Sdjirmpflanzen. Die monogamen 2alten zeigen große Sorgfalt füc ihre SBrut, um welche fie angftlid) und mit lagenber Stimme fliegen, menn fie in Sefabr iff. Edjon ben gten Sunius babe ib bie fleinen sungen gefeben. Sn ben beiben lesten 2 sodien oes Sultus fommen Junge und 2rtte fobanenweife an den Strand; im 2lnfange bes "sctobers zieken fie meg. Merfwürbig ift, daß cinzelne scurbeilem zuruce bleiben; fo fab ich now sinige im Rovem: ber und December I820. Sie fdrwimmen von felbft, ob= gleid) felten. Son feimem wadelnden Gange hat er feis nen ielænoiften Mamen.

\section{Genus 2 I. Vanellus (Brifr.).}

1. V. criftatus (Meyer.), iรి. - -

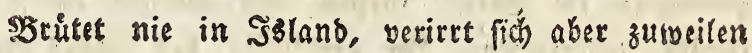

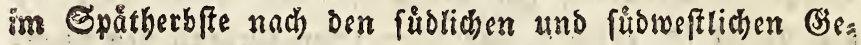
senden. So wurbe er I820 auf ben $\mathfrak{B}$ eft manoern,

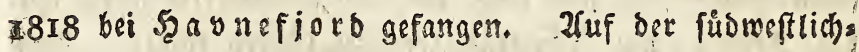

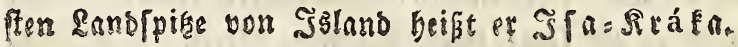

\section{Genus 22. Strepfilas (Illig.).}

I. Str. collaris (Temm.), isl. Tilota. Syaufiger in ben fubriden uns weftliden begen= Sent bes Landes, ats in ben norblichen; ooch fand id fie

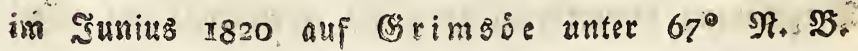




\section{( 27$)$}

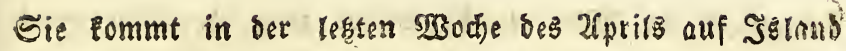
an, und ift bann noch in 23 intertrad)t. Im 2(nfange bes Mni's fieft man fie im liebergantgéleibe zur Som: merpracht, worin fie im 2 nfange ses Simius gefleibet iff. SBo fie auf Şšland brůtet, ift mir unbeEannt, aber fie verfdinindet im Commer, vielleicht boch hinanf zroif chens

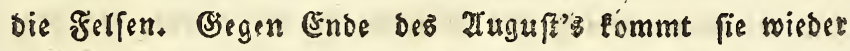
(charentweife mit ben gropen Sungen am Strande zume Borfchein. Die Zlten fangen nun on bie פsintertrad) anzumehmen, weldse fie in bes Mitte Des Geptembers ers balten baben. Sutz barauf verforwinden fie son ber șns

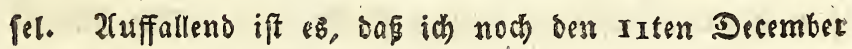

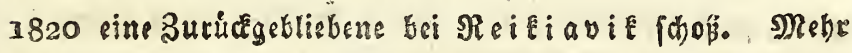
furcthtfam, ats Tr. alpina, mit bis fie' zumeilen in Sehaaren ift, giebt fie jener burch ein mieberboltes wo

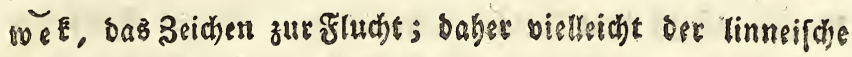
ఇame intergres.

\section{Genus 23. \\ Tringa (Briff.)}

1. Tr. cinerea (Linn.), iฮึ. Raubbryftingt:

Şin und wiebsr, zumal in ben firblichen Eegens

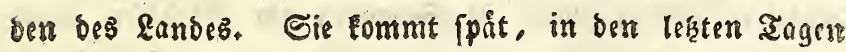
bes Mai's, und ift bann in ihrer, unten blutrothen, Sommertracht. åu biefer zeit fiefht man fie am Mecr: ufer in (Sefellf haft mit Str. collaris; fie if eben fo furchtfam als biefe. Sim Sommer verfomindet fie als Den Ighålern, unb ziebt vermutblid auf bie hohen Berg=

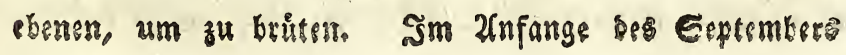




\section{( 28$)$}

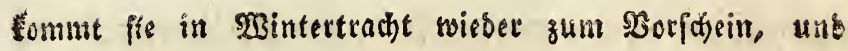
in ber Mitte biefes Monnths zieht fie von Jistano weg.

2. Tr. maritima (Brünn.), is̊l. Selningr.

Die biuffigfte von biefer Gonttung und ein Stand: vogel in Sistand. Begen Enje bes Már fingt fis an

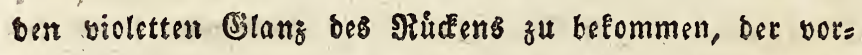
snemmlich ifre nicht felye abweidhende Sommertracht auss oseidnet. Eie if monogam, brütst auf hoben \$ergebes nen, wo ith melbrmals im Sommer sie 2utten gefolfoffer babe. Nur folten legt fie Cier in freinigen abålern, boch fand id an einet polchen Stelle, ben 22 ften Sunius

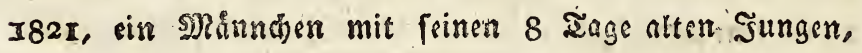

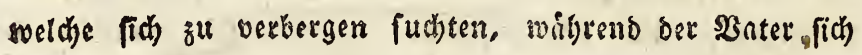
ångftlid, mit aufgeblåbeten Feoetur und pfeifeno, auf bem 3autdie lings bem Boben fortichleppts. Giegen Ende bes 2lugulfs Eommt fie von ibren sgruteplifigen berab at bas Deerufer, und man fieft fie ba, und aud) an bcm Ins meren ber fobmalen Meerbufen, bis in bie shitte bes Nos nembers, ba fie geinglict) an bas ttfer bes offenen Meerez ziebt, two fie ben gangen SBinter in ungehouren Echanen zus bringt. Noch in ber Mitte Des Sünius fieft man,

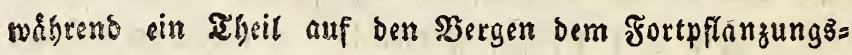
gefdafte obliegt, visle in Echaren am Etrande, benar fie lebt, wie $\mathrm{Tr}$, alpina, gern in Shaaren. Sie ift die

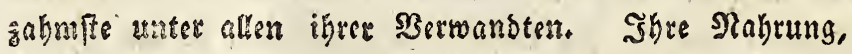
Nerita, Patella and andere Zrten von Testacea uns Mollusca, forn fie nut finden, wenn bie Edjeren zur

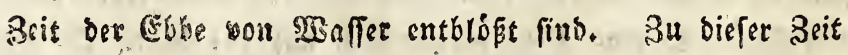

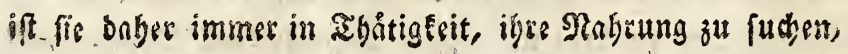




\section{(29)}

fogar in ber Demmerung und im Monsponeta, soobai fie fith gut vor ben gegen bie Sdjeren anfälagenben wellere ful hüthen weis. Sis fhrmimmt zwar langfan, nber iffer uno speiter vom Ufes, ats bie ober genannten. Sth babe fie in . Winter bei ftark roogendem Meere sin Stücechers Eis befteiges fohen, wornesf fis whyig in bis Ese binats triet.

\section{Tr. alpina (Linn.) ) iริใ. Ló}

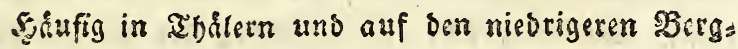
ebrnen. Sie fommt ungefähr ben I8ten 2rpril an, uno if sam foron is Sommertradt. Cie lebt nun sine

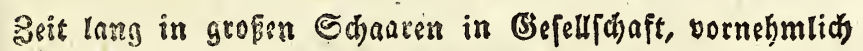
mit Char, hiaticula. Eine mertwutroige Eigenbeit findet

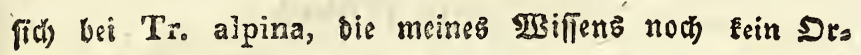
nitfolog erwaihnt bat, uno bie wisber cuf bie abeorie

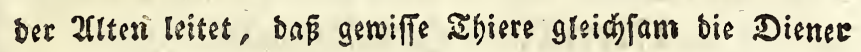
anderer Ibiere wâres. Begen Enbe des Mai's vereinigt fich nimlich eine sinzelne Tr. alpina mit einem einzels nen Char. pluvialis, führt biefen an, giebt" bas zeichen

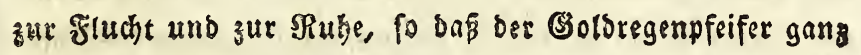
aunter ber Reitung ber $\mathrm{Tr}$, alpina freht, welches aufzuhds sen fheint, wenn ber Char. pluvialis feinen Gatten gefuns

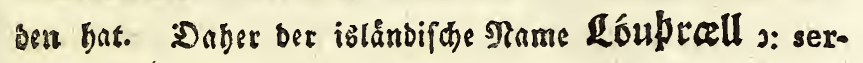
vus charadr. pluvialis, Sie if monogam. Sn bec

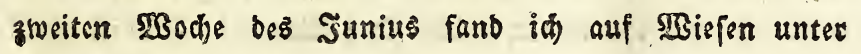

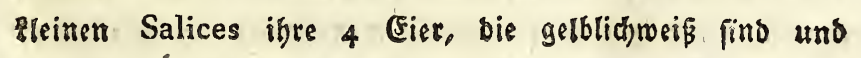
braune, am biden Enoe beinabe zufammenlaufenos, Flecten

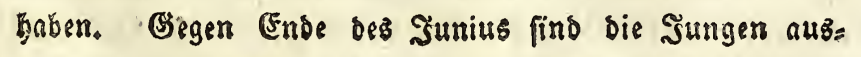

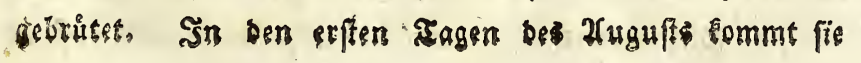




\section{( 30$)$}

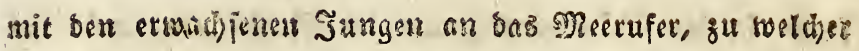
3eit faft alle ije Şerbftradit befommen baben. Sim Znfange des Sctobers fino nach cingetne auf Sztano zuts rict, welche gleich barnath reggielen.

4. Tr. pugnax (Linn.), izి. ....

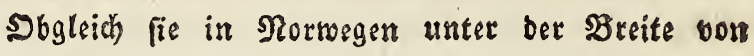
Sisland gefunden wirb, fo fieft man fie bod) nie in Jze tand. Ein cinziges Mal, in Jinfange bes Septembers

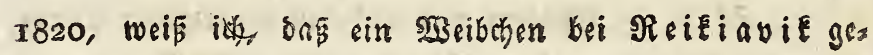
sefchoffen roordent iff.

\section{Genus 24. \\ Scolopax (Illig.).}

I. Sc. gallinago (Linn.) iริ. Miyrifpitan nyrifitr, brosfagoutr.

Niobs felten auf 2 Biefen ano den niebrigften 2 Bergs

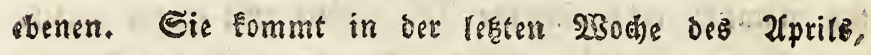
und fingt fohon in ber sMitte bis Nai's an, ihre Som= anerftimme bỏres zat laffen, die ouf bas Erwachen bes forts pifanzungstriebes beutet, uns in sinem tangen brummens Den, ober vielmege wielfermben, mit sinem wieberholters

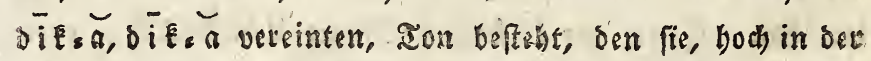
seuft mit zitternden flitgelt bin uns bet fawebend, bơen

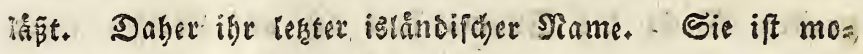

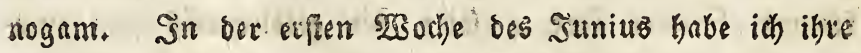
4 grinlich gelben Eier, mit großen braunen Fleden, 'weldye an bem bicken Ende eir zufammenthängendes Ganzes bit:

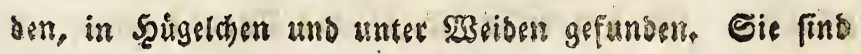




\section{$(32)$}

gel, in Sostant bimgegen ein Otansvogel ift: ba feine Eurgen Flüget ifn an birfe ifolitte Snfer binben, $100 \mathrm{er}$ im 2 Binter cint trautiges Seben bai bon warmen Suellen fübren muß. Sein 2rufenthatt boi Sủmpfen bat ihm feinen izlänbifden Namen gegeben. Den erften, ben idj fand, griff idh, ben 23ften December I8I9, im Sordan. be mit bent Şänben, ba er bei hodygefallenem Sdines. aubgefungert in bem Şandelsplage \$D fioro cine suflucht

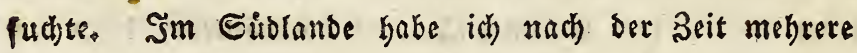
gefelen, bie bort gefangen maren, und ein glaubroirbiger Mann bat mir erzåblt, daß er bafelbft dab ఇeft besfelben, mit $x_{3}$ weiffen, braungeflecten, Eiren, auf einer fumpfigen 2Biefe gefunben babe. Sn Rangeavalle=Eyzfel

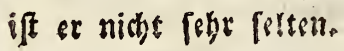

\section{0 do 6. \\ N. $t a t a t s$.}

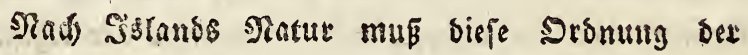
Bögel ben widttigfen æheil ber Sunttgologie der Snjel

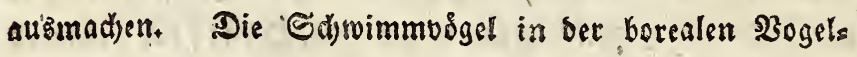

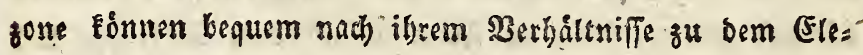

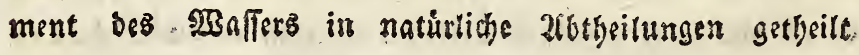
werber.

Die Eี

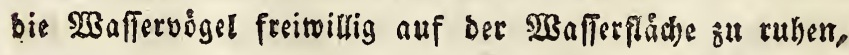
und bafelbft alle Berridtungen aแgugutben, im Stande fint, welü) bie ůbrigen, Bogel auf ber srlache bes trodfes nen sandes vernebmen, fonnte man sinfa hi nentren, 


\section{( 34$)$}

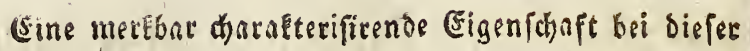
Zit Monogamie, die idh bei Esinem Edorifteftller erwihnt gefunden babe, befight barin, bas bas Månndhen, wie bas 2Barbdhen, ba bie meifen Epecies berfarben burchaus lein Neft bauen, fid , fatt beffen, an ciner doer an mehrern Stellen des abdomen federn und fraumfeosen austupfen,

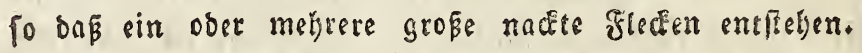
Diefe nadien fleden bilber fo zu fagen an sem Reibe be Sagels felbft bas wairmenbe \$ieft, indem bie Eier, wels difes ich mefrmals gefrgen habe, von bem 20 gel in biefe

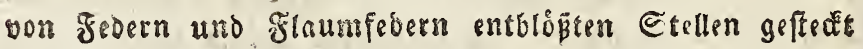
seerben, fo bas die feoern nebern biefen fich wis ein Futs

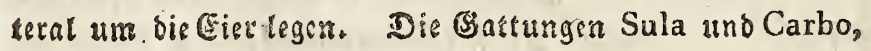

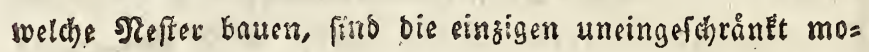
nogamen Eănwimmoógel, Denen dicfe entblópten Etellen mangeln; boch bat bie Bontung Larus, bie boch in

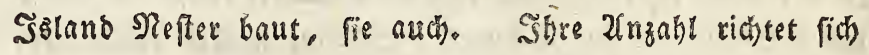
nitht immer nad) ber a 3 zabl ber (5ier, benn Uria alle und bie Gaattunger Alea uno Mormon legen nur sin einziges (Ei, uno baben zwei folhe Scruteffeden, ba binge: gen Larus marinus und L. glaucus Brünn, welche 3 und 2 Eier legen, nar einen baben. Die Brúteffecten

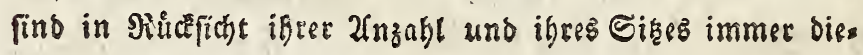
felben für iede Epecirs.

Die meiften borealen $23 a$ affervoggel, welche in uns singefhrånter Monogamie leben, briten in fteilen Jelfen am Meere, wo fie in Bemsinforaft mebserer Iaufende ganze Republiên bilben, und die vercübisbenen 2 trten liegen zers fresut unter sinander in den fecten zerfenfeiten, wåhreno

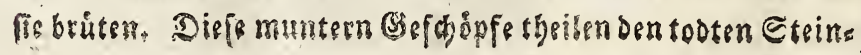




\section{$(36)$}

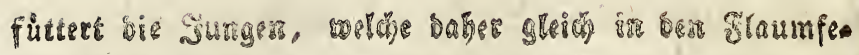

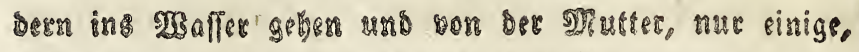

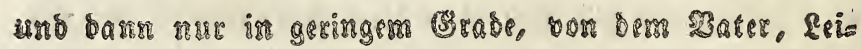

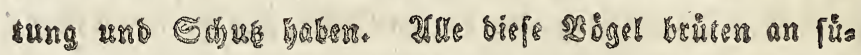

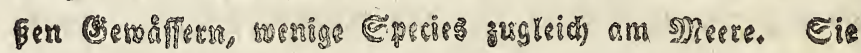

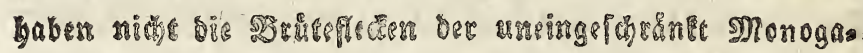

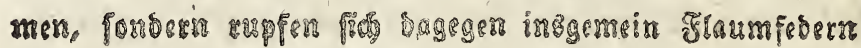

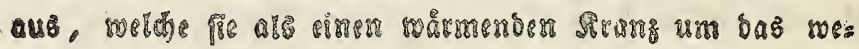

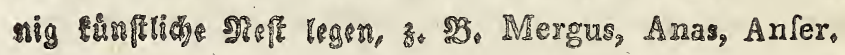

\section{* Dif cinfotyer Gobuimmforbigert.}

\section{Genus 26. \\ Pbalaropus (Bris C).}

Itneingef

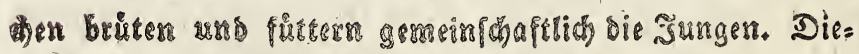

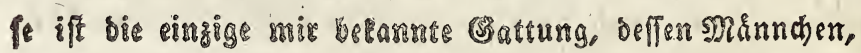

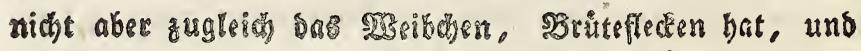

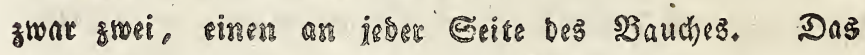
TEsibdjen iff grơ

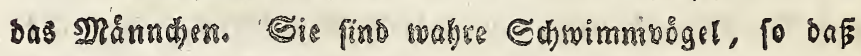

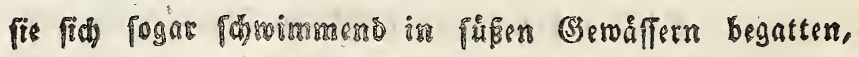
und bei biefer, als sime Jusmathe yon ben uneinges

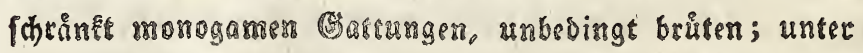

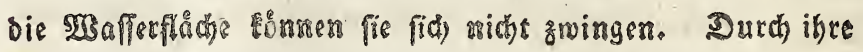
Jungen machert fie eimere maturlichen Uebergang zu bent

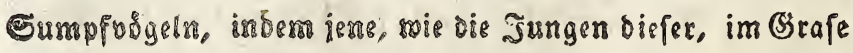
umberlaufen, Do von ders zrtien gefüttert trerden, und erft anfangen gu formimmen wenn fie befiebert fint. Die als 
Den heiffen Quellen, soorin man faum bie F̧and balten fant, mit 2 Bohlgefallen fotroimmen fiebt.

\section{Ph. platyrhincus (Temm.), ig̊l. ....}

Sth hatte beinabe bis Şoffnung aufgegeben, biefen feltenen Boget in Szlano zu finden, - weil id die Sniel fothon in zwei Sabren kereil't hatte, obue eine Epur vont

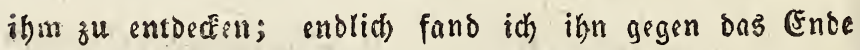

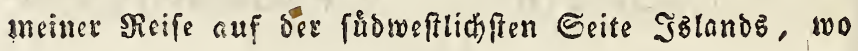
ox: nuch ba folten, nur eine Etrsce von ungefähr feds Mrilkn, bei bon nathe am Strande befindridyen Ieiden mit

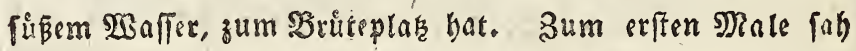
idh ihn ben 2 Iften Sunius I82I am Escufer nabe bei

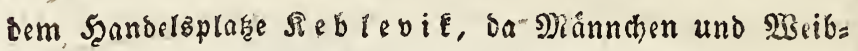
then unter sinem Eleinen Irupp Ph. cinereus fotham:

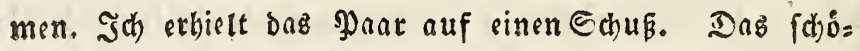
nere und grósere $\mathfrak{B e i b d i e n , ~ b a s ~ s i n e ~ f o h l e c h w a r z e ~ S ̧ a u b e ~}$ hatte, und unten ganz blutroth war, batte beinabe vodlig

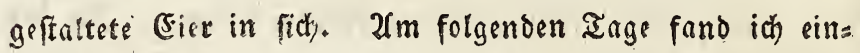

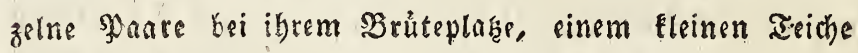

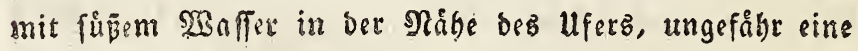
Mrile fubserftich, von Rebrevik. Sie hatten dieferben Eitten, wie $\mathrm{Ph}$ cinereus; alid bie Britefleden, wie bei

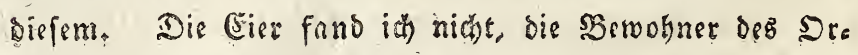

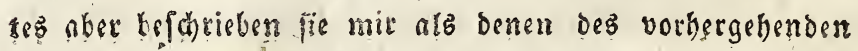
Sogetş an Zaht und Farbe gleid), nur ein wenig gróser.

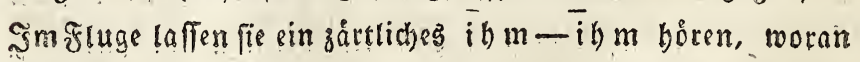
man fie gleich von jenter 3ert unterforeidet. Endich fand

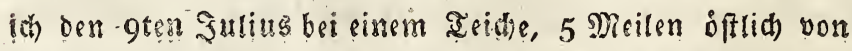

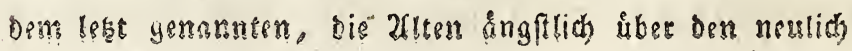




\section{(40)}

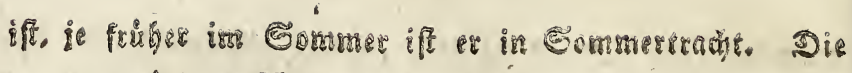

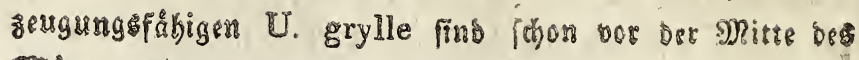

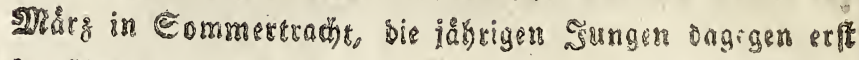

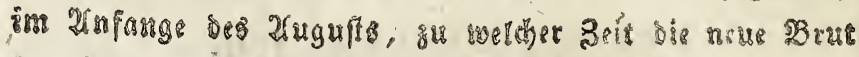

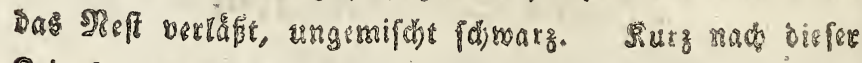

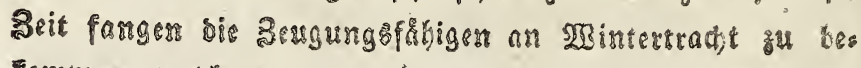

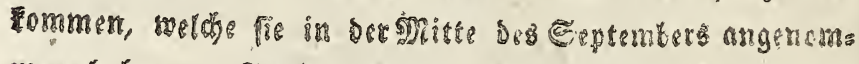

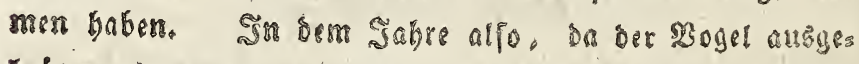
brütet mits, und im polgendon Eommer, hat ot 5 braune Duerfreifen nuf Dem Spiegel; gleith im SRefte, wie auch Dest exfen 2 Binter, iff ex atmeten weis mit vielen braunés Doncten unb Etreifen, aber je weiter hin in Dem barauf forgenden (berm zmeiten) Eommer, ie ungemilchter, fotwarz

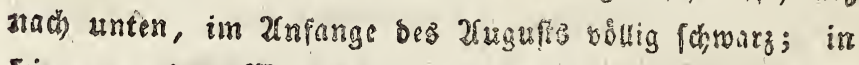
feinem zrmeiten 2 Sinter noch 5 Crecifsn auf Dom Epis=

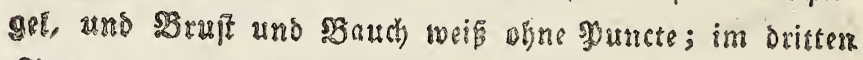
Sommer 2 braune Sureftreifon auf Drm Epiege!, un

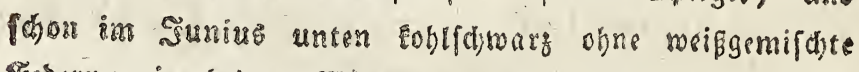

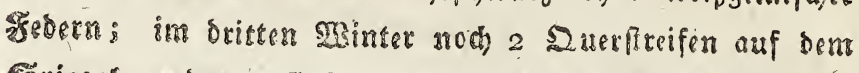

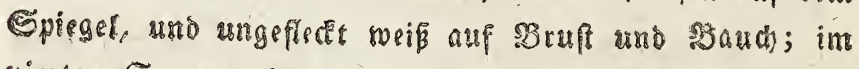
vierten Sommer ber Spiegel granzeno weip, und ban

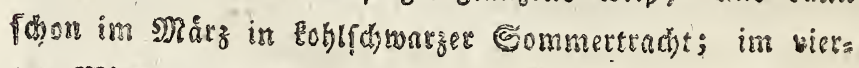

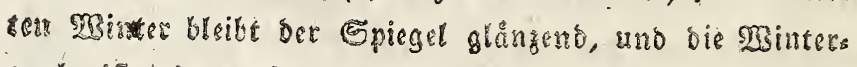

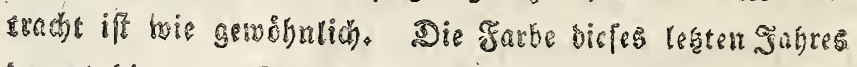

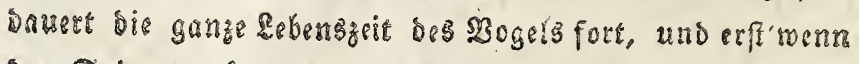
Der Epiegel glångens ift, brutest ex。 3u bemerEen if, oas

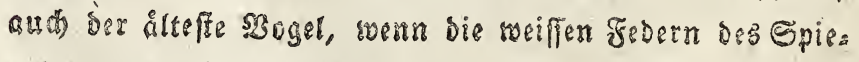
gets auf bie Seite gefboben werbon, einige unsent liegende fistratze Froerat bat; biefe werben aber bei dem lebendis gen Boget ganz you ten sosiffen bebect. - U. grylle bat 


\section{( (4)}

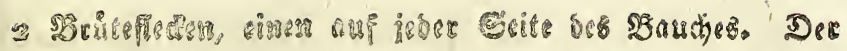

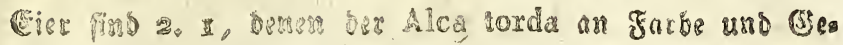

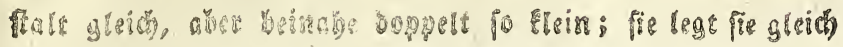

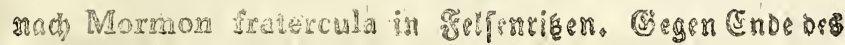

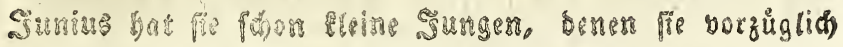
Elennius gunellus ims CEnabel bringt. (S)gen Endo Deg

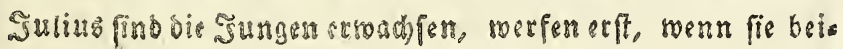

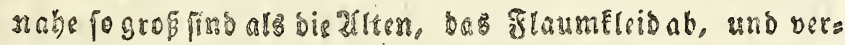

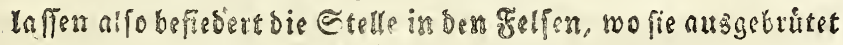
wurben. Mieten im Saptember vertaffer alle bie Sroutes

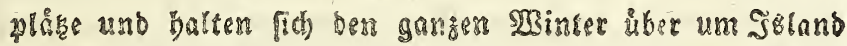

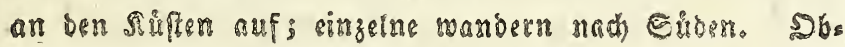

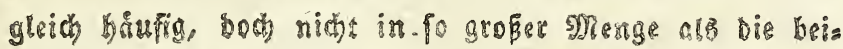

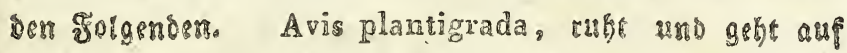

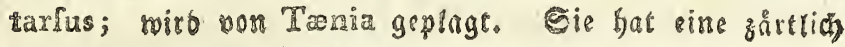

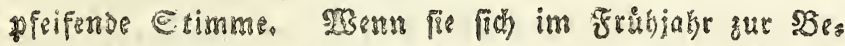

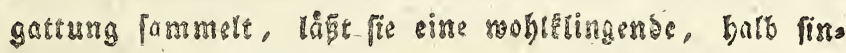
gende, Etimme höres, dis vielle mit bert exferen Etrophers von dems Cefange des Anthus praterafis gemern hat.

\section{U. Brünnichii (Sabine), iริ. Stuturefra.}

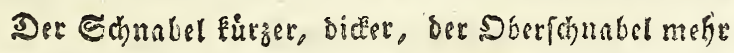
gervörst; an ber Bafib berfelber sin weifier Streifen bis

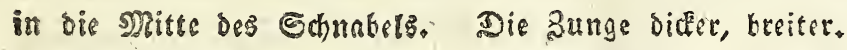

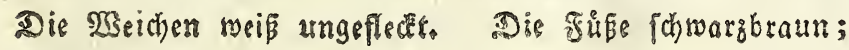

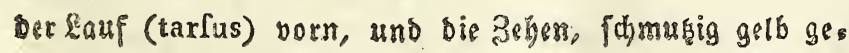

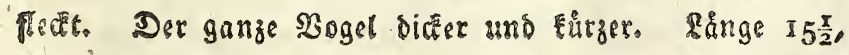

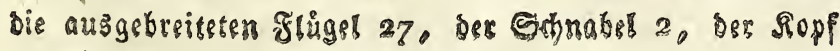

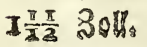




\section{( $\left.4^{2}\right)$}

Befobteken von gahriciub in Fauna groenlan. dica unter bem Mamen Alca pica.

\section{U. troile (Linn.), iêt. Lángmefia, Lángoía.}

Der Gthnabel långer, fohtanfer, ber Sberfornabel treniget gerwólbt, obne den weiffen Streifen an ber Bafiz,

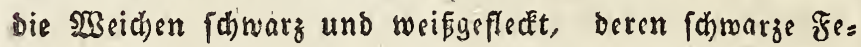
Derri fo weit gegen ben abdomen geftredét liegen, dá̉ man fis auffer den zufammengefalteten Flügeln fieft; die súne fohwarzbraun; ber ganze Bogel lánger uno mehr langges ftrect. Rånge 19 , Die ausgebreiteten Flügel $28 \frac{x}{2}$, ber Ednabel $2 \frac{7}{\overline{1}}$, ber Sopf 2 3oll.

a. Var, extraord. U. troile le ucophtalmos, orbita et rima aurium alisis, isl. Jringlángnefia, Żtingyta. Brünn. Orn. bor. p. 28 No III.

Sbgleich U. Brünnichii uno U. troile einanoet in ihrer ganzen Raturgef chichte aufferorbentlich ähntich fino, fo machen fie boch, nach bem Begriffe von Epeciez, zwei verfchiedene Specieg aus. U. Brünnichii ift ffets, mit U, Br, , unb U. troile fets mit U. tr. gepaart. 'Menn

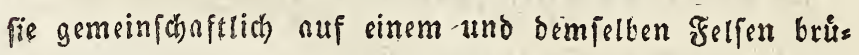
tẹn, fo liegen immer beibe Zlrten, jebe für fich, in šeiben beifammen. U. Brünnichii, oeren Stimme ein weniger geoehntes exre ift, als bas ber U. troile, iff ein noch mebr borealer Bogel als biefe; alle, bie idh von Breontano sefeğen babe, waren U. Brünnichii. Sie brůtet in gróster Menge auf dem noirdtithen Sstano, zumat auf (3) tims òe,

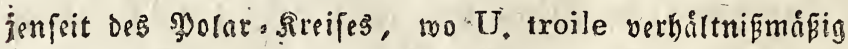
folten if: biefe bingegen brittet in gróbter Menge anf orm 


\section{$(43)$}

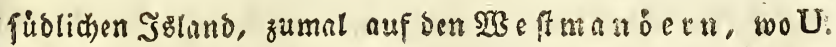
Brünnichii verbaltnißsmåsig fetten iff, fo tois aud $U$. troile im Spitiabr bie hảufigfte Uria an ben bånifhet Sieffen ift, wo man U. Brünnichii febr felten fieht. Stad Den Eiern biefer beiden Epecies Fann man nidutz urtbeis len, denn fie variien bei jedem Sndivio ber Farbe nad ins unendiche; nuch bie sungen im Nefte find bei, beis Den sinander gleich. Oenn ibr Echnabel if gu biefer seit micht viel anders gebilbet, als bei ben Jungen ber Alca torda.

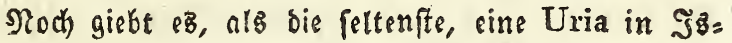

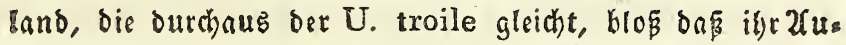
genereis und die Futhe hinter bem Dob fets meíf find. Diefes ift wohl beffandig, benn bei ber Berglieberung bes

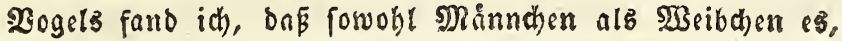
bei ber Sommertradit wis bei bet Msintertradt, hatten; Doch muß ich fie blö fur eine Race ber U. troile anfes ben, womit biefe fich pants benn ich fond fie, obgleith ids sicht fo glüelich war, fie in bem 2agenblice der Begnts rung zu treffen, ftets in ber Befellfhaft der U. troile: fie lag unter biefen in ben Felfen auf Eiern; fie war ims mer an oen verfhiedenen Etellen nach dem Berbåltniß̄ oer U. troile mehr ober weniger baifig, batte biefelbe Stim: me, und war nicht on Sitten bavon'zu unterfteiden. 2us batten bie Jungen im Nefte nicht jenes erwibnte Meres mabl.

U. Brünnichii und U. troile haben nur einen Bruetefleck, mitten auf bem Baucte. Sn ber Mitte bes Marz find fie in Sommertracht (oet fd)warze Unterbalb)

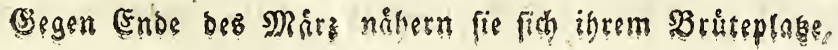




\section{( 44$)$}

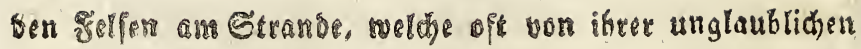

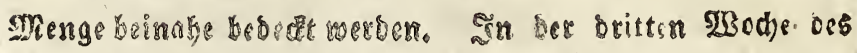

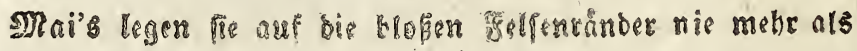

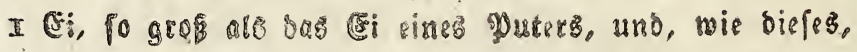

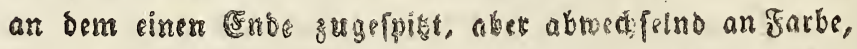
yon grán mit vielen bunkeln griecten uno Etrichen, gu feegrün ungeflect, und tweip bunfelgeffect. Im anfange bes sultus fint bie sungen flein, im 2lnfange bes Xlus

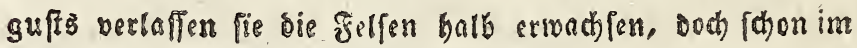

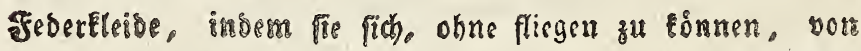

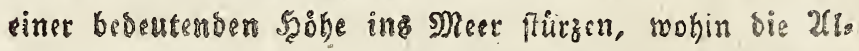
ten ifner unmittelbar und föreiento folgen. Dis Jungert snudien gleich unter, uno von biefem 2lugenblide an müs. fen fie fetbfe ibre Tabrung fuchen. Die Jungen baben

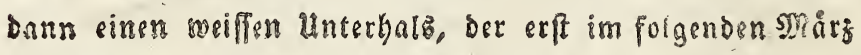
braun roits. Sobglein bie artsen eine fonnartende Etimme baben, To iff body bie Stimm Des jungen fein, Elar uno

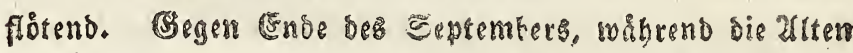

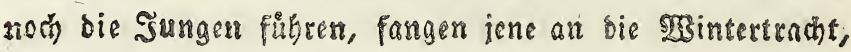

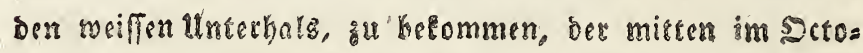
ber ungemifrat tweis ift. Gar viele bleiben im Binter an

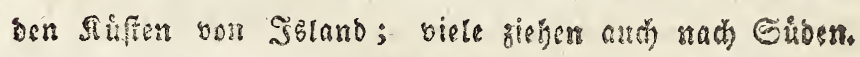
Sie sugn und gelyen auf tarfus.

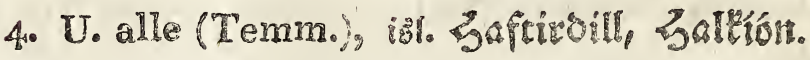

Sher Naturgefichichte ift eine Mifhung yon ber Uria, Alca und Mormon. Ein Eranbuggel. Ëegen Ende bes Miks iff fie in Commeristache (framer Unter

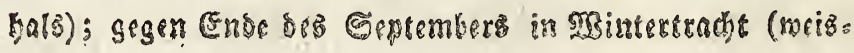




\section{( 46$)$}

tefledten, einen an jeber Seite bes SBauders. Ifm Iage find bie, weldhe nicht brủter, braulfan auf bem Mieere, Des a loends fersen fie fich unter ftatem Schtsien, Edynatterm,

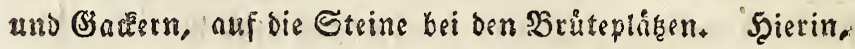
swie auch barin, baß fie auf ber Epur (pelma) felbit geft uub ruht, unterforsibet fie fich von Uria und Alca. She glug iff ungemein hurtig und anhaltens, gleich bem oer Anas glacialis. Den Binter bringt fie auf dem off nen

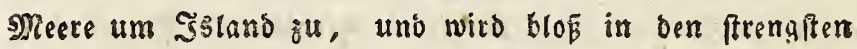
Mintern in bis tiefen Sbudten binein, getrieben, wo fie

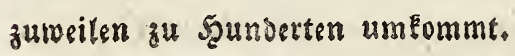

\section{Genus 28. \\ Alca (Linn.).}

Bie Sientzeidben ber binttung, in fofern biefe aus

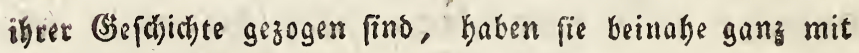
Der Uria gemein; zumal if Alca torda genau mit U. troile Auctorum vermandt.

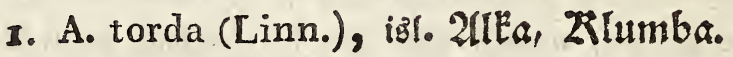

Solgleich nicht vôllig fo båfig atร U. Brünnichii anb U. troile, bat fie fonft einen grosen sheil ibrer (sies

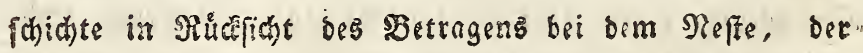
Gitten, bes Fiuges u. f. w. mit beiben gemein; bock hat fie 2 Breireflecten, einen an jeder Seite des Bauches. Sas Ei, immer nux $x$, ift mei tert, senig eleiner, als bas ber U. Brünnichii, nicht to šugefpiąt, uno nur wenig variirent. Eie legt es auf bem

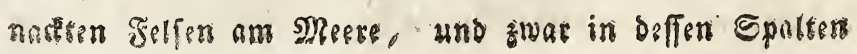




\section{$(48)$}

2. A. impennis (Linn.) )

Diefer po feltens Boget ift ope cingige Sohromms

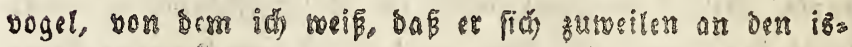

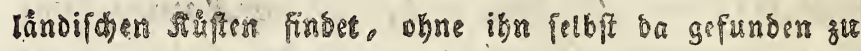

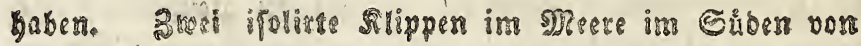

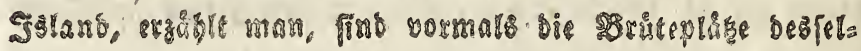

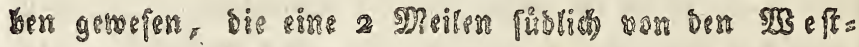
man o̊:

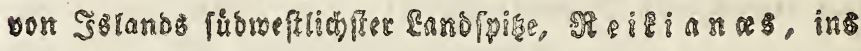

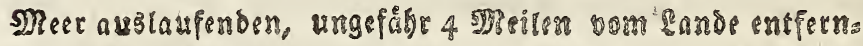

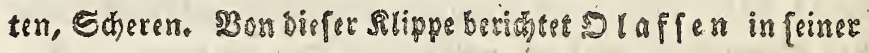

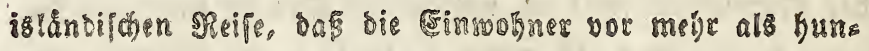

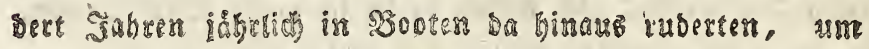
A. inperais zas grsifm, roulche fie in groper Menge nebf

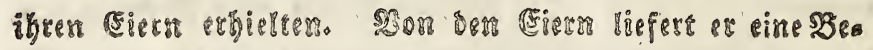

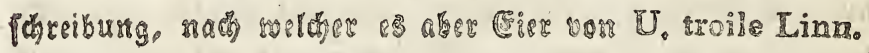

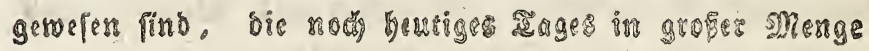

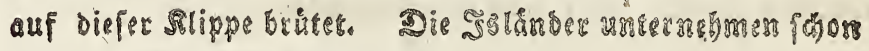

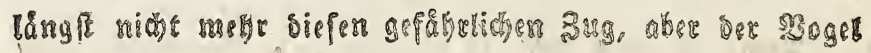

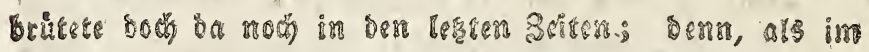

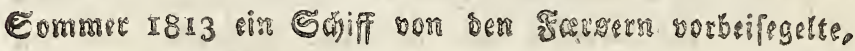

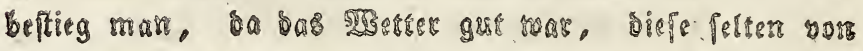

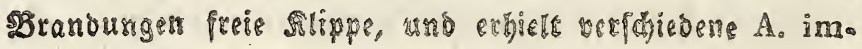

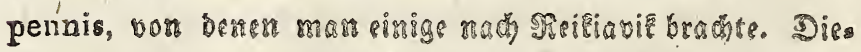
Fez, befurchice idh bat sem Bogel ganz yon ser Stippe vers

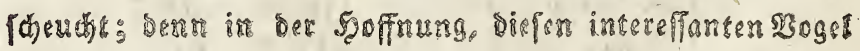

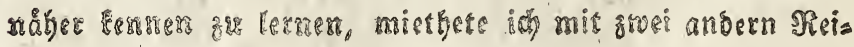

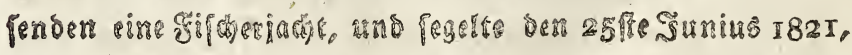

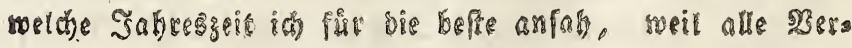

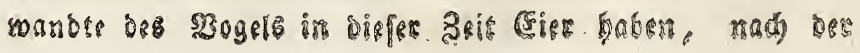




\section{( 50$)$ \\ Genus 29. \\ Mormon (llliger).}

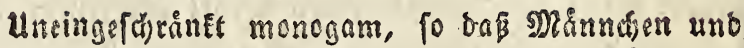
25ieibion bruten, und den Sungen Futter im Schnabel

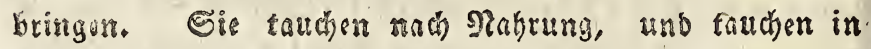
Befribr, mit ball ausgebreireten Flugeln. - Minnnchen uno Eseibchen, wie bei ben Borbergebrnoen, sinandex glaich at Jarbe unb Grope Gie brben Eerne eigene

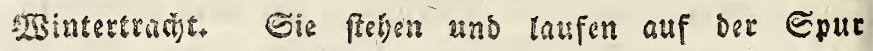
(pelma), baber fie burtier auf ben Frifen find uno Eeine fo aufrechte Stellung baben, als die Borbergehenden, U. alle ausgenommen. Mrit orm forarfen Slauen uno bem gropen Sonnabel graben fie ellenlange Lecher in bie Dammerde auf Den felfere, worin fie, ftets in Dnşelbe Roch, ihr Cei leger. Das Fraumeleio oer Sungen ift nicht, wie bei ber beiden vorbergehenden und ber folgen: sen Sattung, Furs, fondern lang uno weich, beinabe wie bei Procellaria und Puffinus.

\section{M. fratercula (Temm.), iat. Runbi. Linsakofa (jurs).}

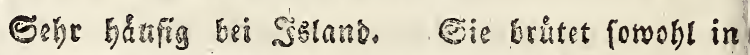
sen Felfen am offenen smeers, als in bon $\$ 3$ uchten, uno geht tiefer in sie SButhen binein, wh bic Gattungen Uria uno Alca, um g̊เ briten, U. grylle auggenom:

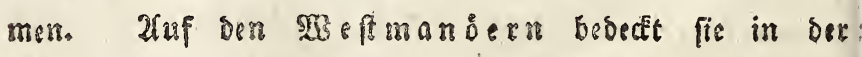

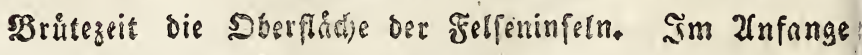

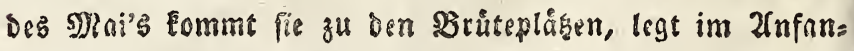
ge Des sunius in bie Felfenrigen, und zumal in die von ite 


\section{( 52 )}

3afhl unb Eis, wie bei $A_{0}$ torda. Im Zunfange bes Des cobers baben fie fió, von ben siuffen entfernt, und bewoh=

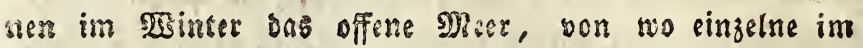
Eturms todt an bie furdidjen silffers bes gandes getwor: fen werden fornen. Bon den in sempelben Sabre aus. gebruteten Sungers fiebs man tod cingelne im Rovem= ber uno December an ben Riffen. Dirpo Bagel wird vom Bandmutm, unb bei ben Mefferat, amter allen am meifter, von serajen geplogi.

\section{Genus 30. \\ Carbo (Mieyer).}

Ulueingef

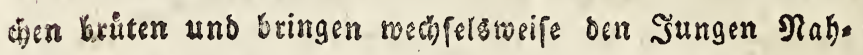
rung, welche fie, wie bie Talben, aus ber Epeiferobre (celophagus) auffoirger. Sie tauthen nach Nahrung, amb tauschen in Befagr, mit sicht angefthloffenen flügetn uno cinem fleinen Eprunge auf bem $\mathfrak{B a}_{\text {affer, }}$ thben auf ber Epur (pelma), boch ziemlich oufrect)t, gehen niche ibel, fliegen burtig aber wadetno, uno fisen gern auf oen Eches

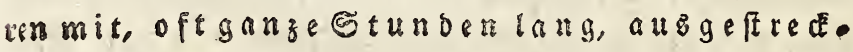

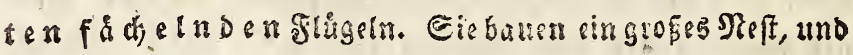
brủten weit fưhber, ais bie anbern Berguogel, Larus marinus uno glaucus albgenommen; haven Eeine Srutitrfecéen. Der

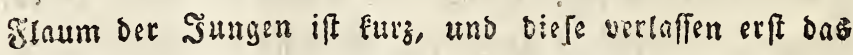
Staft, wenn fir fliegen Eomnen, and fo grop find als bie wtten. Sorwobl C. cormoranus ais C. graculus bat sin vom Seintertopf: (occiput) Gerborfertenden Sinochen, ser gin Gorfersun mon crifta occipitalis ift; bifes 


\section{( 54 )}

feinen auth in Sommer ziemlid) langen Edeitulfedern entfelben fornte, fonbern einen Sorberfobopf (crifta frontalis), ber aus 2 zoll langen zugefpiaten Fedetn beffeht, selche er im Sdywimmen lothrecht an ber Stirn aufrid)s set, fo ois man ibn weit weg fehen fann; fifend legt er ben

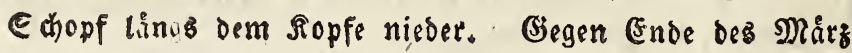
iff oer Sdyopf noch bollfandig, nach ber aeit fallen bie Sebern besfelten nach uno nach aus; bodh babe ith noch mitten im Sunius cinzelne beim Refte gefdoffen, bie noch eine ober zuei Frebern yom 2 sinteristopfe befalten bat: ten. Uérigens find alle biefe Bogel im Commer glatts Eorpfig. - Drgleidy die Jungen meiftens gegen Ende bes Suniug flutu find, fo baben ooch einzerne noch zu siefer

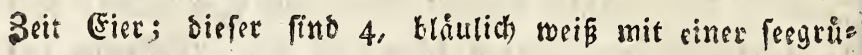

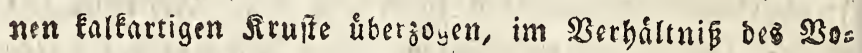
gelò tlein, ein wenig fleiner und fthmiler als bie ber $U$. grylle. (S)ewón, nlich ift das eine (Ei faut. Dab Reft ift grof, von fucus, infonderteit veficulofus, in den slip: pen gebaut, und fets nof. Die hungrigen Sungen fditeten laut und oft; bis Zelten laffen pelten igre tiefe Stimme boren, verlaffen bas Neft niche, wenn man fith Demfetten näbert, beobaditen aher den 2hnfommenden mit Beberden, als wollten fie fich erbrechen. SBBcoer im Eoms mer noch im Wointer baben fie weiffe Schenelffecere

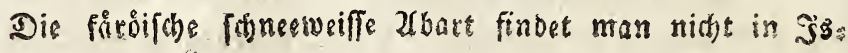
lanb.

\section{Genus 3 I. \\ Puffinus (Brisi.).}

MRiuncthen und 2Beibct)en briten, da fie uncinge* 


\section{$(56)$}

meinem Sch feben.

\section{Puff. arcticus (mihi). isิl. Slvofa."}

\section{Próc. Anglorurn (Temm.).}

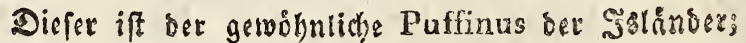
ein Stanovogel im Neere um Salans, obgleich ziemlin pelten,

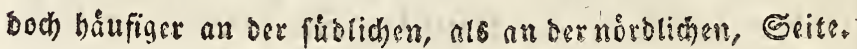

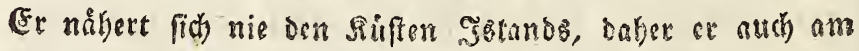
meiften nur von ben fifchern geferten wirb. She an cines Etelle bei saland britet er, noimlich auf ben firolidjen SWeftmaniern, uno auch tor nibt iberall. Seine

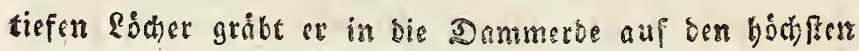
Stellen ber F̈elfeninfelm. Mormittag ben 26 fern Sulius I82I fand ith fectis foldter risher auf oen bodsfen Jelfen Der Tseftmanoer, aus beness ith folbft 6 balberwactjene langflaumige sunge, uns cben po vist 2ulte, zog.

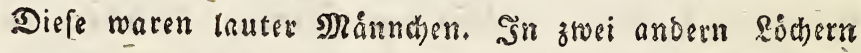
fond idh die 2frten noch ouf bem Eie; es ror nur ein einzigez, wsí, Eurz uno dick, wie das ser Proc. glacialis, aber bobbelt fo flein. Er fliegt, ferwimmt und taricht freitich aud bei Iage, iff aber am meiften in bet Dånmerung in Brwegung, und lespt bann feine ftarke

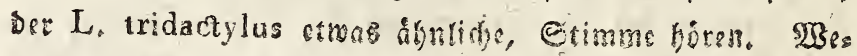

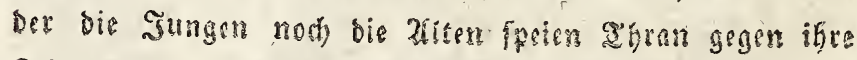
Feinde aus. Gegen Cnbe beș Espembers zichen fir aus, uno bliben orte gangen SBinter itbor, ouf bem offenez Ineere.

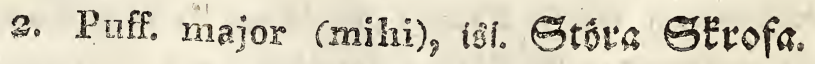

Prec. puffizus (Tomm.).

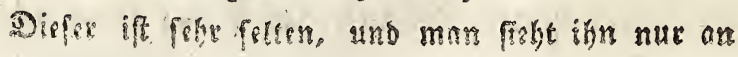




\section{$(57)$}

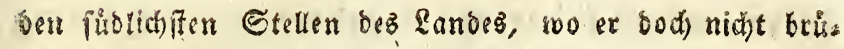
4et. Nur sin sinzigez Jndivid ift mir onyon in bie Şinos gefallen. Die Fifwer erzåglen von einem Puffio. nus, den fie zutweiten fehen, und ber boppelt fo grab ifie, alb ber Sorbergefende; es mag woht biffer ferm.

\section{Genus 33. Colymblus (Latho).}

Eeben in ber mittlern Monogamie. MRnnden

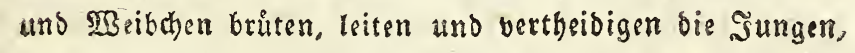

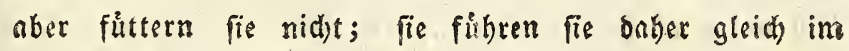

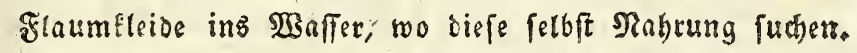

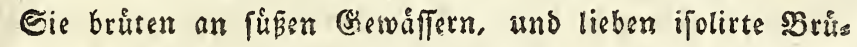

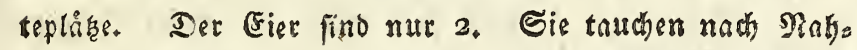
rung, uno tauthen in Befabr, mit angefoloffenen Sthigetrs obne Eprung auf bem 23 nfferfpiegel. Rubend nuf bem Lauf (tarfus) gehen fie fobledts, und ruben felten auf Dem Eande, fohwimmen beftåndig und find vorzuglide Taucher; bloß in ber Brittezeit fliegen fie, hurtig, bods und range. Shre Stimme if burdjoringend. Eis baben

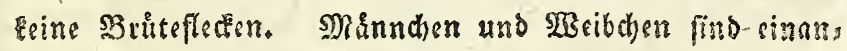
Der gleich an Farbe; obne Mintertracht.

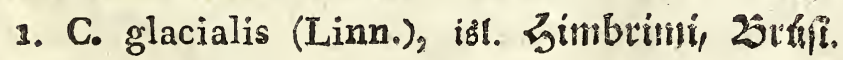
S: nidft felten; nach bem Sordtande fommt et

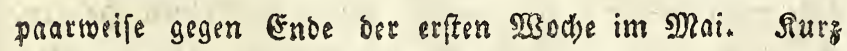

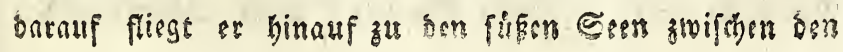




\section{$\left(58^{\prime}\right)$}

SBergen, um zu bruten, tro ex auf ben Eleinen Snfeldat in biejen Seen nut 2 längliche Eise, bie, gut jo gróß als bie ber U. troile, graubraun mit vielen bunfetn flecten fins, ohne untetlage nabe am $23 a$ affer legt. \$ogleidh fonft febe furctifam, noibert ex fidy boch furchtlog benen, Die feine Eier beunrubigen wollen. 2tuf einem Eleinen Ins

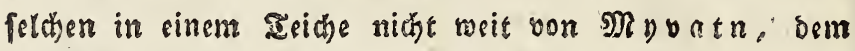
grósten Landpe auf Szlnnds norbofftichen Seite, bemerfte id) Diefen intereifanten $\mathfrak{B}$ ogel bei feinem feltenen Neffe.

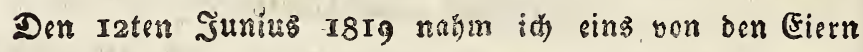
soeg und legte eine Sajlinge aiber bas antere. 'Den fols genden Norgen fá bas bentende 2 seibclien sefangen.

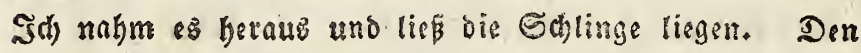
Iften Suแnius bes פlorgens Gatte ich aud) ons Minndben auf. Dem Eie gefongen. Diefe waren beinabe ausgebrits tet. 'Nitten im 2utugut fiebt man bie Eleine Familie ifolitt auf ben sinfament Borggersáffeen formimmen, wo fie infondertheit bem Salmo carpio und S. trutta nach) feeltt. Die Sungen Cóer bas sunnge, benn einz yon ben Eiern siefer (Gattung if of faul) find bann erwach fen. Seine burboringende beulende Gtimme giebs ein fonats derhafees Eetho in ben umliegenden Bergen, und gleicht Dem Megetagen cirtes Menichen in Rebentgefabr. Ges

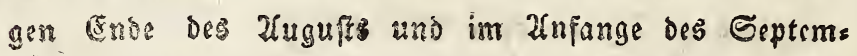

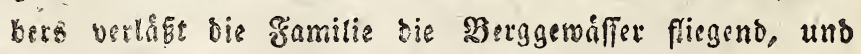

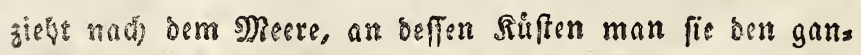

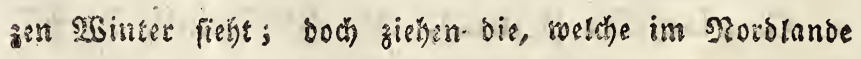
brister, nolih bem Eectfer bes Siblandes. Jm Meere

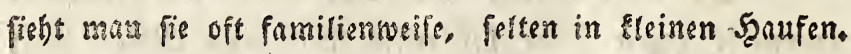

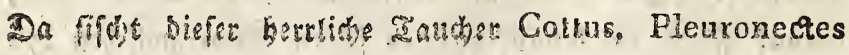


firght er Salmo arcticus, Clupea, Pprattus uns andere - Eleinere Fif be.

Intm. C. arcticus Linn. wits beftimmt nidet in Jthanb gefunber.

\section{Genus 33. Podiceps (Lath.).}

Leben in ber mittle $x$ n Monogamie. Mhinndgen

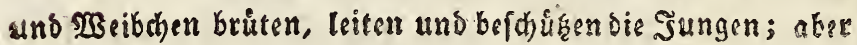
biefe múffen gleich im flaumfleibe im saffer fortrimmen, um felbfit Nafrung zau fuden. Sie britten an füpen Gerwaffern unb bauen, im 2 saffer ferbft, cin immer fruchtes, feftes oder fojwimmendes Ref. Die Cier find weís unb sungeflect. Shyte siebe unter sinanber ift grop. Das

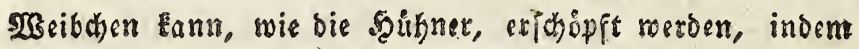
ez fortfälet, bie Eier, wenn biefe weggenommen werden,

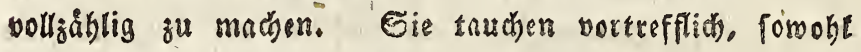
sach Nabrung, als in Eefabis, mit angefoloffenen Flit: gein und mit ciner Eleiner Sprunge auf bem $\mathfrak{B a f f e r}$ Sie ruben noch weniger auf bem Lanbe, und fliegen feltes ner, als Colymbus, aber bann auth how und buttig.

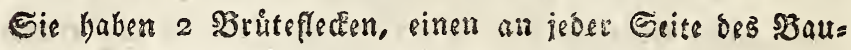
(4)ร, uno verfălingen bie baran auşgerupften Federn. zinmertenswerth wäre, menn es vielleidht einen sૈug zus bet natirtichen Unterfheibung ber ganzen Esattung abgé be, was idj bei Pod. criftatus in Dåmmare uno bei P. auritus in Satand bemerêt babe, sos nimlich die $2(1=$ en bie zarten Sungen, wenn bisfe is Gesfahe find, unter bie flitigel netgmen uns mit ibnen untertauchen. Eis brs 


\section{$(62)$}

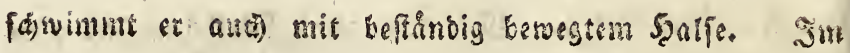
Dentriculo, wåhrend er auf bem Meere ift: Conferva ru. peftris, und auf ben firsen (Berviffern: verfchicdene 23 ng: ferpflangen. Ere gielft weg - - ? noch im December

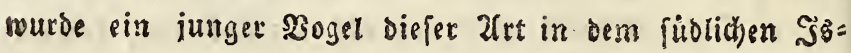
lons gefbofiert.

\section{P. auritus (Lath.), idt. Sloitgooi (bei spovatn), Slócio (im 2roefren).}

Şâufiger als jener in beal norbliden und weft: licten (Siegenden beb Ranbes, aber infonderbeit håufig bei Myvatn, soo ith Eeinen anbern Podiceps als biefen brủten fand. P. auritus begiebt fich boher binauf ins

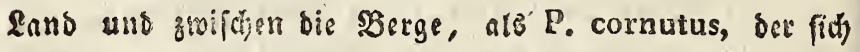

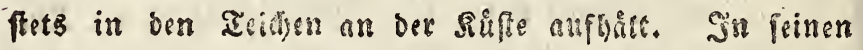
Gitten bat ex vieles mit bem 2 Borigen gemein, bodh ift

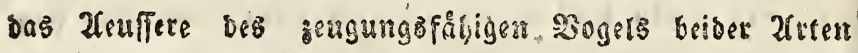
leicht zu unterfdyciben. Ex if boshaft gegen bie, welche fein Neft beuncubiges. Die Weitern, zumal bas Mån= den, bráten bis Syulsfebern auf, und machen Mieme, auf ben Feind los za fakren, inbem fie einen Enitrendent, zornigen faut boren taffen; oft fotreien fie g $\bar{i}$ s $\bar{a}$ u. Eie find febe zortlid) unter cinandes. - Der cine (Satte fojtwimmt foltz un bas Nefit, borauf ber andere brütet,

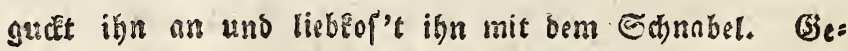

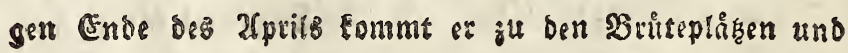

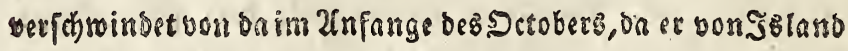
wegsieft. Meft, Z2nzabl uno farbe ber Eire, wie bei 2. cornutus; sod) bie Cier ein wenig throget und bifer, 


\section{$(64)$}

sauben nad) Nahrumg mit zufammengebaltenen flugela ano simem Spmnge auf bem 23 affer, wie Carbo; in Gefiabr fiegen fie, und tauchen bann felten unter. Sas Ijseibchen ift von einer weniger fobonen Farbe, unb teis ner, aik ons Manmdien.

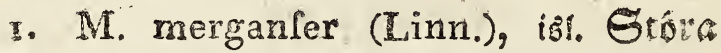 Coppono, Gulsno.}

Eeltener auf dem Sublande, als auf oem Tordinde. yo man iba ben ganzen Winter ủere fobarenweife in ben f(bmalen sbuchten fieht; Dodh, zisben sinzelne weg. Er

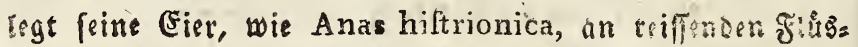
fen, nicht an rubigen Steriffiern. Sch forb fie mitten im Sunius an bem von Myoatn aus̆laufruden Etrome enraj; fie gleichen benen ber Anas clangula. Sn ben frengften Bintertagen bilt er fich, wie $A$ beiscas uno clangula, bei ben warmen Beweffern auf. Im ventris culo, bei ben Fluffen: Salferpfanzen, anf dem Speere: teine Jifote.

2. M. ferrator (Linn.), išl. Litla Toppsins (bei Sivoatn), 马rafnswino.

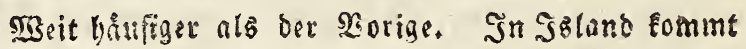

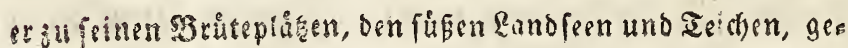

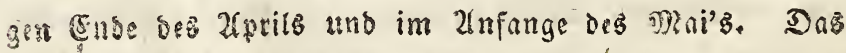

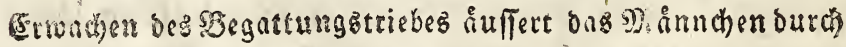
wunderlide Ribbrofungen gegen das Sreibchen, zumal ba =

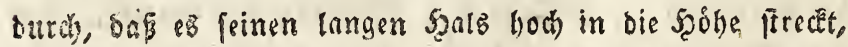

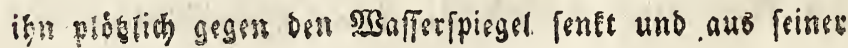




\section{$(66)$}

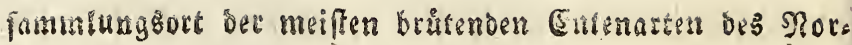
Dene, baher biefer Eee eirs withtiger Etandpunct für den reifenten Sonitlologen ift. SBei diefrm Ëe findet man in ber Şruterezeit alle bis Enten verfammelt, bie man conft

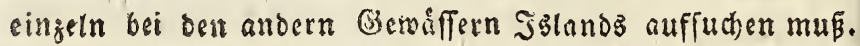

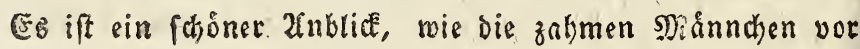
ben Neffern ber brutenden $23 e i b$ chen fthrommen, wie fir, seenn bie şeibchen von, bem Siffe gejagt werden, mit zartlichen Sieblofungen biefen entgegen über bas 2 Baffer bin freeiden, und fie, wie Der Tabuber feine Taube, yor fich ber ins $\mathfrak{B}$ affer treiben. Heber 50 Snfetchen giebt es in Nyontn, und auf diefon legen infonderheit die Enten ihre Eier unter 2rtgctica und andern Echirmpflanzen, und bie Einwehner um Mgoatn fammén tåglid) im sunius bier sine Menge Cier, beren 2 (nzahl von Den sierlegenoen

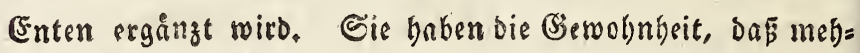
rere 2 seibchen, fowogl non eimer ullo berfelten, als von verfohisbener 2 Utt, zufammen Eier legen, bie bann alke ents

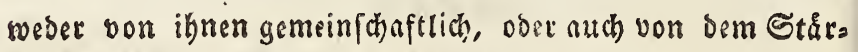
Eeren, bas bas Echwaschere veringt, ausgebrutet werben; infonderheit ift diefes der Fall mit $\Lambda$. marila uno A. glacialis. Das SReft iff funftrog. Um bie (Eirr legen fie eis nen Siram von Flaumfeosen. Trseroen fie plóglich yom Mefre verjagt, fo befubern fie bie Eier mit ihrem Soth,

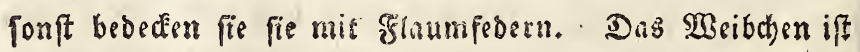

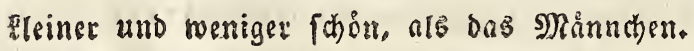

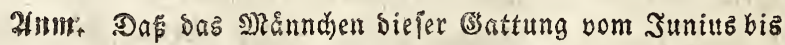
zum Rovember das Rleib bes Weibd)ens betommen follte, babe ich, fo weit meine Erfabrung fireckt, nict) bei bert 20rten gefunben, bie in Jgłanb bruten- 


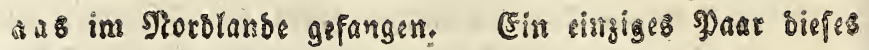

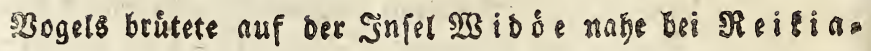
vi in ben Commern I819 und 1820 , unb lag ba unter Den ungạhligen A. mollisfima. Din 25 ften December 1820 batte idf Das (S)túd, Daß in einem frarfen Sturme sin als tes MRnnthen von A. Spectabilis bei Dreba Şnndelsphrase, no id mich ben Dzinter aufleilt, toot ans

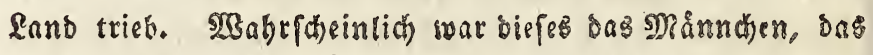
auf $2 B$ i do e beete, benn ben folgeriben Sommer fand bns

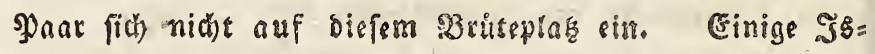

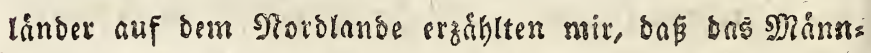
ben von A, mollisfima, wenn es febre alt wirtbe, eine

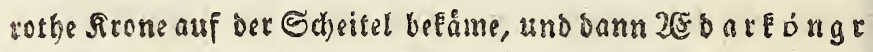
genannt wirbe. Boiefe unrichtige Solee foheint von ber

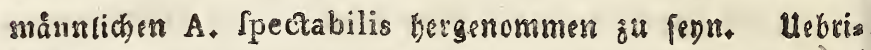

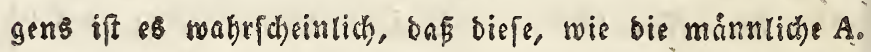

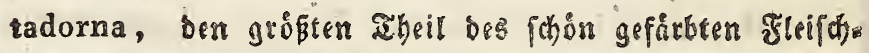

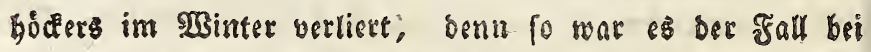
Sem oben genaunten Minnocien.

3. A. mollisfima (Linn.), iti. 22out, 2Eourfugl,

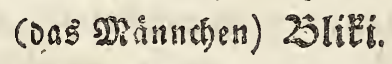

Uteberaus båufig. Ein Stanivoget. OSegen Ende des

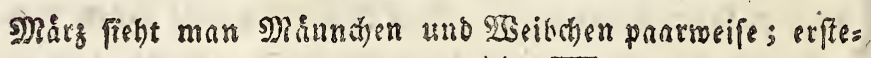

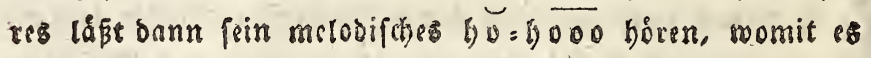

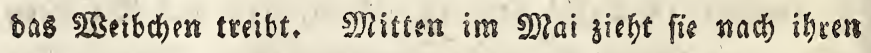

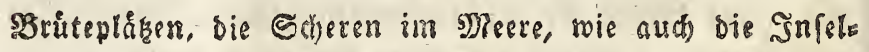

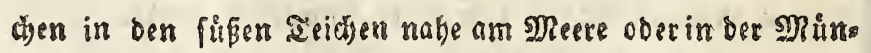
Sung ber Flufife, yon \&

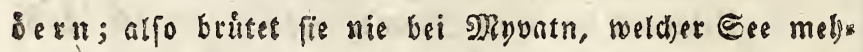

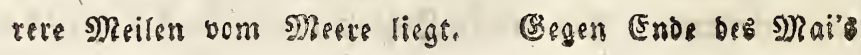




\section{$(70)$}

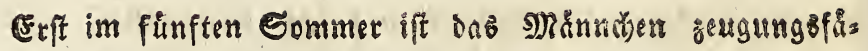
big und in volles Mract). Die jungen Bogel fand id

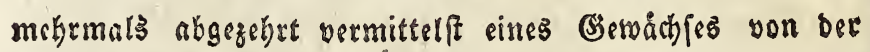

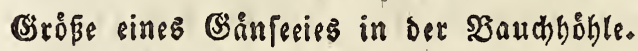

4. A. glacialis (Linn.), isิ Ђávelli, Sópella.

Segr båufig. Es ift unlåugbar, dap fie (meines smiffens aber ifit fie aud bie einzige istandifate (Ente, bie)

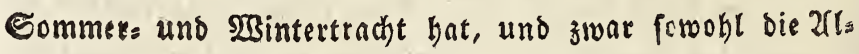
sen als bie sungen, boch ift ber unterfobied am beutlichftent

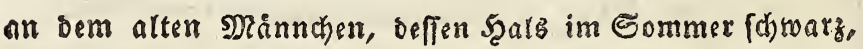

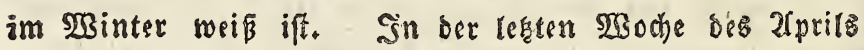

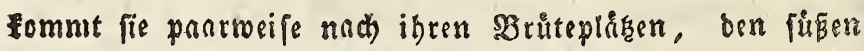
Gerwiffern in ben agalern wie auf oen nisbern SBergebles nen. 3 ut biefer zeit hat fie beinnte bie bunklere Commers trad)t befommen, bie boch bin uno wieber am Scats und Sopfe weiffe Flecten bat. Diefe Fleâen werben immer sweniger und weniger, fo dáp brinate alle biefe $\mathfrak{B o g e l}$ in Der erffen 230 che des Mna's in Eommertracht fino, ob= gleich noch einzelne im Mai in ber $23 i n t e r t r a d y t$ gefunden suerben. S'segen Ende bes Mai's legt fie unter Edhirm: Pflanzen, oder im Erafe, ifre $5-7$, mit sinem grunlichen Sthimmer grautweifien, 3 zoll langen, Eier. 2fuf bem Cidolande fano in forjon ben 18 ten Mai igre exfen Eier.

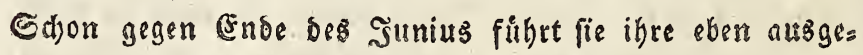
britteten Jungen. Im 21nfange bes Septembers find nus

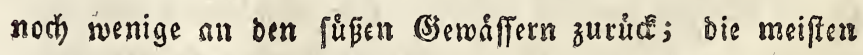
find foron aufs Meer gezogetr. Mitten im Setober find fie fdyon misoer in Bintertractst, und bann fommen fie,

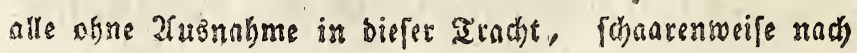

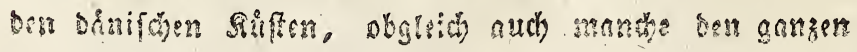




\section{$32)$}

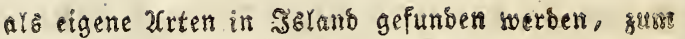

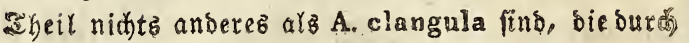
delaffens izh, Reife und Mituller prodr, Zoolog. danic. zu siefem Jirthum 2unlä gegeben bas. Meine Brrunde bier zu entroickeln, bưrbe zu weit=

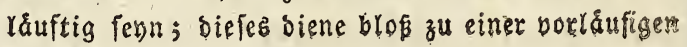
Somertung.

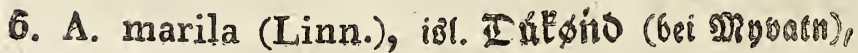 కrafneфno (im Siven).}

Sekr båufig, zumal boi gnyoatn bie båfigh brŭtende Ente. Echon mitten im März finbet fie fich auf ben füen Ieidhen im Sủdlande eirs, mitten im 2Tpril am Myoatr. Segen Enoe Des 2lprils treibe bas Mannchers fein SBeithen mit zåtlicher, der ber Iurteltauben \&hnlis cher, Stimme inş20ffer. Sie legt su gleidher asit mit A. glacialis, am licbften unter Schirmpfranzen nuf bese Heinen Jnfeln, ifre $3 \frac{3}{2}$ 3oll langen Eier, in gleidber Zujahi mit A. clangula, uno von Farbe wie die bet $A$. glacialis. Wie megrere Entemarten, legen aud mebrese

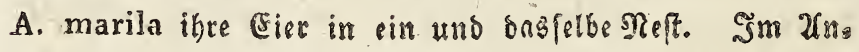
fange des Septembers fübre fie ibre beinabe erwachlenest siungen, weide fie in (befabe mit einem fthnarenbert a $\mathfrak{r} \mathfrak{r}$ zatfammen ruft. Sn ber exfern Şålfte bes Sctos bers fomm fie fonarentorife in die Suchen, uns vers

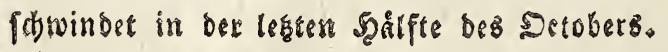

\section{A. leucophtalmos (Bechlt.), iฮิ......}

Gelten. Sum exften Male fand idh fie, ben zoften

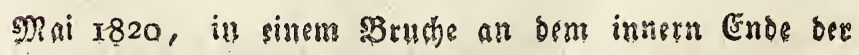

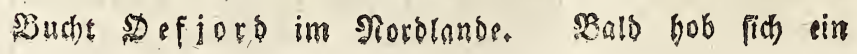


Trupp biefer febs twilben Enten bod in bie Ruft, bal

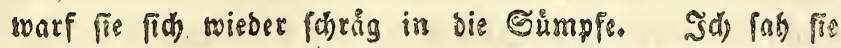

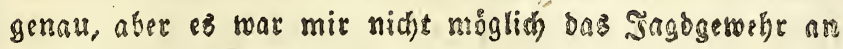
Die Bacte ziu bringen, the fie fhon trieber aufflogen und

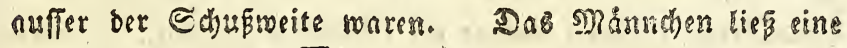

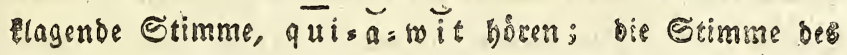

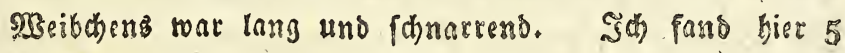
Eier, an Fatbe unb Geftalt beirabe wis bis ber $A_{0}$. glacialis, boch ein menig lainger, wethe in fir sie teier bies fes Bogets annahm, do seine anders Entenart in Brudhe

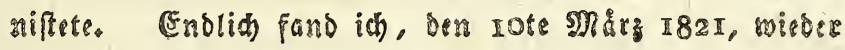

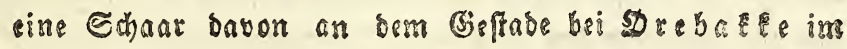
Gublanbe; vermuthlid wat fie gans neutidy angerommess.

\section{A. hiltrionica (Linn.), เร\%. Straumdns, ¿rimøno, Srimbufa.}

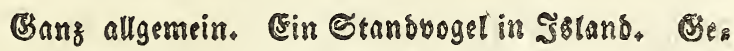
gen Enbe bes Dctobers verlaffen bie, welctie ficts im গtord

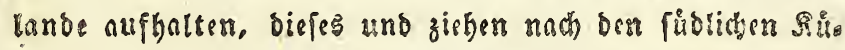

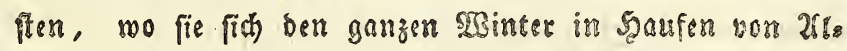

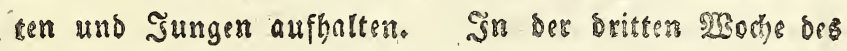
3prits Eefren bie, welthe im Rorstande britess, wiessn

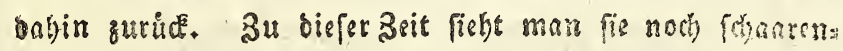

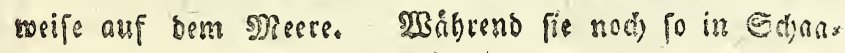

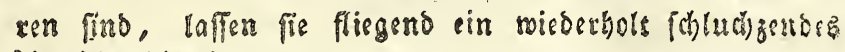
Q beiferes, leifes, b $e=$ he aus. Mitten im Mai figen fie

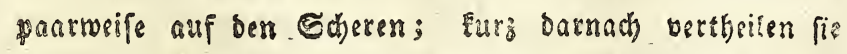

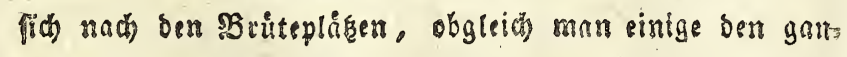
zen Eommer hiber auf bem Meere fient, wo fie fir you 


\section{$(74)$}

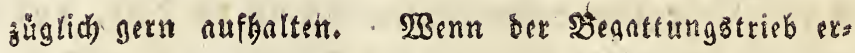

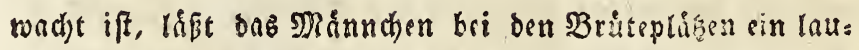

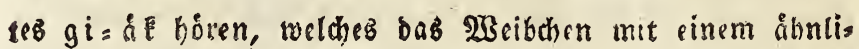
aen $\bar{g} \hat{i}=\bar{a} \bar{\varepsilon}$ beantwortet. Sie briten nie an ftehendent Beswiffern, fondern immer an reiffenden gluffien, in beren

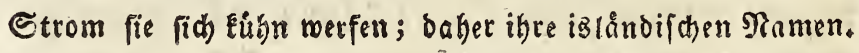

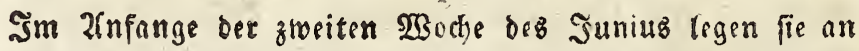
ben Uffern ber Fliffe, gern unter Eleinen Mseiden, ihre 5-7 weipselben, Eurzen und Diden, (Eirr, keinate von bers ferben CSrópe wie die ber A, clangula. Im 2rnfange des Suliub fủhrt bie Mutter ihre Eleinen Jungen in sie Flüffe, und im 2rnfange bes Eeptembers bie erwach fenen Jungen aufs Meer, wo fie nod bis zum Ende bes Monaths ithre Fůbrerinn ift. Die Riebe bes Månnchens und 2 seithens anter cinander, und dic Eorgfalt bes leğtern für die Suns gen, iff grof. Edjeét man ben Gsatten oder eins von den sungen nieber, fo nályert fich bas traurtnbe 2 Bsitchen un: yerzagt bem Iodten, ftóft ihn mehrmnls teife mit bem Echnobel an, um ibn zum 2luffechen zu ermuntern; erft, senn biefes vergeblich ift, fdimimmt es fort. A, hiftrio-

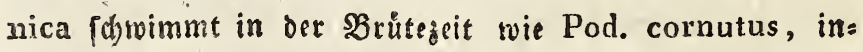

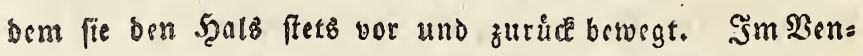
Ariculo: Cancer pulex, Nerita, andere fleine Echalthiere, Manferpfanzen。 Das Minndjen iff im oritten Eommer in volfer syercht.

2nn. arue bisher angefübrte Sd)wimmodgel (aubgenommen bie erite (s)attung, Phalaropus) find im Sefiţe ber

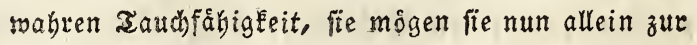
Xufiudung ber Nabung, oder. zugleid) zur Sicherung

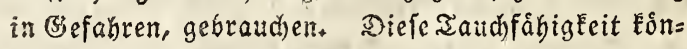
nen wix baber bie regulate nennen. Die Sdyimm= 


\section{$(75)$}

vosgel bagegen, weldhe wir nach bielem, bis zu senen, bie bas araudjpplement üben, abhandern werben,

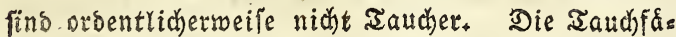
higkeit, bie eigentlid bei innen folummert, tritt als forche nie in Tyatigkeit, fonbern wird blok in bem einzelnen zalle getwedert, bap fie augenblidelids Der J゙ăbigkeit zu fliegen beraubt fins, da fie in bies fem Zralle, und zwar blop wenn fie in (Sefabr find,

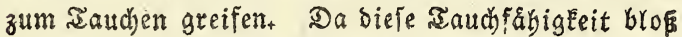
als sothguiffe (in fubfidium) gebraudst wirb, fo Eonnen wir fie die fubfoistre nennen. Diefe less

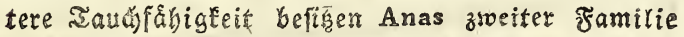
und Anfer, twelche brop taudjen, wenn fie zu einet zeit verfolgê weroen, ba fie nidjt fliegen Eonnen.

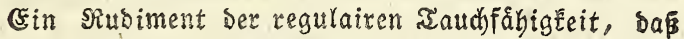
siefen beiben, wie Cygnus, als ein natưrlidjer ảug geblieben ift, ift folgensez, baj fie fich nåmrich fenterects auf ben sopf ing Wsaffer zu ftellen, uns ben

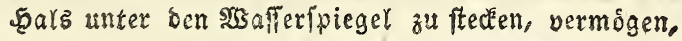

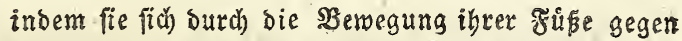
Diefen in Fentredter Gtellung barten. 3ur 2Tusubung

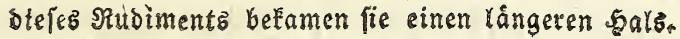

\section{Smeite Familie.}

Mit uidjt flügelförmiger Şintergebe.

Gie firtu bo̊ber anf dem waffer, als sie vorber genanten Entten.

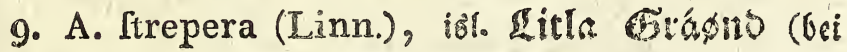
2800060)

Sm Siniug I819 jagte id ouf sinem SnTelderen in Nyvatn ein Naar Enten yom Mefte auf, bie ith für Diefe anfah. Die Fier waren bernen ber A. penelope an

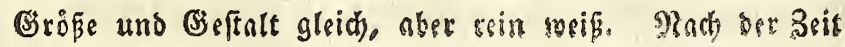
bibs ich fie nid)t gefunbem. 


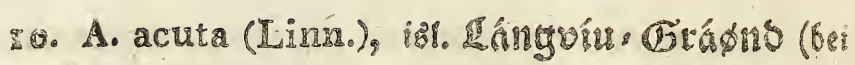

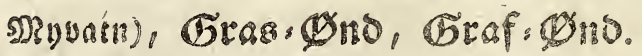

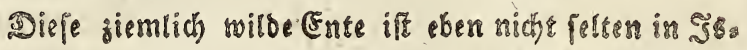

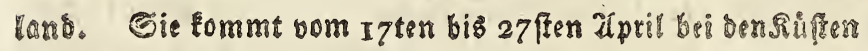

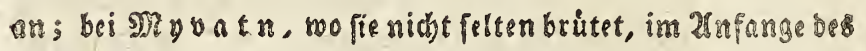

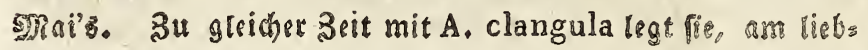

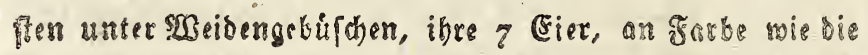
bee A. glacialis, $3 \frac{3}{\mathbf{T}}$ şoll lang. Mannchen un Weibs ben fliegen mit ångftidden Geberders umber, wemn mase

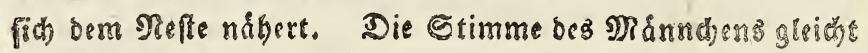

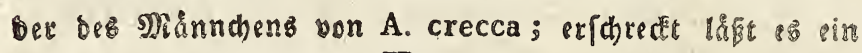
febr [leifeg] beiferes que $\bar{e}=e$ boren. Jie Etimme be

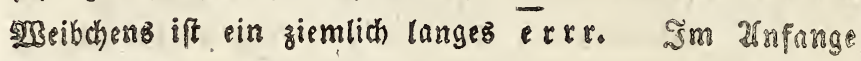

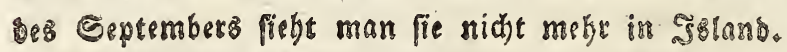

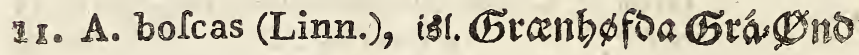 (Gei Myuatn), Stóta Stoldro.}

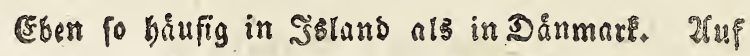

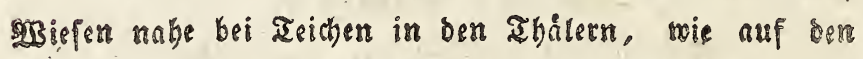
niebrigern Bergebenen, findet man iges Eirs, Deren nis umter ro find, zut gleicher seit mit beneri ber A. acusa.

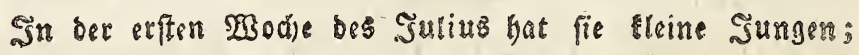
noch) gegen (Ende bis Septembers iff fie bei ben Brütes plåkan, im 2lufange bes Sctoberg ficht man fie am Ges frebe; cingerne gieben weg, bie meiften bleiben ben $\mathfrak{B}$ in: ser weer in soland, am Etrande, in ben Fluffen und ben warmen (S) fie in grofen Etyaaren am Stronde, imi 2tnfange des Mni' s̀ finder man fis, jost you dem nirffamen seugungstriebe 


\section{$\left(37^{\circ}\right)$}

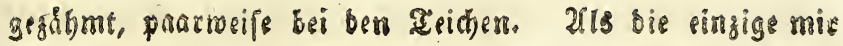
beÉannte 2rusnabme unter den Enten verlåpt ons Månns

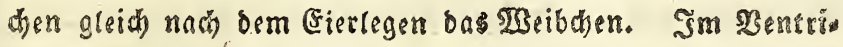
suld: Nerita, andere Eleine Sd)althiese und TBafferpflanzes.

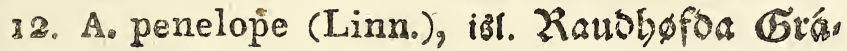
Dno (bei Novatm), Raudoufa. Cono.

Geliener alb A. acuta, Sie rommt pait, in des

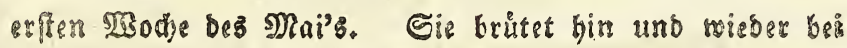

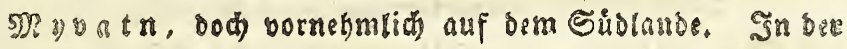

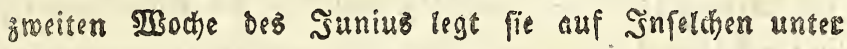
Echirmplanzen, ober auf $233 i[$ en, 6-8 getblich weifte, 3 3orl lange, Eirr. Shhe laute flagende Gtimme pirs if

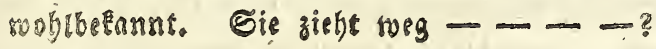

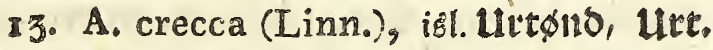

Nidit felten. Sie fommt in ter oritten 30 ochedes 2rprite im Merre an; im 2rnfange bes Mal's firbe man fie bet bers

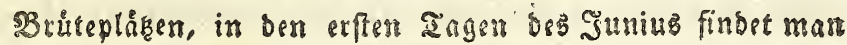

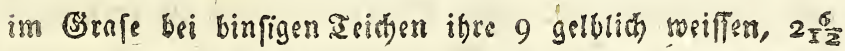
Soll tangen, (Eirr. Ehon ben 28ften sunius brbe ich fie

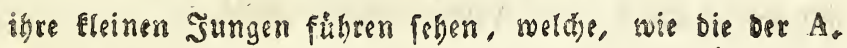

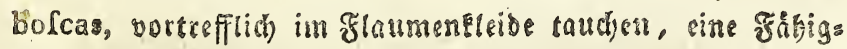
seit, roeld)e bis Erroddfenen im Geberfleide in ber Megel swisber verlierew. Das Månnthen begt eine unter den ens

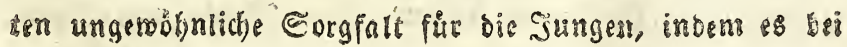

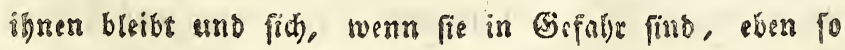

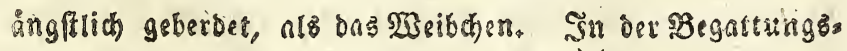

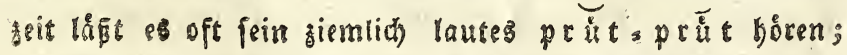

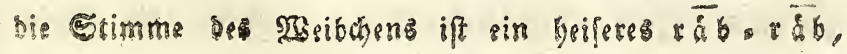




\section{$(78)$}

frifer als bus des MBribchems von A. bofcas. Gegen Ende

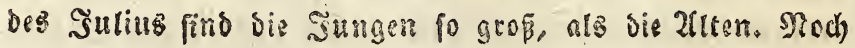
gegen Ende des Eeptambers bât bide (ente fï) am Strande, oder in ben nalje gelegenen seishen, auf; imalnfange bes Srobers berforwindet fie.

\section{Genus $3 \%$ Anfer (Brisf.).}

Leben in ber eingefbrån

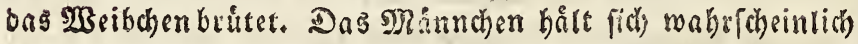

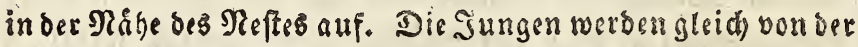
Dutter ins $\mathfrak{B a f f e r}$ gefübrt, 'wo fie im Flaum fich felbfe ct: nåbren. 3um $\mathfrak{B a f f e r}$ Element verbalten fie fich, wie Anas sreiter Familie, benn blö, wenn fie angefthoffen find,

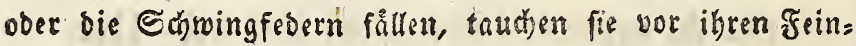
ben. Sie fino im sefife des Siadiments ber regulairen Iauchfobigheit; fie beben weit beffer als Anas, uns fuchen Dober in Scharen gobrung oft auf bem Trodenen, flie= gen aber lnatamei. Ghe Thenderungszug ift regelmifi:

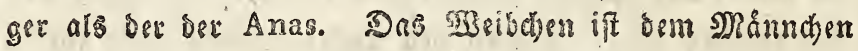

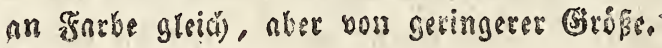

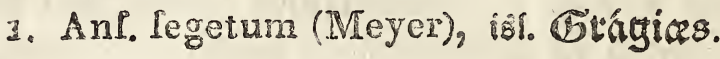

(5) babe ifn blop a

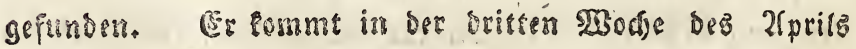

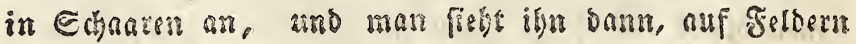

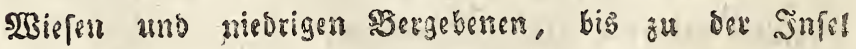

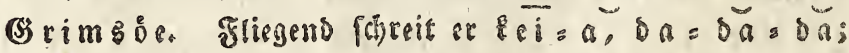

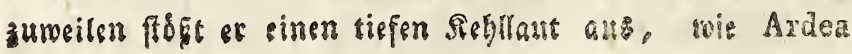




\section{( 29 )}

cinerea; mit Anf. leucoplis fat er rin breites $\bar{a}$ b gemcint, bas ber áhnlichen Etimme des $\mathrm{L}$, glaucus Brünn. nithe

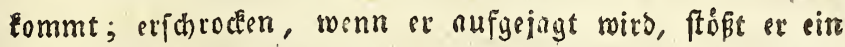
lautes flares $i \mathfrak{h}=$ i h aus. Gegen Enoe des Mnai's vers fchmindet er aus ben Thălern und zieht auf bie Serge, um zu brủten. Co fano ich im Suniub 1819 frine fosmuģig wciffa Eier auf sinem Felfen bei My im Eeptember Eefret or wieber mit ben erwadjernen Jungen in bie Thiter, auf 2 Befen bei Berchen und Getwâffern, zurúck, und ziebt bald oarauf meg.

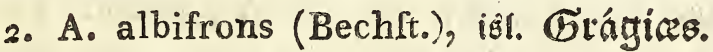

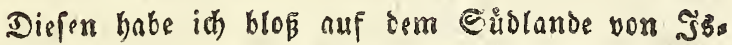

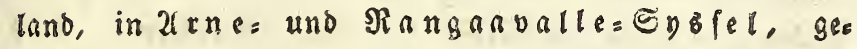
funden. Gr fommt mitten im 2 pril, und man fitht ifn

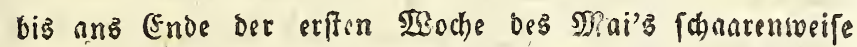
auf den Eel'ern. Berfhiedene Etimmenverånderungen hat er mit dem $\mathfrak{B o r h e r g e h e n o e n ~ g e m e i n ; ~ w e n n ~ e r ~ e r f h e d e t t ~ a u f s ~}$ fliegt, låpt er, sinen fefhr leife Elappernden \&aut bơren. Ex britet in Rungaavalles Sysfel auf ben Wisien unweit bes Jlůkcheng buera. Mitten im Mai, fagt man, legt et 5. 4. 6 fhmutig meiffe Eire. Die Sungen find gegen Ende bes Junius tlein. Die Mutter ziekt gleich mit ifs.

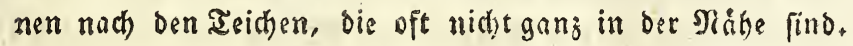
So wild er fonft iff, fo zathm foll er bei bem Mefte fenn, fo daß er, wenn er bavon aufgejagt wirb, zifheno um bie Fier låuft, Geigen Enbe des 2lugutes fah ich) Junge und Xlte in Shanen bei bem flúphen piors a. Sm Som= mer if fein Stitnband gelb, aber Bruff und Baud baben 


\section{( 80$)$}

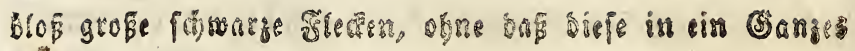
รufommon เoufers.

\section{Anl. torquatus (Frifch), iş.....}

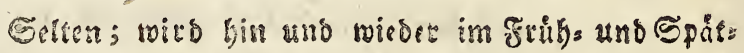

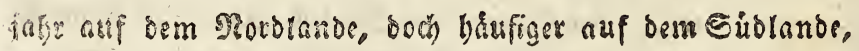
geftuofen. Ër Ecmmt zu gltidjer zeit mit Anf. fegetum.

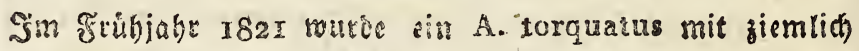

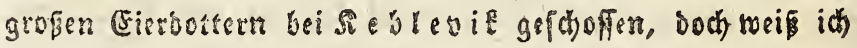

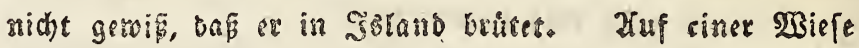
an bem Snnern you stofiore rourbe gegen Enbe bes Sunius ISig bas Reft siner Ban gefunden, bie nach Der Befdreibung Anf. torquatus glidy. Ber Eier, bie

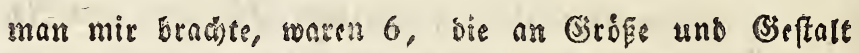

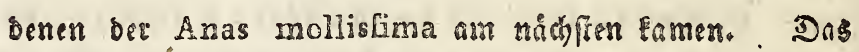

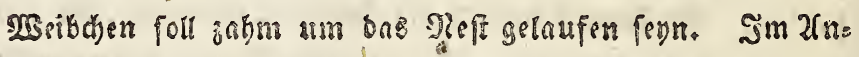

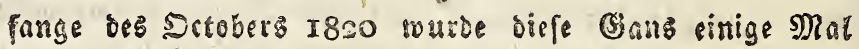

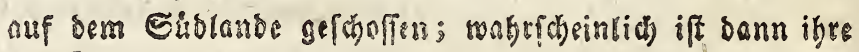
3uggeit.

4. Anf. leucopfis (Bechlto), isl. Jelfingi.

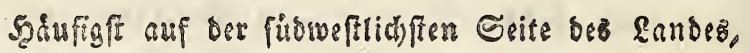

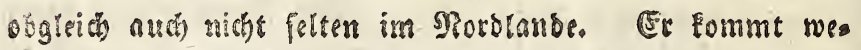
nig Iage frutger nis Anf, fegetum, bleibt, wie biefer,

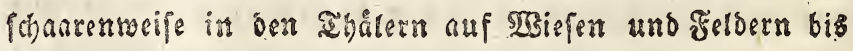
gegen Ende des Mai's, yerichmindet bann, und mú ents soeder nuf dent am menigfen hefuchten Bergen Sztands, ober gar nicht auf biefer Snlel, brinten, da man ihn im Gommer niemals fietht. In oen erffen Iagen des Geps

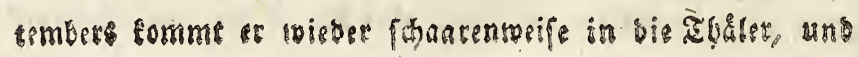




\section{(82.)}

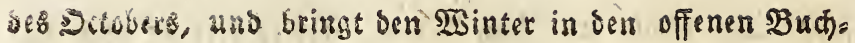
ten und warmen (S)ewifiern bes Süblandes zu. Biegen (Enbe bes Mlárs reenden die, die im Nordtande briten,

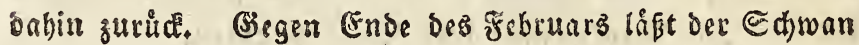

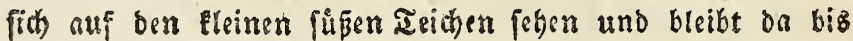
gegen bas Ende bes 2rprits, da bie meiffen auf bie bơbes een \$ergebenem zieflen, um in ben Ieichen Derfelken zu brutem; boch bieiben einzelne in ben Ibålern zuriek. Das Neft wirb grof und breit von Binfen und andern WSafferpflangen, oft, mie bas bes Podiceps cornutus, mitz ten im $23 a f f e r$, angelegt. Darinlegt bns $2 B$ eibchen im 2 nfana ge des Mai's 5-7 getbbraune E ier, sin wenig Eürzer uno bider, als die bes Cygnus gibbus. Das jårtlide Minn, Wen fiete oft bei bem brutenden 3 seibden auf bem breis ten Nefte, boch ofne felblt sie Eire zu wårmen. In ben erfen Tagen bes Sulub finb bie Jungen elein. Mitten im Sctober forwimmen bie Writren mit ben er.

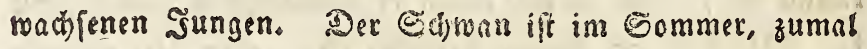

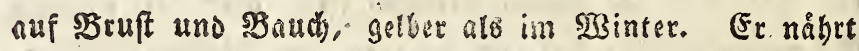
fiĕ) von veribiebenen wafferpflamzer. Den Namen muficus verbient or zu bebalten; wenu of nåmlich in Fleis men Edharen boch in ber luft eingergieft, fo låft et pei= Me moblelingende metandjotifose Etimme wie fernter tó

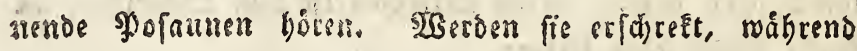
fie forwimmen, fo rufen fie sinander, ber sine mit einem

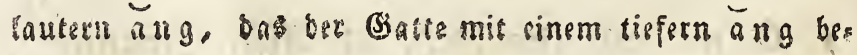
ontroortst. 
get water ben Sajwimmern; fie battu fid gern zu bers

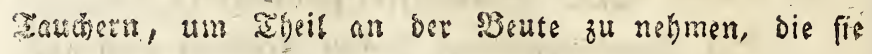

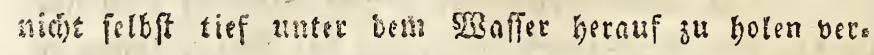

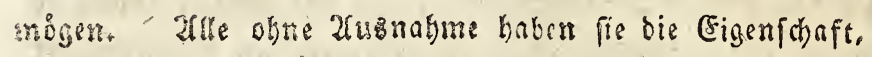

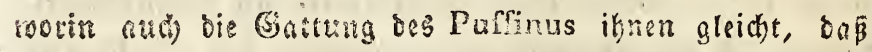
fie fich firgend in şaufer, zamal um gefdofferte oder

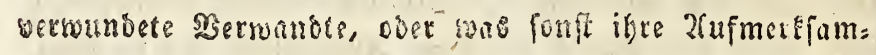

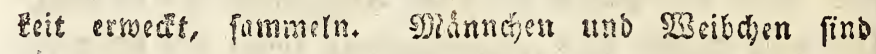
eimander an Garbe uno Brópe greich.

\section{Genus 39.

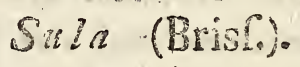

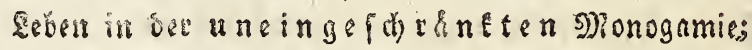
smanndien und Tseibchen buiten, und füttrn gemein= fdaftlich bie satmgen, bis birfe fliegend bas Neft ver: Iaffen: Gie fibren Shabrung in ber Epcifershre (œfophagus) berbei, und whrgen fie vor bin Jungen auf. Sogleidh fie auf sec Epur tuhen, fo geten fie

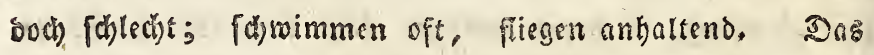

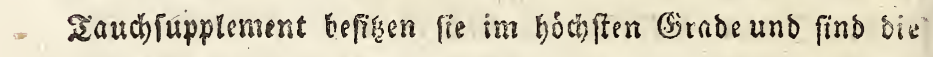
Repråfentanten biefer Grảigheit in ber Jone ber boreaten SBöget, baben aber frine Epar ber Tauthfähigleit; fogne wern fie angeforofien fäbimmen, varmoggen fie nid)t uns. terzutaumen. Gie balten Meffer; baben Eeine Brủtes

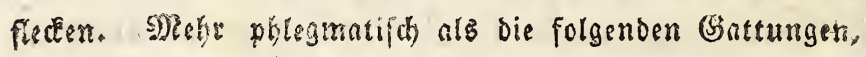

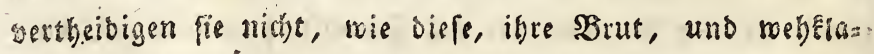

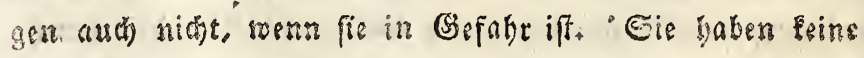
anintertacht.

1. So alba (Meyer), ist. Sala, Zoffáta.

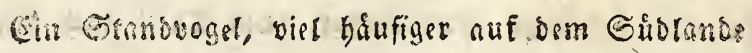

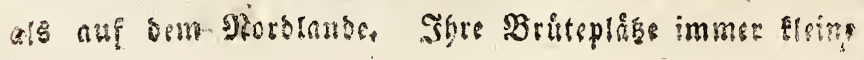




\section{$(86)$}

Meffern aufgetwirgt batten, Befabe lief, von bet fahrågen

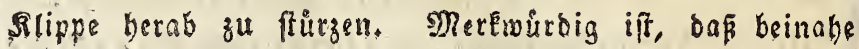
sin Dittel der Siefter foule (Eist hatte, weldhe bennods yon den 2ftten beburtet wurben, uno biepe pogar, von dem zu Diefer Sabrşzeit bei ihmen ertsachtan Ernägrungstriebe irregefíhrt, forohl vor ben Meftern mit foulen Eiern, ais vor denen, die Sunge enthielter, Nabrung aufgerwirgt batten. Diefe Rafrung erbait der Boget Durth fein auss. gezeichnet ausgetildetes Iouchfupplement, indem or fich fohe hod in bie suft erlbebt, uno wie ein Speeil herab und giemlich ticf, fowohl fentrect), als forråg (melthes bie übrigen Ginttungen nidts vormogen), unter bas Baffer

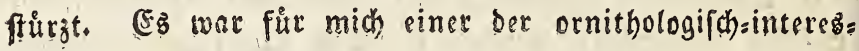
fonteffen Znbrite auf meiner ganzen Reife, So alba ununterbroden und in Menge auf biefe 2 seife in ben

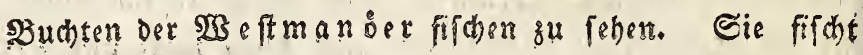

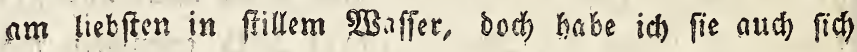
in Branoungen ftürọen Prben. Wenenn fie volle $\mathbb{R}_{a}=$ sung in oer Epeiferobre batte, fo flog fie mit fdrowes xem Fituge zu den Șrngen; ưbrigens fliegt fie fohnel= ler hle die Meven und macht oft Edswingungen in be: 2uft, Die sernen des Etordhes gleichen. Bsegen Ende bes

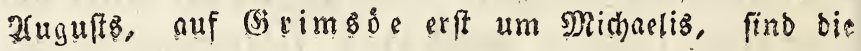
Jungen beficoset, und bann auch foft grófer uno vief fotter,

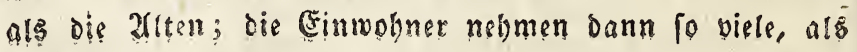
fie exreichen fonnen, zum Einfalzen sus, Sm Mefte find ihre Febern dann fow war mit singselnen weiffen झुuncs ton, Diefe Jarbe gegt nath und nad) zat ber geibmeiffen

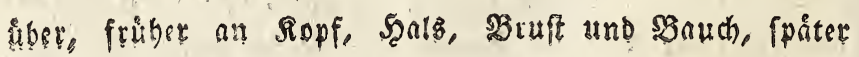

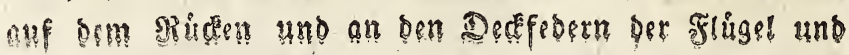




\section{( 87$)$}

bes Sdtwanzes, am fpateften an ben mitteliten Steuers federn und den inneren Sdwungfedern. Sm vierten Sommer (bas Sseburtsjabr bier roie immer mitgered)net), ift Der Sogel zeugungsfäbig und in alter Iracht. Sm 2rnfants ge des Dctobers verfhrwinden die Sungen uno 2atten von ben Geburts: und Briteplifen, und blsiben ben Minter über nn ben Siuften im offenen Si?eces. Mit Dem Sonnabel unter ben Flugeln treiben fie fo fid)es fehlafend auf bent Meere, Daß fie Eaum von einem unhe vorbeifegelnben Schiffe aufgewedt twerben. So wie fie uberbaupt, zumal im Nefte, febr von Lirnfen geplagt fino, fo trerden fie ouch zuweilen von eimer anftectensen . Seuthe angegriffer,

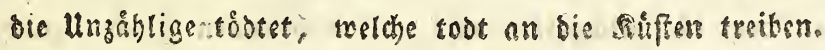

\section{Genus 40. \\ Sterna (Linn.).}

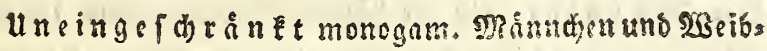
dien briten, und futtern gemeinfdyaftidi dis Sungen auf, oenen fie Futter im $S_{\text {dh }}$ mabel bringen, bis fie fo groß fint, als dic 2tten. Sie vertheidigen heftig ihre

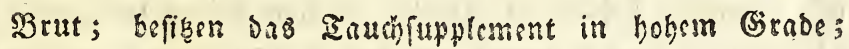
baurn Esin Reft; ruhen auf ber Spur, geben aber nicht fo glit als die Meven; fisgen langfam und biupfond. Die sungen laufen, wie bei ben Gattungen Larus uno Leftris, bald nadbem fie ausgebrutet fino, bleiben aber

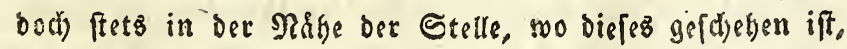
unter ber Pflege ber Xeltern, uno verbergen bann gern den

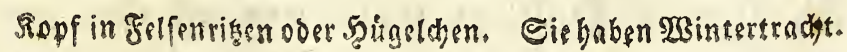




\section{( 88$)$}

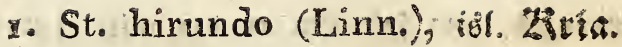

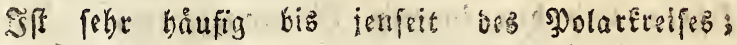

Pomm an vom "Isten bis I 7 tem SMai. Eie biutet ges

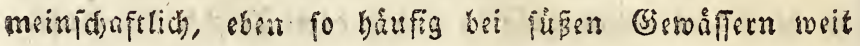
inne im Rente und auf ben niedrigrten Bergebenen, als

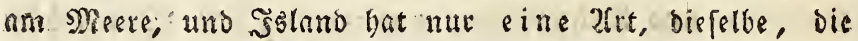
bir jo biufig an unfern dåniftben silfen baben, o. $i$.

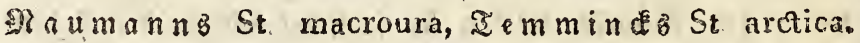
Zluf oen blopen fitfen am Mcere, ober auf bie nackete Eroe, legt fie zu gleidter zeit mit A. mollisfima, in bes

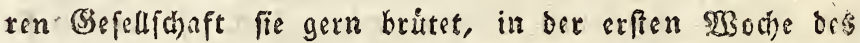
suniug ibre 2. 3. I. Eier, bie fobr variiren, noimlich

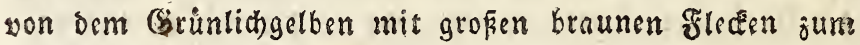
angefledit Secllgrinen, und benell ber Sc, gallinago alt

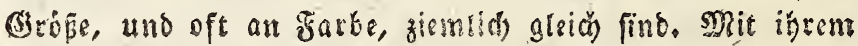

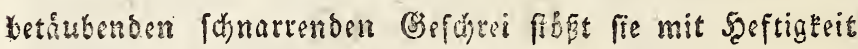
nuf bie Soppe Derer bernb, bie itger, \$3rut nabe Eommen.

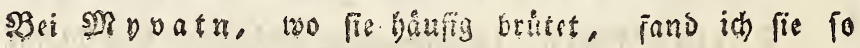

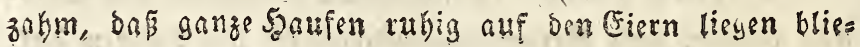

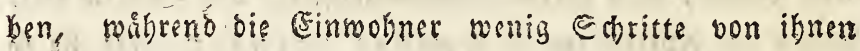
bei einem greken Fetue und unter lautem Setummel

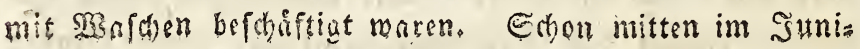

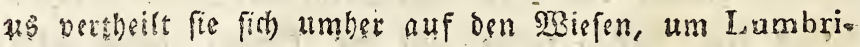
cus terreftris zul fuchen, bomit bie an bin Landeen

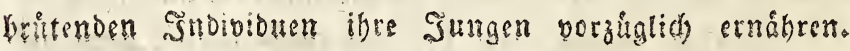

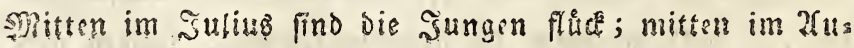

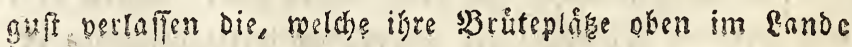

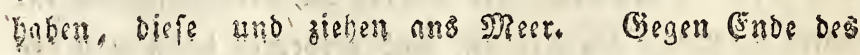

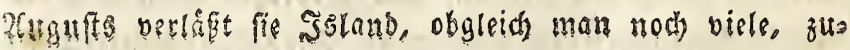

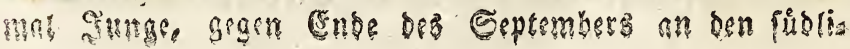




\section{$(89)$}

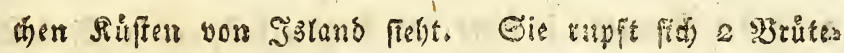
flecken unter cinander alf bem 2 auche. Das Truthjup.

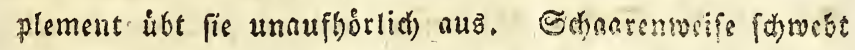
fie in ben $B$ utdenten her ben Sirgen son Clupea fprattus, und fifcht biefe unter beftandigem befhrei, Suweilen muß fie bér Leftris parafitica igre Beute übretaffen; sorb habe id biefen Rhuter zur Bergettung oft yor ber in Şaufen angreifenden Sterna flichen fengen, wenn ex วgre Eier rauben und ausfaufen wolte.

\section{Genus 4 I. \\ Larus (Linn.).}

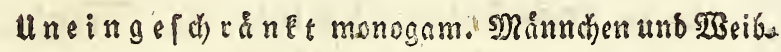
den briten und fütterm gemeinfd)aflich bie sungen aus Der Epeiferógre (œlophagus) auf, bie biefe ben Weltern

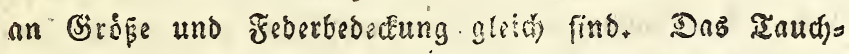
fupplement befferen die eleinern Speciss in böberem Erea be als die grosern, weldge lebsere zugicid) sine raubgies

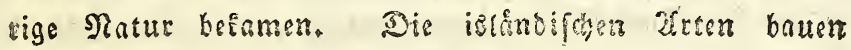
alle Nefter uno baben Brüteflecers. Sie frgreien viet brim Nefte, welches fic oft muthig vertigrisigen. Sie fiefen und gehen, wie alle Gatungen tre Taubhpupplss ments, auf oer Spur, gehen abes wirl beffer a!z Sula ober Procellaria. Soggleich alle Mpevea mebrere Sabre binbringen, ehe fie in alte aradit formen, fo bes

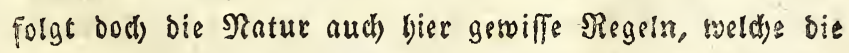
ueberficht oerferben erleichtern. Die fprenslidse, geffexte uno gebinderte Iracht, die aus metreren Farben zoufammenges

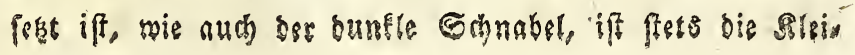




\section{$(90)$}

bung ber Jungen; je kilter ber $\mathfrak{B o g e l , ~ b e f t o ~ m e b r ~ E i n b e i t ~}$ in der Farbe, is beller (gelb ober roth) Der Sdynabet. Eo wie die fiecten abnelgmen, nimmt nudb bie bungle Farbe bez Edinabels ab; bie 30ogel, von beren Federn bie Şålfte ber Garbe der Zltten angenommen, Die nnoere Scälfte aber nod bie ber sungen bebalten bat, baben aud sinen Echnabel, deffen sine Sedifte roth ober getb, bie ans

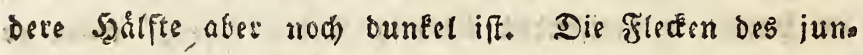
gen Bogels verlieren fich zut allerlegt auf ben Steuerfes Dern. Diefe Regel gilt fogar aud bei L. tridactylus, Deffen Federverinderungen von benen ser ưbrigen Meven abmsinen. Sie baben alle Wintettratitst.

\section{I. tridactylus (Lath.), iš. Skéglo, \\ Zîtul, Ritfa.}

Eebr båufig im gnnzen Rande, zumal gegen Not.

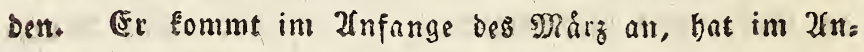
fange des 2(prits die 23 intertrad)t, Das blaugraue \$and ilber bem Racken, abgewerfen, und verfdrwindet miebet gegen Ende bez Septemberz, obgleich eingerne um Szinno alberwintern, und zwar vorziglith im offenen Meere, das et mehr, als bie ribrigen (Sattungsperwandten liebt. CBes gen Ende dez Mai's fangen bie erften Sndividuen an,

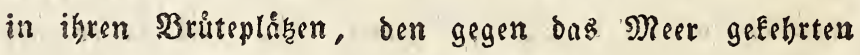
Felfenminden, nuf ben zebfiken biefer Bainde ibr grobez, wie bas. bes L. glaucus geffalteteg, Neft zu bauen, Er legt 2. 3. 4 Cist, bis fehr, wie bie ber St. hirundo, yon gelbgrau, braun und grau gefledt, zu ganz unges

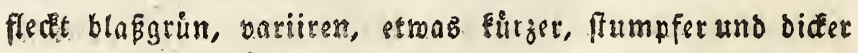
str bie opr U. grylle, und 3 avil lang find. Bri dem 


\section{( 9I)}

Mefte forreien biefe sBogel tunter allen am meiften, inbras fir entweber fliegell, doer boi bem Batten filen, ben fie nickend liebEofert mit ifrem andern 2rtgertwandsen aber

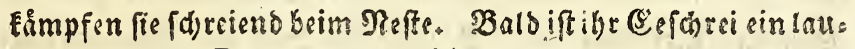

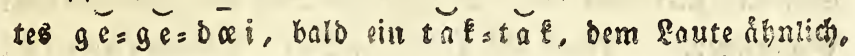
Der Sylvia curruca ifyen beutfoten Namen, bas Miluess

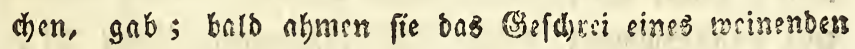
Rindes auffallens nad\%. Celbft wenn fie (Erbe zumm Bart

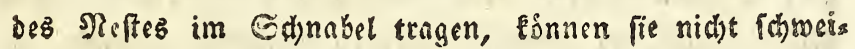
gen, fonbern froben einc beifern Eaut auz ber Sishle nus. Sic ver fammetn fich zumeilen auf ben Eleinen füpen Teichen auf ben

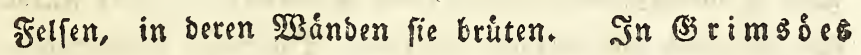
Bogelberg niften fie in fold Mer Menge, Dá fie die Eonne. serbergen, wenn fie auffliegen; bie Ccheren besecken, wenn fie firen; die Shen betauben, wenn fie forsiem, und ben von Roffeltraut grủnen Felfen beinatge meip machen, wenn fie brüten. SBenn bas Gortpflangungswes fen zu Enoe gebractht ift, fo werben fie geóstenthoits spie.

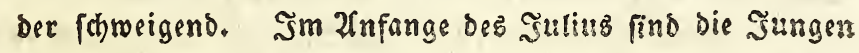
eben ausgebruitet; im 2tnfange uno iat bre Mitte des 2rus guftz fliegen fie, ebeit fo grof nts dis atten, aus bem Mefts, Shre ganze Natur iff ůbrigens fanft und zahm. Sie ba: ben an 3 ober 4 Stellen, und bann ủter Sircuts, Strưses flecten am Baudje. Sie ủben bns Iaudjupplement eben fo brufig als St. hirundo und L. leucopterus, I? zrugungffähiget aradt im vierten Commer.

2. L. leucopterus (mihi), iริ. Zuitmáfi, Ђvitfugl, (jun.) Grámáfi.

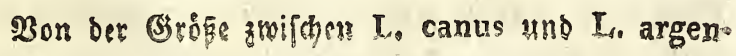
tatus $\operatorname{Linn}_{\text {, }}$ 


\section{$92)$}

50

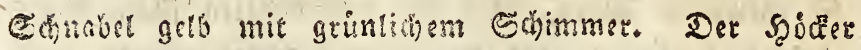

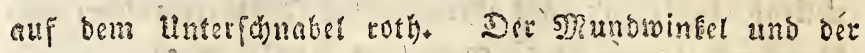
Shluno fleifofarben. Dis Dunge beis mit bleifarbenem Echinmet. Die جugestander fleifofarben.

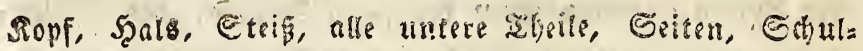

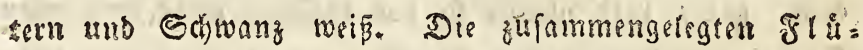

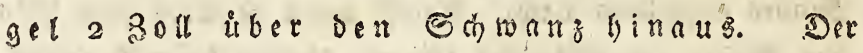
Rheten und bie ntern scefebern graublau (cana), die (Shmungfobcrn binf canefcentes, gegen bie Spige reip. Die Shwungfebern der britten sobung von ber Farbe

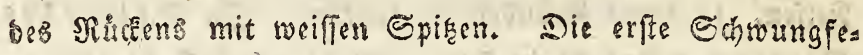

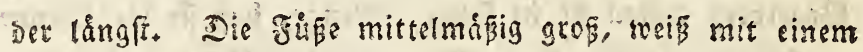

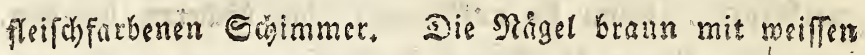
Spisen.

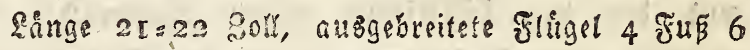

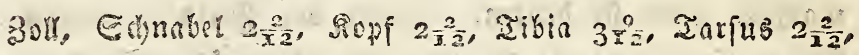

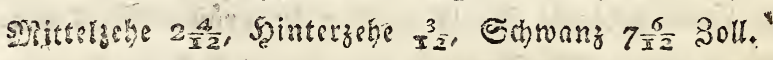

Som Segtember bis zum 2infang oes 2rprils it grintertratht, mit groum Elecen an Sopf uno. Scals.

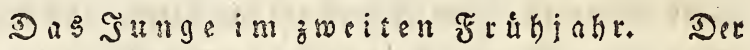
Sonnbel fomurig frifoforben. Die Shalfte gegen die Epiąe formary. Fontund und Bunge blos. Die angen mit brauner Şris. Die, 2Tugenrinder graubraun. Sben weiflid) mit afdgrnuen beinabe vermifden Gleden, am meiften auf Sopf, Şals uns Etriß fichtbar. Inten blä

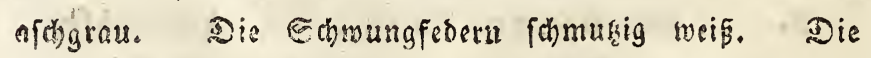

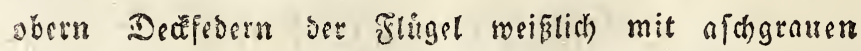
Feren, bie untern weistich. Die Struerfeoern fhmusig

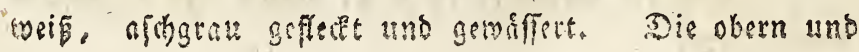




\section{(93)}

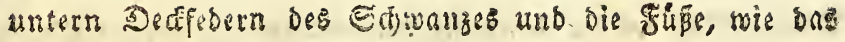
folgentis Sunge.

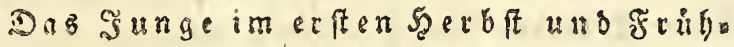

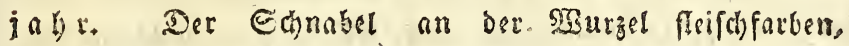
an ber Epine fómarz. Echlund und sunge bla bleifarben. Die Zlugen mit brauner Sris. Die Zfugens ránder gralbraun, vor den 2lugen sin bunter Fled von

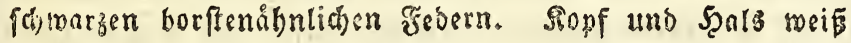
mit grouen Etricher. Der Midtern canefcens, mit

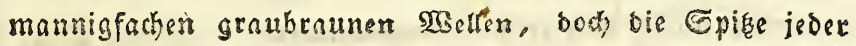

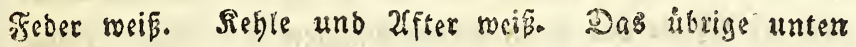

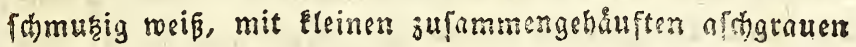

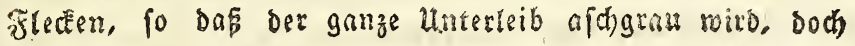
Die 2 Beichen uno bie untern Dedfforern ber frliggel mits rociffen Flecken. Die Sdjwungfedern fohmuşig canæe mit btafferen Spisen, bie großen oberen Decepedern ber Flü

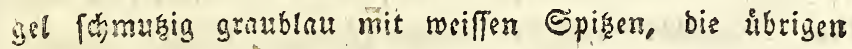
von ber Farbe bes shithens. Der Edwanz afchgran uno

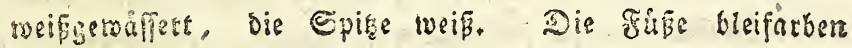
weif. Dis Miagel graubraun mit btafferer Spife.

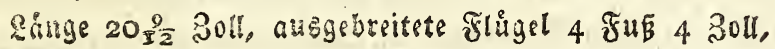

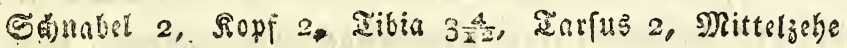

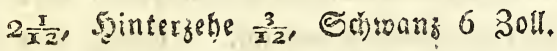

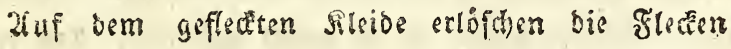
nath unb und. Sim viersen Sommer baben fie oie Far

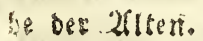

(E⿱

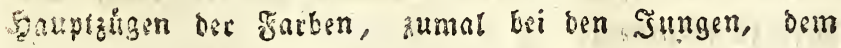

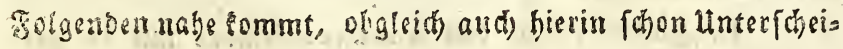
bungszeichen genag flegen: mer aber bie (Gefobichte biefer 


\section{(94)}

59eve getwat temnt, Eann fie nie mit anderat verwechpetr.

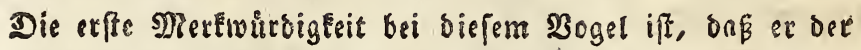
einzige iff, ber den 2 Binter in Salans zubringt, ofme bafelbft

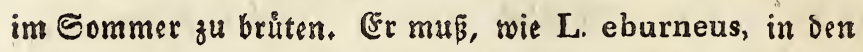
nórolichen \$olargegenden brîten, und in Winter als

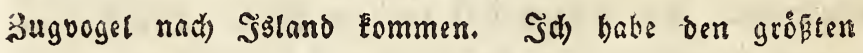
Iheil der Siffen bes fandes bereif't, und habe da nirgends peinen $\mathfrak{B}$ ritteping gefunden; in ben Felfen voat $\mathfrak{F} a \mathfrak{x} e=$ und SB redebugt gegen $23 e f t e n$, wo L. glaucus in grobent Eolonien niffet, war fein L: leucopterus. SBenig Iage กrach der SRitte bes Eeptembez fommen dia etfen, Sunge

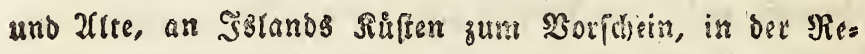
gel mur blos auf bem Morolande, wo fie in groper Metert

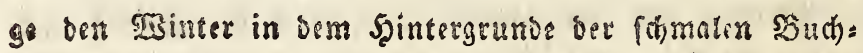
ten zubringen. So warent fie im Winter $1819=20$, als

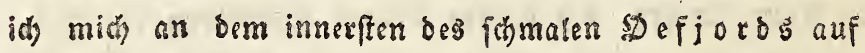
bem Rorbiande aufbielt, unfre tågliden (S)affer. Brgen

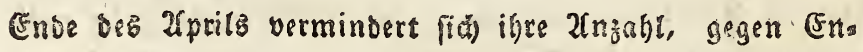
be deg Mia's find fie faft alle von sastand verfchwunden. Diefe zanmen soogel gingen zurcilen bei meinem Winter= lager auf bem Notolande an Eand, sum die von ben Eins

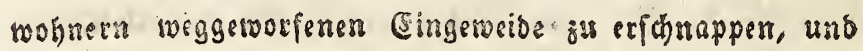
Fimpften beftig mit Corvus Corax barum. Einen yon biefen Larus batte idi) fo zalim gemactit, baz at jeben

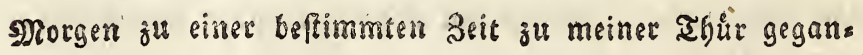
gen Eam, um einige Stabrung gu befommen, umb bann

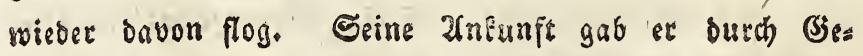
f̧hrei zu erEennen.

L. glaucus bat bas rauchfupplement nut in ges

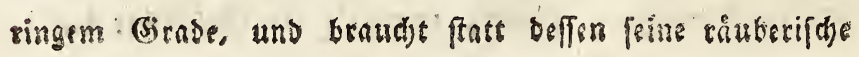




\section{$(963$}

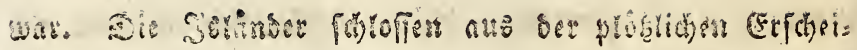

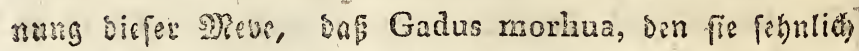

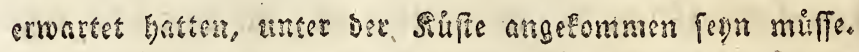

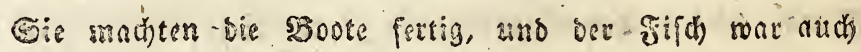

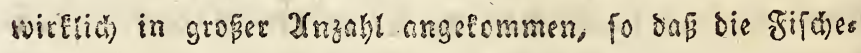

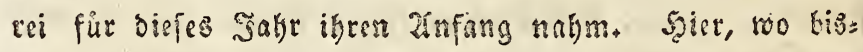

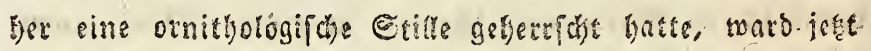

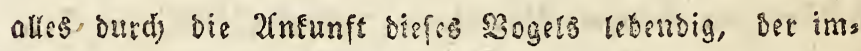

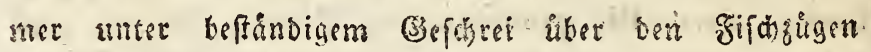

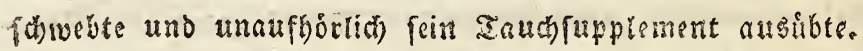
rssolfte ich biefen Boget fohieffen, fo nabm id nut bie Seit in 2(d)t, wesn bie Fifd)erboote antanorten, ba biefe

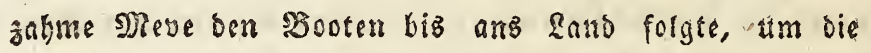
yon ben Fifchern aubgrworfenen (Eingewribe aufoufhnapz

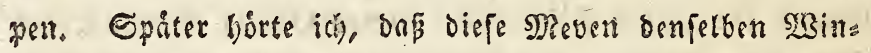
ter auf bem Rorbinne filten gewefen fey, weil bas grons tåndifche Sis bafelbft alle Buchten voll geffopft batte, wo witch

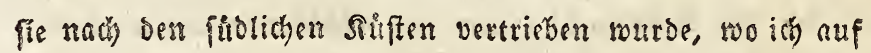

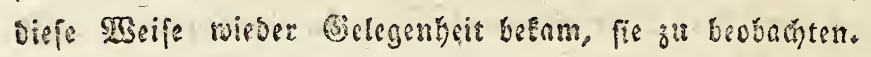
Bis Minten im Mar wlieb fie im Sobre 1821 nuf bom

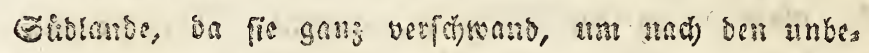

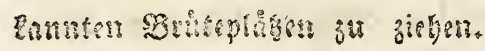

L. leucopteras bot eine gans anbere Etimm, als L. glaucas, who sie altsm fallen nic einer in ben

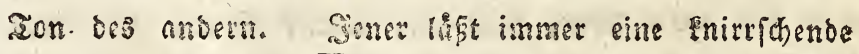

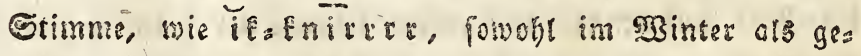
gen bas fribjalje joren, wsm L. glaucus mit feinem

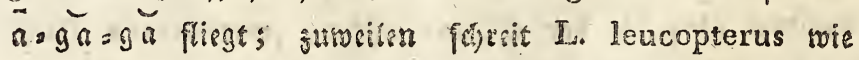

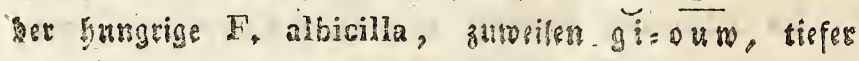




\section{$(97)$}

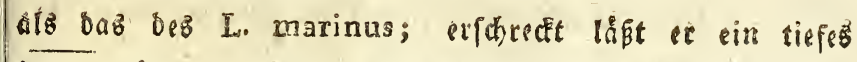
hood boren. Die Jungen baben, wie mebrere sungen

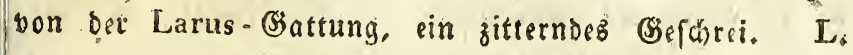
leucopterus war mein 2 Bettecprophat im 2 Binter. WBent: er wahe an bas beftade fatramm und da, gteichfam ürgftlich, mit aufgefthwelten Fesern tribb, fo muste ich,

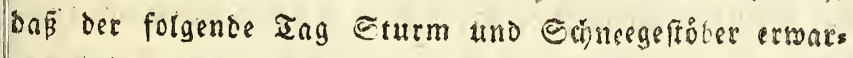
itn ließ. Sri gutem Wetter mucht er Cajmingungen bocit in ber Euft; oft fist er zu Scunderten auf einer Eisz icholle und treibt fo megrere $\mathfrak{N e i l e m}$

Sein Iemperament ifi gang yon dem bes L. glau. zus verfchieben. Dicfer hat bie Citten deg L. marinus; fährt mit mely Etårfe uno Germaltfameeit einher, ift brges genủbrigenz. megr phlegmatif h. L. leucopterus h̆ingegen haf ime bem L. argentatus Linn, mebr ågnliche Natur; fein Benefmeri und fein Flug find fanfter, er foherbe mit reniger Siraft úber friner $\mathfrak{B}_{\text {eute; }}$ aber ůbrigens ift

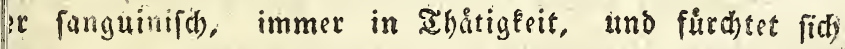

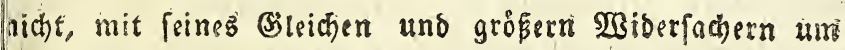
fine Nafrung zu Łåmpfen.

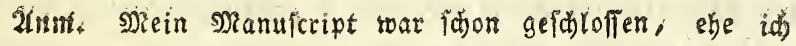
wupte; ba官 biefer Mese yon irgend einem Sdjrift: fteller (Errwåhnung gethan war. 3ufąllig bekam id Sabine's Memoire yon ber gronländifhen sigogeln gelieben, uno fano barin unter sem unridtigers.

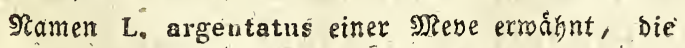
grope 2ehnlicheit mit meinem L. leucopterus hat.

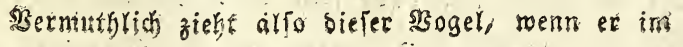




\section{(98)}

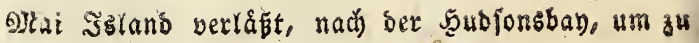
bruten.

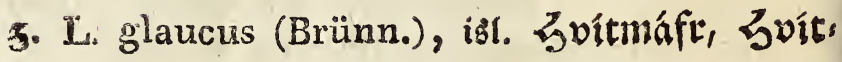
fugl, (jun.) Orámáfi:.

S2ont ber Ģro̊ke b:s L. marinus, Die Epiken dee

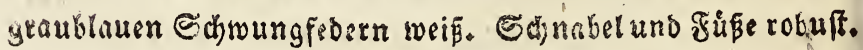

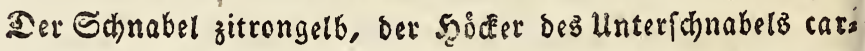

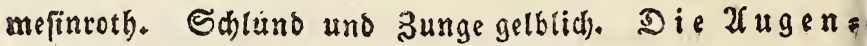

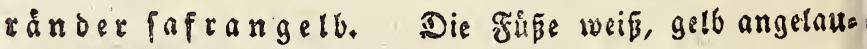
fen. Die Ertwungfedern ragen $\mathfrak{n} \mathfrak{r}$ wenig $\mathfrak{u} b e r$ ben

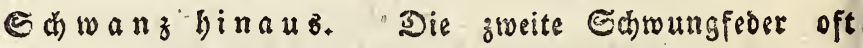
langer, wenigftens eben fo lang, als bie, erfte.

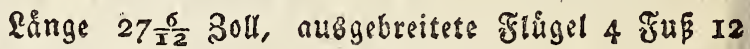
Boll, Schnabel $3 \frac{3}{T^{2}}$, Sopf 3 , Echinang 8 2oll.

Die Jungen mit mannigfaltigen graubraunen

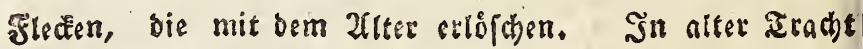
im vierten ङommer.

Sุhufig, zumal auf bem ธủd, und 2 seftande. Ein Eranboogel. Den Minter bringter nn bem offenen \$Reere ober

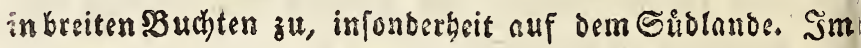
Znfange des 2(prits fommt, ex in ben tiefen unb engen

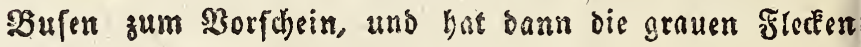
Des 2 Binters am Şalfe uno Ropie abgelegt. Rutz barnuf

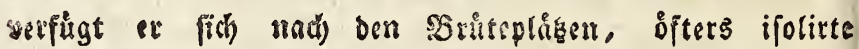
Scheren im Meere, vorzugglid) aber brůtet er båufig uno

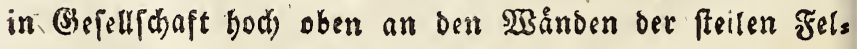

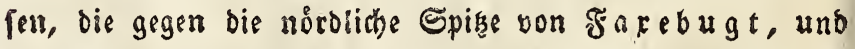

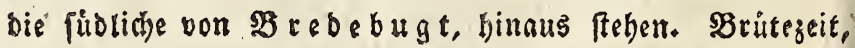
wie ber Folgente; baut fein Neft roie diefer; frine 3. 2. Wiev fino nicht non senpm bes $I_{4}$ marinus an Farbs, 
getgende, Den winter bringt er auf bem offenen 9 hesere und in ben breiten $B$ Butten zu. Sm 2nfange des 2(prits,

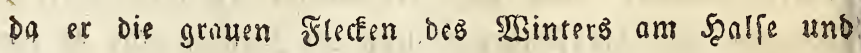
Sicpfe abgelegt hat, fommt er in bie fdhmalem unb tiefert Buchten, uno begiebt fith Danm nach den Briteprasen,

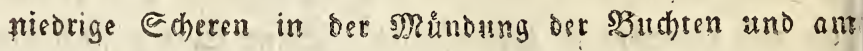
offerm Meere; feltnse gefte cr binnuf ing \&ano zu ben

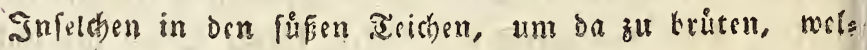
dez boch bei bem See Dinguallavatn uno bei $\mathfrak{F}_{i=}$ favatn in Shappedalb= Enģel ber Fall ift. 2luf Der Sberfläche ber Echeren baut er ein grofes Mefi von Erde, MRergrag uno Ióffrlfraut; in Difcus Dürre Mflans zen. Im Xnfange Deș Mai's legt er 3.2. 4. gelbgraue, mit mebrecen gropen uno Eleinern braunen uno grauen Jlecten grorithnete, $4 \frac{2}{x^{2}}$ Zoll lange, Eirr. Daz Neft pertheibigt ex fhreirno, indem ex auf Den Saerfolger ftófte foch nidut fo, mie Sterna oorr Leftris. Mitten im Sus nius find oie Jungen bálb erwachfon and im glaumklebd: gegen Ende des surtus find fie befiedert. Eeine (Ses

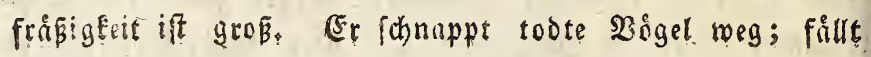
Dị Eroufen an; folleppt die Eier yon Uria uno Alca im Ect)nabel nad) feinem Jefte, und foruft fie ba aus; verfolgt I. glaucus, um ifm feine Beute abzuzmingen; "Das Iauchfupplement benught or nur, um Cyclopterus lumpus za firden; formmelt am Etranoe Cancer pulex, frife dif Shisre aus Venus islandica, Pecten islandi-

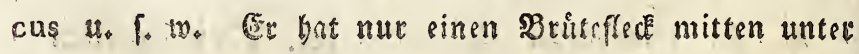
Dem Bauche, uns if in alter Iratht in vierten Sommet,

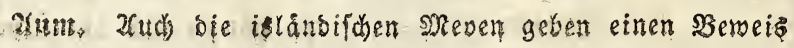

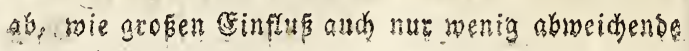




\section{( $\operatorname{IOI})$}

Rangengrabe auf die geographifale Xubbreiturg ber Bogel baben, mo pogar die sreitengrabe bieferbel

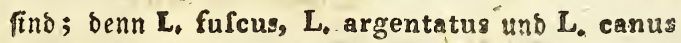
fieft man, obgleidf fie in Rorwegen, unter Jేlands Breite, båufi find, nie auf biefer Snfet.

\section{Gènus 42. \\ Leftris (lllig).}

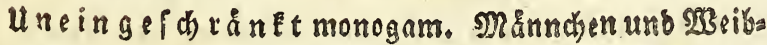
chen briten und würgen gemsinfhaftlich Jurter aus ber Epeifes

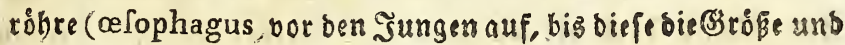

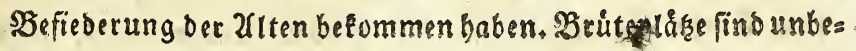
Dingt Biefen und Snndebenen bei füpen Berwåfern, nie Felfext an Meere. Sie knuen fein Meft, legen 2 Eiex, baben Bruteflete

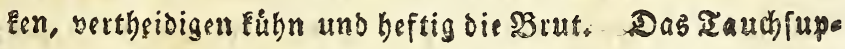
plement uben fie felten aus, uno es if wenig aubgebils bet. To baß fie fidi Eaum aus ber Inft berabfturzend bis an bie Spise bes Sdmanzez unter ben 2 Bafferpiegel zu -zwingen vermogen. Statt bes wenig ausgebilbeten Taudhs fupplements baben fie sine befondere Fibigkets, nach mals doer fie andere Shroimmoogel, um ihnen ifre sacute abs zujagen, fo lange verfolgen, bis biefe erforroden die Beus te fabren laffen, welche Leftris, inbem fie fich beratfir:

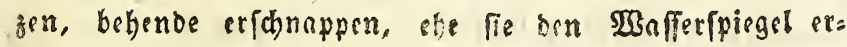
reicht, unter wichem fie forbft fo fchlectst verfechen fie zut bclen. Ebenfalls fteblen disfs mutbigen Råuber bie

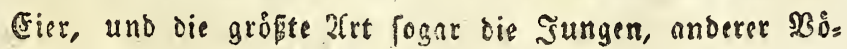
get. Die biattung firth uns geht auf ber Spur, flisgt anbalteno, forwimmt aber aud nich felten. 


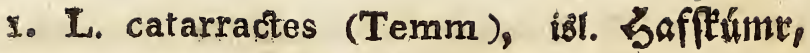 băkallaftúm:}

Dieler interffinte Bogel ift redft allgemein an

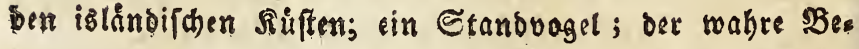

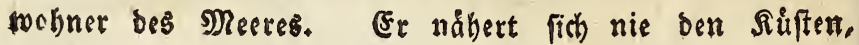
auffer in ber Brůtezeit, denn bann fliegt er zumeilen eine

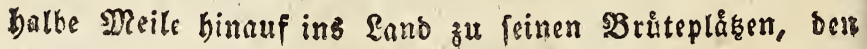

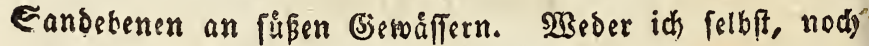
sin yna mir borum befragter Jallnber, bat jemals feinen Brúteplac anf dem शororande gefunden, obgleich id) bies fen Sogel boch oft da auf bem Meere, mebrere Reilen

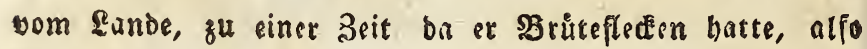

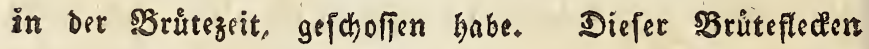
fino 2, einer an jeoer Seite bes \$audses. Zúuf oem Eủolande bagegen brütet er an 4 mir hekannten Stellen: auf einen Eandinfeldyen in bem Flüsdsen 1 bifa; auf

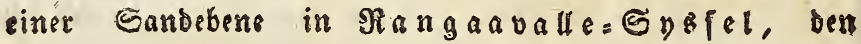
Siseffmanbern gerabe gegen uber, $\frac{x}{4}$ Mrile vom Meere;

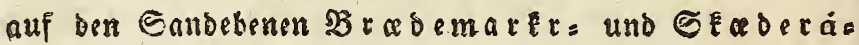
Sandut in Senptafells: Sysfel. Spire fammelt st fidi) in Colonien unb verrichtet bas \$Brůten in

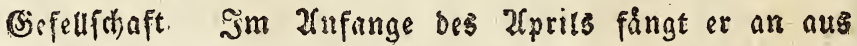

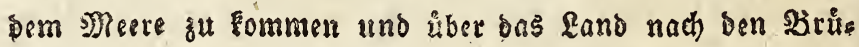
teplakgen zu fliegen; mitten im nie mefir als 2 , in ben bloben Sano, bie an Bróge und (Spffalt zmifhen benen bes Lar, marinus und ber Leftr. poa

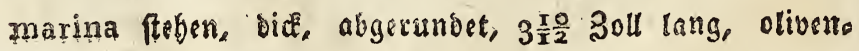
brekn ober olivengrtin fint, und, befonders am biken Ere

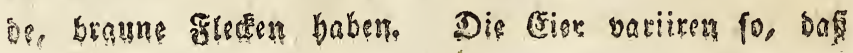




\section{( 103 )}

id) in sinem Neffe 2 bellgrůne ungeffectete (Ficr gefunber babe. Im 2rnfange bes Sulius find bie Sungen Elein, mitten im Julius mit grauem Fraum befegt, gegen Ende bes 2lugufts fo gró und to befiedert, als die zltest.

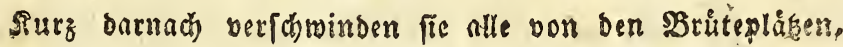
entfernen fid yon ben Riffen und halten fict ben SBins

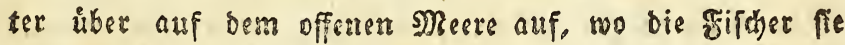
feften und biefen gefrápigen und zatmen 2 bogel zutroeiless an dem Zngerhaken fangen. - MRittern im Julius 1821

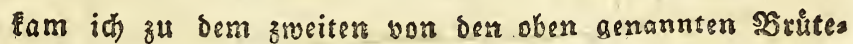
plågen, wo eine Eolonie, von umbefige I00 Paar, balb

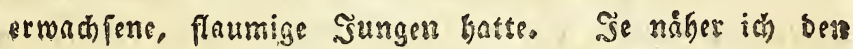

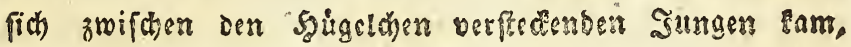
Beffo beftiger fielen bie zetten mich an. Gie prieffen Edhleg auf Edylag aub ber enft berab auf meinent Sopf, indem fie ein tiefes boo nespteffen; mein Szunb, Den fie noch beftiger mit bem farken Edmabel fotugen, war gleich verzagt. Sd' Eemne Eeinen 20 gel, ber feine

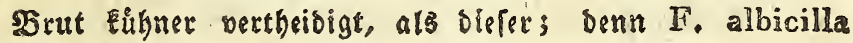

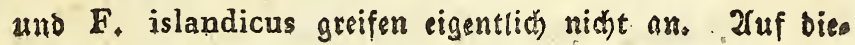
fem intereffanten Plase fhos ids fo viele L. catarractes, als ich sollte, unter andern ein Mantnchen, bas sben im כ3egriff wax, ein ganzes verfohtungenes Sunges vons Proc, glacialis vor feinen sungen aufaumirgen, bos es Den 2feltern auf bem 2 Meilen entfernten $3 o g e l b e r g e$ auf

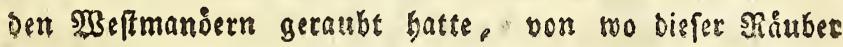

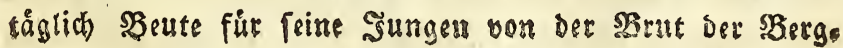

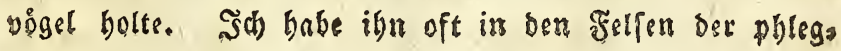

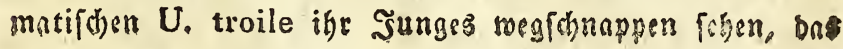

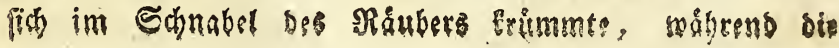




\section{$(104)$}

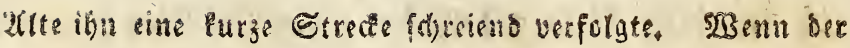

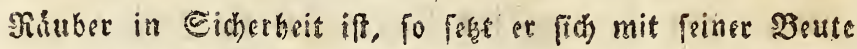
aufs 2 Baffer, tobtet und verphlingt, fis, und fliegt fo domit zu feinen fermen Jungen. Ee gebt beffer uno låuft fohneller, als feine Battungsverwanden, ungefăge wie die Meven, und iff, wie biefe, feht bafur, bis an bie Sthiste im $23 a f f e r$ zuftehen; aud fliege er fohtller uno niche To hupfers, als bie beiben Forgendert. (Er verfolgt, Doch nue felten, Sula und die groben Larus, um fie zu zrmingen, bas von fitit) zat geben, was fie-für ibee Jungen in oer Epeifes

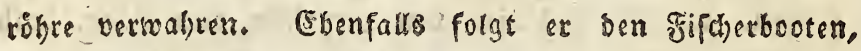
vorzuglith benen, bie ben iztandifdyen Squalus carcharias fortgen, ganze Mcisen, um osz, was nus biefen ins

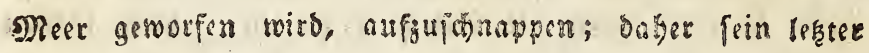

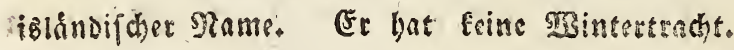

2. L. pomarina (Temm.), iș. Zijói.

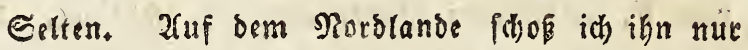

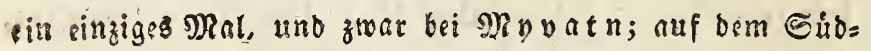
lanoefano id im Sunius I82I, auf einet Biefe" bei sto

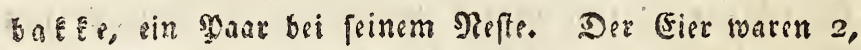
niober renger als bie ber L. parafitica, aber viel bicker, an (3) rópe und Farbe benen des Num. phropus fobr åbn (id), nus nicht fo zugefpizt. 2 Un $\mathfrak{B}$ id o e mirb zuweilen sine cingerne nebjt ber Rachfolgenden in ben Ealingen gefongen, die man ithen lege, wann fie die Eier ber $A$. mollisfima nubfatfen trollsh. Sige etimme ift ein

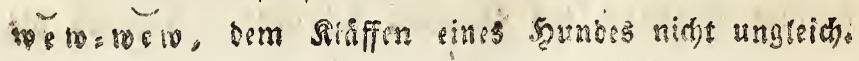




\section{( 105 )}

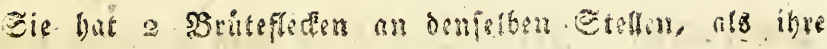
ऊattungserrounder.

3. L. parafitica (Temm.), iâ. Kojói.

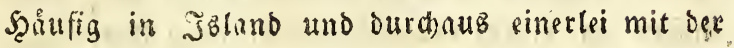
sormesichen. Man findet einige mit braunem, einige mit weisem, Untetleibe, welches weder Rennzeichen dez zelters nod) bis (3efertichts, fonbern sine regellope Paries sat, wie bei Canis lagopus unter ben Cáugthieren, iff. J4) babe jwei unten $\mathfrak{B r a u n e}$ und zmei unten $\mathfrak{B e i f f}$, unb ebenfalls sine von jeber Corte, bei dem Nafite ges funden, und bei ber zerlegung fand ich, baß bie unters

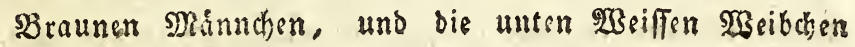
soaren, und umgekefrt. Eine Baristat von L. parafitio ca nach bem zitter, beren wichtigfte Diagnofis bie unges woinnlid) langen mittrlfen Etrusifeosen waren, welche

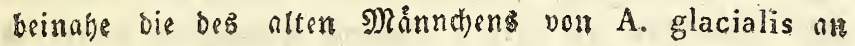
Range ubertrafen, erbielt ich ben $17^{\text {ten }}$ Junius 18 I9 be?

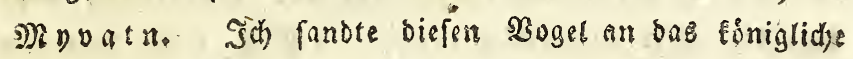
zoclogifthe Mufám in Sopenhagen, wo ids ifn bei

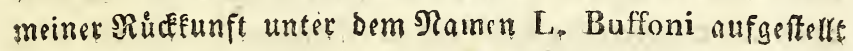

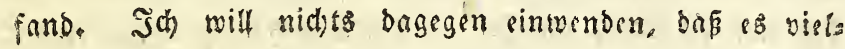
leicht eine $\mathrm{L}_{4}$ Buffoni als eigene 2 ret geten famm; obee in Siglano ift fie nicht yorbanden. Sener Sogel ran sin altes spanndsen unn L. paralitica, mit einer nmoarne L. parafitica gepant, bas ich bei frinem Meje mit ets

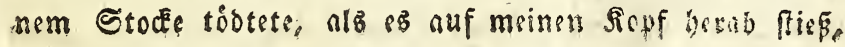
. um bie (Eier zu vertbeibigen.

L. parafitica Eomme ungefinte oen 25 ffin Xeril

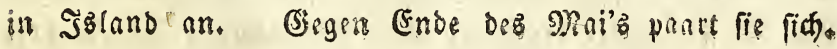

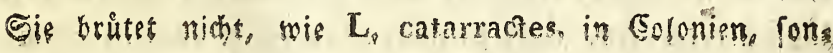




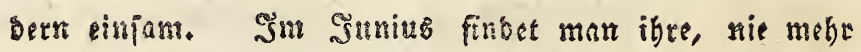
als 2, Eier, etmab zugeppist, 3 zoll lang, olivengrau mit

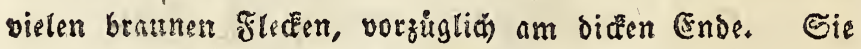
liegen in einem birabghigethen, obme Unterlage, meiftens auf : Biefen, wo bet Brủteplas sin wenig von bem Maffer ber Biefe umfloffen ift, foroht in ben abdern als auf ben niebrigern Bergebenen. Bei Myuatn, zus

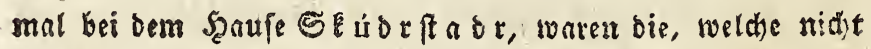
bruteten, in grobe Sraufen verfammelt, wo fie auf ben Wiefen uno Selbern, wie C. monedula, Nabrung [ü̆= cen, vermuthlich Diptera uno Lumbrici.- Dann uno wann erloben einzetne fich aus bem Şaufen in bie Suft, un cine vorbeiflegende Sterna zu verfolgen. Mitten im Zluguff find bie Weltetn noch in Bsefellychaft mit ben ers rachfenen befieberten Sungen ( $L_{0}$ crepidata). Sh babe bas Miannden bei feinen sungen gefchofien, inbem es Clupea Iprattus vor biefen aus ber Epeiferóbre aufs soirgte. Eie vertheibigt tapfer bas Neff, wenn man bie

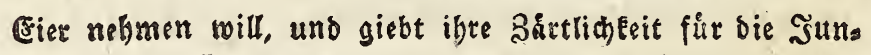
gen burch wunberliche (Seberben zu eréennen; fie wieft fich nàm:

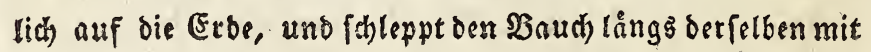
aufgefdrwellten Federn, herabbångenden flügeln und teifem

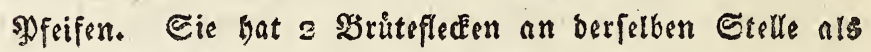
bie Borbergebenden. Dogleich fie fonft langfam und hupfons fliegt, fo verfolgt fie bow Sterna hirundo, bie tleinern Mevest und Enten mit ber grósten Echnelligseit, wenn fie ithnert bie gemadtyte Bente abjagen will, soelche fie mit eines Fertigfeit obne Bleiden in ber \&uft arfhrnappt, the fie

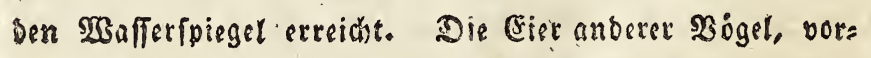

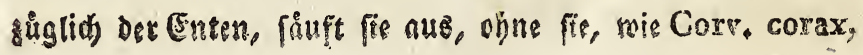




\section{( 107$)$}

L. glaucus ober L. marinus, fortzutragen. Sthre traurige

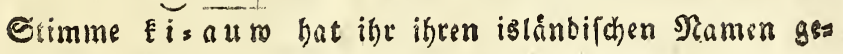
geben. Mitten im Geptember verlåpt fie Sstand.

\section{Genus 43. \\ Procellaria (Linn.).}

Ut ne ing e f hon brüten uno füttern bie sungen auf, bie biefe bie ßrutteplåge fliegend verlaffen. Cie wỏrgen bie Rahrang aub Der Epeiferóbre (œfophagus) in Den Radien DeE sungen auf, wie bie Tauben. Sie find phlegmatifh, uno vertheidigen die Jungen nicht, wis bie 3 vorbergehender (B)attungen. Die Srůteplåke find Felfen an bem offenen Meste. Sie bauen Eein Neft; baben Brütefleden. Das Iauchjupplement iff bjer verfhtwunder, nur ein fhroaches Subiment if innen geblieben, nach weldsem fie fliegens cinea -Bogen gegen ben $\mathfrak{B a f f e r}$ piegel berab madien, um bie auf diefer forwimmende Rabrumg zu erhafden; daber

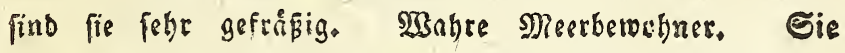
tuben auf ber Epur felbft, geben absr foblecht; mit

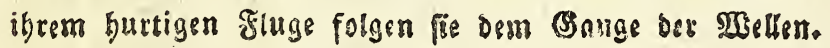

8. Pr. glacialis (Linn.), iă. Silúngr, fill.

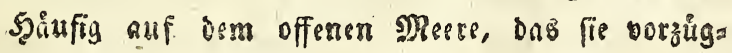
lich liebt. 2fuf oer gahrt nad) und yon Șకtand fiebs

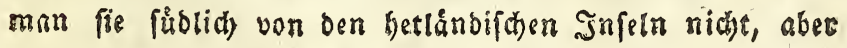

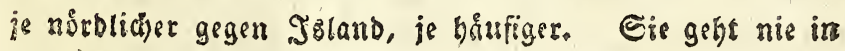

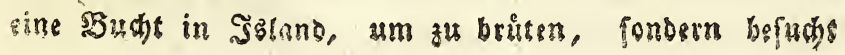




\section{$(108)$}

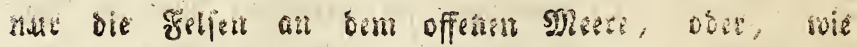
Sula alha, bie un SBbtano liegenoen Suferm amo Echerent Shre meriswirbigften Bruteplïge find: gegent"

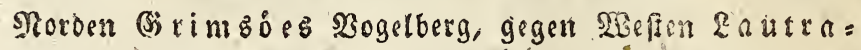
bjerg, gegen Suben Szafnarblerg und sivplevits

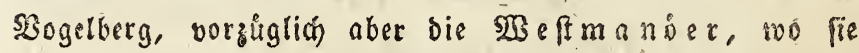
son allen bort in ben zelfen brutenden Bogetn die bratufigfte

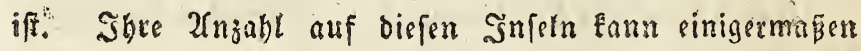

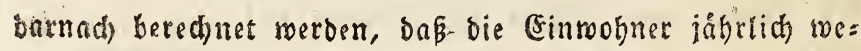
nigften 20,000 Sungen von biefem 20 oget ausnebmen; ba jeocs \$aar nie mebe als a Ei bat, fo briten wenigs

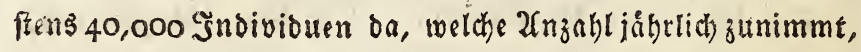
ba viele Sunge nicht erreicht merben, wo bie Tatur bee Jetfen biefes nidtertaubt, obgleid bie Einwohner, bier wie bei andern 20 ogelbergen in Sstano, firth mit um ben deib gebun= Denen Barten an ben freilen Gelfenwinden herab láfen, wenn fie $\mathfrak{B o g e l}$ auf bem Nefe, suunge ober Eier zur ๔peife ausnebmen wollen. - Mitten im Mårz nágert Pr. glacialis fict) ben Srůteplágen, legt frih (Fier, im Znfange des Mai's, ia auf den $\mathfrak{B} e$ ftmanórn im Sabre IB2 I fogar făon in ber Mitte des Zprilb. Dás Ei, ftetg

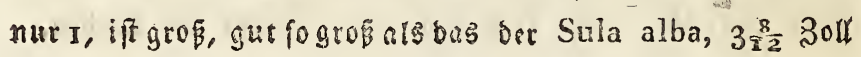
lang, abgerturbet uno rsia weip̈. Eic regt es auf bic

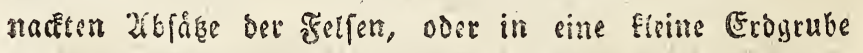

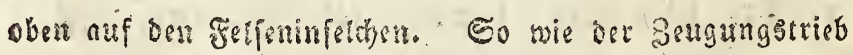

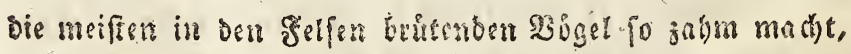

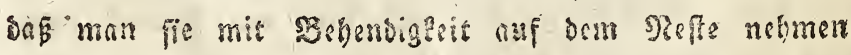

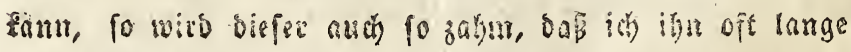

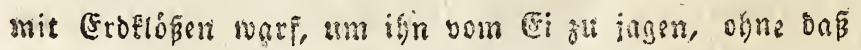

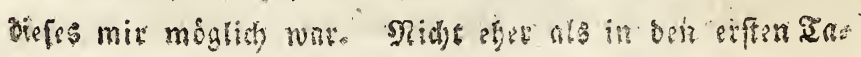




\section{$(\operatorname{tog})$}

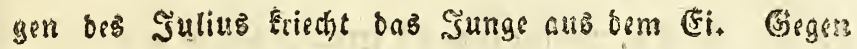
(Ende bes Sulius ift es balb ersodhfer und rate langers graublauen Flaum befleidet. Schon oann fpeirt es, ebers fo gut als bie 2riten, feint thtanige Feuthtigers, zurocia

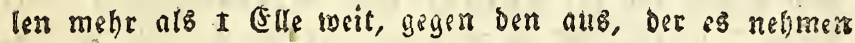
mill, inbem ss diefe freuditigfeit mit SServegungen, als

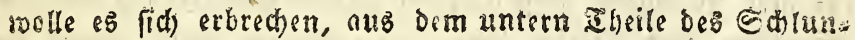

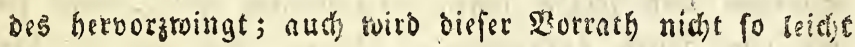

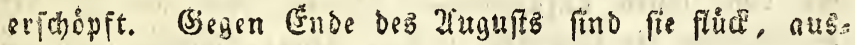
ferotosntich fett, uno riecien febr übel. Die Einmoknes

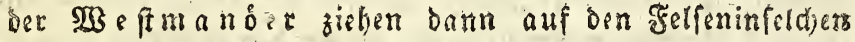
umber, tobten fie ju Taufenben uno folzen fie zurn

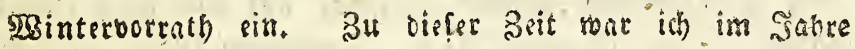
I82 I nuf biefen Snfeln. SDitten im September vertnfler Sunge uno alte bie S3ruteplág?, zieben auf das offene

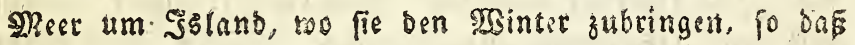
Reine zu biefer 3eit gejeben werden; nur einzelne neibert fich) zumeilen ben Felfen, two fir bristen, oder tratben im Sturme todt anz Rand. Sis ift bei Iage ant meiffer in servegung, fhrommt uno babs fich oft in oen reis:

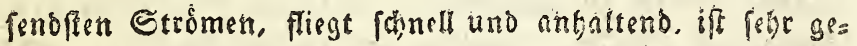
frakig und verzeint nidus altein Sifche. Medufa und ans

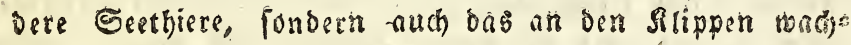

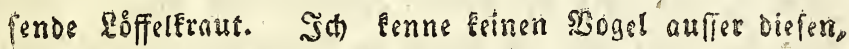
ber bie za der ₹nmilie Medula geborenien Edteimthlece strübrt. Shre Ctimme if firmlith trife; zumeilen eir

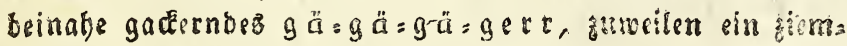

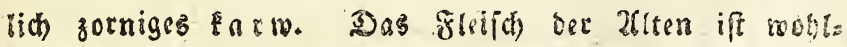

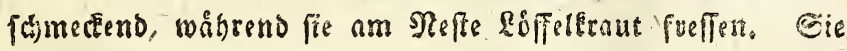
bat nur sinen 2 ruteflete mitten unter bem, Baucle. Dse zauchfuplement if bei ing gleichfom ausgeftorber, uno

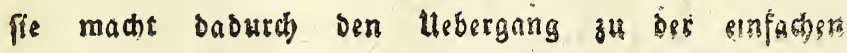

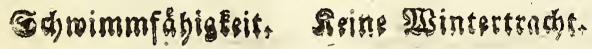


2. Pr. pelagica (Linn.), iž. - . -

Stritet nicht in Sziano, Eommt aber, zumal wents

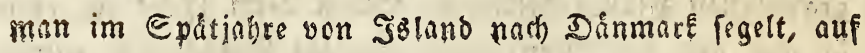
Dem Mecre um die Fåróer und Şetland zum Vors

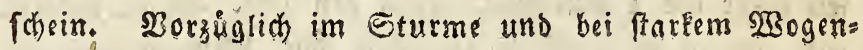
fat lage fammeln biefe Eleinen Mestbesoobner fich bei ben Chiffen und folgen itren viele Speilen sosit, inbem fie bie ron innen aufgepfligten Eleinen Mollufea in bee હuiffefpur auffommetn. Sim Fituge, theils auch on

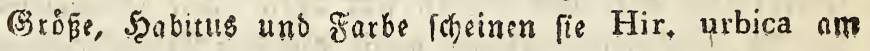
meiften ähnlid), wenn fie nothe binter ben Eshiffen fliegen. Eie benugen bas 2 saffer Element auf cine gang eigene Sorife; denn ich babs fie nie fostrimmen fehen, fondern

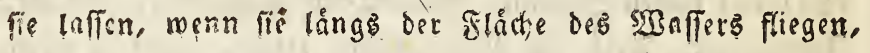
die Fífe fonkerd)t ouf ben Mafferfpiegel nieder, laufen mit fitl geholtomen ausgefpanntra Fliggetn eine sleine Etrecke üher daș 2 inaffer bin, unb friegen dann wieder;

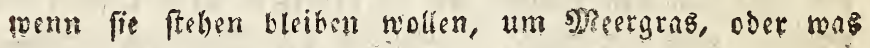
fonft auf Dem 28 affer fhrwimmt, uno ithe Tahrung ent=

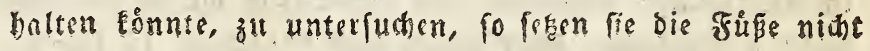
burds bng 23 affer, fonbern auf bie 2 Bafferfigche, und

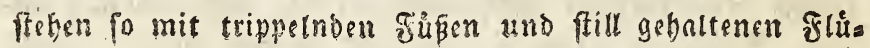
getu dacauf, bis fie mieber anfangen ön fliegen. Cie $_{i e}$

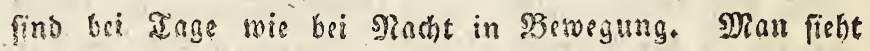

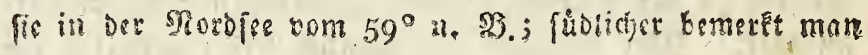
fie die feftcm.

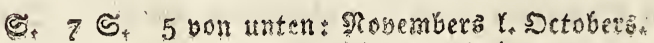

$$
\begin{aligned}
& \text { : } 43 \div 2=\text { oben: ionoarze lo sraune. } \\
& \text { - } 56=\text { I4 = : Den to bem. } \\
& \text { \% } 95=6 \text { = }=\text { oen } l_{+} \text {oenn. }
\end{aligned}
$$


I. Falco.

2. F, albicilla,

2. F, islandicus.

3. F, lanarius.

4+ F, crefius.

2. Strix.

I. St. nyctea.

3. Corvus.

I, C corax。

2. Co cornix.

3. C. corone,

4. Tetrao,

I. T. Islandorum,

5. Loxia,
I. L. ferinus,

6. Emberiza.

I. E. calcarata+

2. E, nivalis.

7. Fringilla.
I. F, linaria,

8. Turdus.
I. $T$. iliacus.

9. Motacilla.

I, M, albá,

IO. Saxicola.

I. S. œnanthe

II. Sylvia.

I. S, troglodytes.

32. Anthus.

I, A, pratenliss
I3. Hipundo.

I. H. ruftica.

2. H. urbica,

I4. Hæ matopus.

I. $\mathrm{H}_{*}$ oftralegus,

I5. Charadrius.

I. $\mathrm{Ch}$, hiaticula.

2. Ch. pluvialis

16. Calidris,

I. C arenaria,

I7. Ardea.

I. A. cinerea.

18. Numenius.

I. $N_{\text {i }}$ arquata:

2. N, phropuśs

19. Iumola.

I. L. melanura

20. Totanus.

I. $T_{*}$ calidris

21. Vanellus.

I. V. crinatus,

22. Sirepfilas,

It $S_{+}$collaris,

23. Tringa

I* $\cdot T$, cinerea

2. T, maritima

3. $T$, alpina

4. $T$, pugnax

24. Scolopax.

I. S. gallinago.

25. Pallus.

I. $R$. aquaticus 
26. Phalaropus.

I. $\mathbf{P}$ cinereus,

2. P. platyrhincus,

27. Uria.

I. U. grylle.

2. U, Brünnichii

3. U. troile,

4. U, alle,

28. Alca.

I. A, torda

2. A. impennis.

29. Mormon.

I. M. fraterculas

30. Carbo.

I. C, cormoranus.

2. C. graculus,

3I. Puffinus.

I. $P$, arcticus.

2. P. major.

32. Colymbus.

I. C. glacialis.

2. C. rufogularis.

33. Podiceps.

I. $P_{+}^{*}$ cornutus

2. P. auritus,

34. Fulica.

I. F, atra.

35. Mergus.

I. M, merganfer,

2. M. ferrator.

36. Anas.

I. A, nigra.

2. A. Ipectabilis

3. A. mollisfima.
4. A. glacialls,

5. A. clangula,

6. A. marila.

7. A, leucophtalmos.

8. A, hiftrionica,

9. A. ftrepera.

I0. A, acuta.

II. A, bolcas.

I2. A, penelope,

13. A, crecca.

37. Anfer.

I. A, fegetum,

2. A+ albifrons.

3. A, torquatus.

4. A. letacopfis.

38. Cygnus.

I. C. muficuse

39. Sula.

I. S. alba,

40. Sterna.

I. St hirundo.

4I. Larus.

I. I, tridactylus.

2. L, leucopterus,

3. L, glaucus.

4. L. marinus:

42. Leftris.

I. L, catarractes,

2. L. pomarina.

3. L. parafitica,

43. Procellaria.

I. P+ glacialis .

2. P. pelagica, 
act sta

fie be

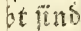
aiven a fir

$\mathrm{mm}$

is

nas:

Dis

im 8103

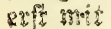

วum SWB

Im spefie

in noc

Eiesrin

when, sen

Uุํำ, 



\section{$N$ a $t$ a $t$ o $r$ e $s$.}

Sd) wo imm=Fablgect.

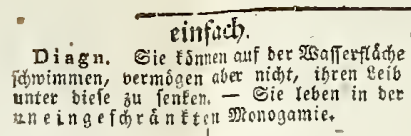

Phalaropits, 3lifammengefest

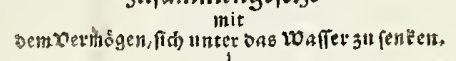
Fdywimmen, bermógen aber nidbt, ibrent Beí

sentortiogen, fith unte

Tanch Sabigent.

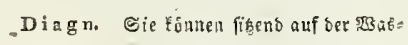
ferflåche ibren Leib unter bię? fenfen.

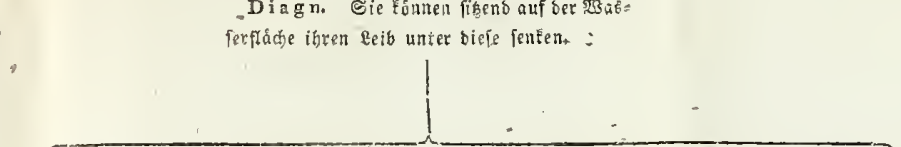

\section{Diagn filbfiotail.}

Diagn Eis tauder in

Ser senet, entweber alteris

nach Mothrung, ober audi) zुu=

- greich in (Befahtr.

minbesinge.

Di agn. Eie tauden naud

stahtung, talken in Gepahr.

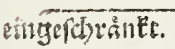

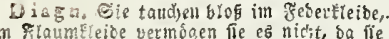

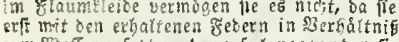

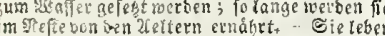

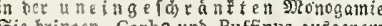

Sie bringen, Carbo this Puffinus ausgenom

men, ben Jungent out
Diagn. Eic tauten in oer $\Re e g c y$ night;

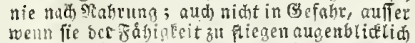

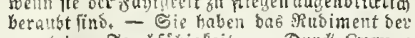

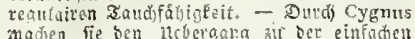

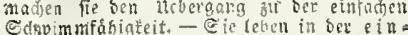

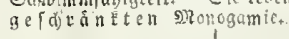

Anas ate శramirie. Auler. C’̀ggnus.
Taud: Gupplement.

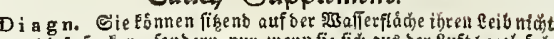
ift herabs fals rent teffen, - Durd Procella ria madeen ie den lebergang zuber eins faden Edjutmmanigate. Sie bringen, Sterna aubgenommen,

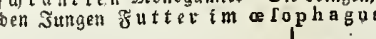
Sula, Sterna, Larus, Leffriso. Procellaria,

Mergus, Anas xt: Zanitie, unteinge fur ontut.

$$
\begin{aligned}
& \text { Diagn. Gie tauthen nidut } \\
& \text { allein im geirefleibe, fondern } \\
& \text { atcó in glaumethibe, ta fie }
\end{aligned}
$$

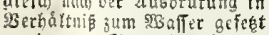

$$
\begin{aligned}
& \text { soertent. - Eie Yeben in bet } \\
& \text { mitteren Monogamie. } \\
& \text { Colymbus, Podiceps, Fulica. }
\end{aligned}
$$









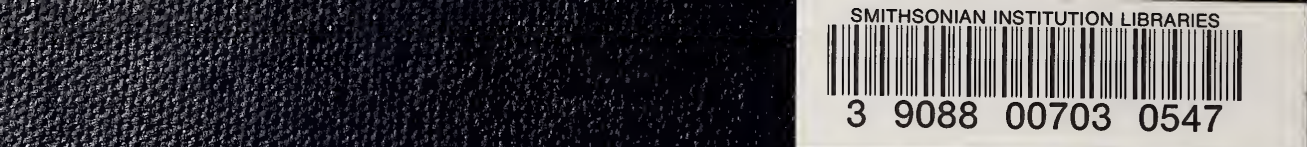

